\title{
Synthesis of a New Class of Furan-fused Tetracyclic Compounds Using $o$-Quinodimethane Chemistry and Investigation of Their Anti-viral Activity
}

\author{
Yuji Matsuya, ${ }^{\dagger, 8}$ Kazushige Sasaki, ${ }^{\dagger}$ Mamiko Nagaoka, ${ }^{\dagger, 8}$ Hiroko Kakuda, ${ }^{\dagger}$ Naoki \\ Toyooka, ${ }^{\dagger, \$}$ Nobuko Imanishi, ${ }^{+}$Hiroshi Ochiai, ${ }^{\star, \&}$ and Hideo Nemoto ${ }^{*+, \$}$
}

Supporting Information

Contents

Synthetic Procedure and Characterization Data for All New Compounds (S2-S14)

Procedure for Bioassay (S15-S16)

${ }^{1} \mathrm{H}$ and ${ }^{13} \mathrm{C}$ NMR Spectra of All New Compounds (S17-S88) 
General Remarks. All nonaqueous reactions were carried out under Ar atmosphere. Reagents were purchased from commercial sources and used as received. Anhydrous solvents were obtained from commercial sources or prepared by distillation over $\mathrm{CaH}_{2}$ or $\mathrm{P}_{2} \mathrm{O}_{5}$. Chemical shifts of ${ }^{1} \mathrm{H}$ and ${ }^{13} \mathrm{C}$ NMR spectra are given in ppm based on solvent signals. Ionization method of mass spectrometry is electron impact (EI, $70 \mathrm{eV}$ ). Melting points are uncorrected. Column chromatography was carried out by employing Cica Silica Gel 60N (spherical, neutral, 40-50 $\mu \mathrm{m}$ or 63-210 $\mu \mathrm{m}$ ).

3-(1-Hydroxy-3-buten-1-yl)furan (3). To a solution of 3-furancarbaldehyde (2) (2.0 g, $20.8 \mathrm{mmol})$ in anhydrous THF (40 ml), allylmagnesium bromide (1.0 M in THF, 31.2 $\mathrm{ml}, 31.2 \mathrm{mmol}$ ) was added at $0^{\circ} \mathrm{C}$ under Ar atmosphere. After continuous stirring at $0^{\circ} \mathrm{C}$ for $1 \mathrm{~h}$, the reaction was quenched with sat. $\mathrm{NaHCO}_{3}$ and the resulting aqueous mixture was extracted with $\mathrm{CH}_{2} \mathrm{Cl}_{2}$, and then dried over $\mathrm{MgSO}_{4}$. The solvent was evaporated off to leave a residue, which was chromatographed on silica gel (hexane : acetone $=60: 1$ ) to afford the alcohol $3(1.80 \mathrm{~g}, 63 \%)$ as a colorless oil. ${ }^{1} \mathrm{H}-\mathrm{NMR}\left(\mathrm{CDCl}_{3}\right) \delta: 2.18(1 \mathrm{H}$, brs), 2.48-2.52 (2H, m), 4.70 (1H, brs), 5.12-5.19 (2H, m), 5.73-5.87 (1H, m), $6.40(1 \mathrm{H}$, brs), 7.37 (2H, brs); ${ }^{13} \mathrm{C}-\mathrm{NMR}\left(\mathrm{CDCl}_{3}\right) \delta: 42.6,66.2,108.6,118.6,128.5,134.1,139.1$, 143.3; IR (neat) $\mathrm{cm}^{-1}$ : 3382; MS $\mathrm{m} / z 138\left(\mathrm{M}^{+}\right)$; HRMS Calcd for $\mathrm{C}_{8} \mathrm{H}_{10} \mathrm{O}_{2}: 138.0681$ $\left(\mathrm{M}^{+}\right)$, found: 138.0677 .

3-(1-tert-Butyldimethylsilyloxy-3-buten-1-yl)furan (4a). To a solution of the alcohol 3 (780 mg, $5.65 \mathrm{mmol})$ in anhydrous $\mathrm{CH}_{2} \mathrm{Cl}_{2}(20 \mathrm{ml})$, triethylamine $(1.10 \mathrm{ml}, 7.91$ $\mathrm{mmol})$ and tert-butyldimethylsilyl trifluoromethanesulfonate $(1.70 \mathrm{ml}, 7.34 \mathrm{mmol})$ were added successively at $0^{\circ} \mathrm{C}$ under Ar atmosphere. The mixture was stirred at the same temperature for $30 \mathrm{~min}$, and diluted with $\mathrm{Et}_{2} \mathrm{O}$ and sat. $\mathrm{NH}_{4} \mathrm{Cl}$. The aqueous solution was extracted with $\mathrm{Et}_{2} \mathrm{O}$, and the organic layer was dried over $\mathrm{MgSO}_{4}$ and then evaporated. The residue was subjected to silica gel column chromatography (hexane) to afford the silyl ether $4 \mathbf{a}(1.31 \mathrm{~g}, 96 \%)$ as a colorless oil. ${ }^{1} \mathrm{H}-\mathrm{NMR}\left(\mathrm{CDCl}_{3}\right) \delta: 0.02(3 \mathrm{H}$, s), $0.07(3 \mathrm{H}, \mathrm{s}), 0.90(9 \mathrm{H}, \mathrm{s}), 2.38-2.51(2 \mathrm{H}, \mathrm{m}), 4.70(1 \mathrm{H}, \mathrm{t}, J=6.0 \mathrm{~Hz}), 5.03-5.07(2 \mathrm{H}$, m), 5.74-5.87 $(1 \mathrm{H}, \mathrm{m}), 6.36(1 \mathrm{H}$, brs $), 7.31(1 \mathrm{H}, \mathrm{brs}), 7.35(1 \mathrm{H}, \mathrm{brs}) ;{ }^{13} \mathrm{C}-\mathrm{NMR}\left(\mathrm{CDCl}_{3}\right)$

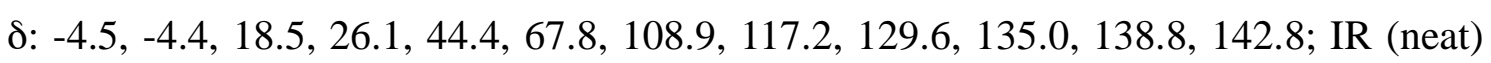
$\mathrm{cm}^{-1}: 1642$; MS $\mathrm{m} / z 252\left(\mathrm{M}^{+}\right)$; HRMS Calcd for $\mathrm{C}_{14} \mathrm{H}_{24} \mathrm{O}_{2} \mathrm{Si}: 252.1546\left(\mathrm{M}^{+}\right)$, found: 252.1530 .

3-(1-Triisopropylsilyloxy-3-buten-1-yl)furan (4b). According to the procedure for the synthesis of $\mathbf{4 a}$, the alcohol $\mathbf{3}$ and triisopropylsilyl trifluoromethanesulfonate afforded 
the silyl ether $\mathbf{4 b}(93 \%)$ as a colorless oil. ${ }^{1} \mathrm{H}-\mathrm{NMR}\left(\mathrm{CDCl}_{3}\right)$ $\delta: 0.90-1.11(21 \mathrm{H}, \mathrm{m})$, 2.42-2.55 (2H, m), $4.80(1 \mathrm{H}, \mathrm{t}, J=6.0 \mathrm{~Hz}), 5.00-5.04(2 \mathrm{H}, \mathrm{m}), 5.69-5.83(1 \mathrm{H}, \mathrm{m}), 6.39$

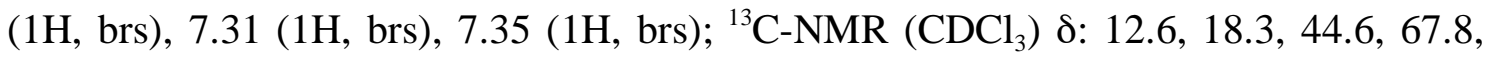
109.0, 117.3, 129.5, 134.5, 138.8, 142.7; IR (neat) $\mathrm{cm}^{-1}: 1641$; MS m/z $294\left(\mathrm{M}^{+}\right)$; HRMS Calcd for $\mathrm{C}_{17} \mathrm{H}_{30} \mathrm{O}_{2} \mathrm{Si}: 294.2015\left(\mathrm{M}^{+}\right)$, found: 294.1953.

3-(1-tert-Butyldimethylsilyloxy-3,4-dihydroxybut-1-yl)furan (5a). To a stirred solution of the olefin $4 \mathbf{a}(1.37 \mathrm{~g}, 5.41 \mathrm{mmol})$ in acetone $(35 \mathrm{ml}), 50 \%$ aqueous solution of $\mathrm{N}$-methylmorpholine $\mathrm{N}$-oxide $(3.81 \mathrm{ml}, 16.2 \mathrm{mmol})$ and potassium osmate dihydrate (40 mg, $0.11 \mathrm{mmol}$ ) were added at room temperature. The reaction mixture was stirred for $2.5 \mathrm{~h}$, and solid $\mathrm{NaSO}_{3}$ and $\mathrm{NaSO}_{4}$ were added. After the filtration through a Celite pad, the filtrate was concentrated in vacuo, diluted with $\mathrm{CH}_{2} \mathrm{Cl}_{2}$, and washed with $3 \%$ $\mathrm{HCl}$. The organic layer was dried over $\mathrm{MgSO}_{4}$ and evaporated to leave a residue, which was chromatographed on silica gel (hexane : acetone $=10: 1)$ to afford the diol $\mathbf{5 a}(1.47$ g, 95\%) as a colorless oil (ca. $1: 1$ mixture of diastereomers). ${ }^{1} \mathrm{H}-\mathrm{NMR}\left(\mathrm{CDCl}_{3}\right) \delta$ : $0.13(1.5 \mathrm{H}, \mathrm{s}),-0.05(1.5 \mathrm{H}, \mathrm{s}), 0.04(1.5 \mathrm{H}, \mathrm{s}), 0.07(1.5 \mathrm{H}, \mathrm{s}), 0.85(4.5 \mathrm{H}, \mathrm{s}), 0.87(4.5 \mathrm{H}$, s), 1.63-1.69 $(1 \mathrm{H}, \mathrm{m}), 1.76-1.96(1 \mathrm{H}, \mathrm{m}), 3.21(1 \mathrm{H}, \mathrm{brs}), 3.40(1 \mathrm{H}, \mathrm{brs}), 3.53(1 \mathrm{H}, \mathrm{m})$, $3.76-3.89(2 \mathrm{H}, \mathrm{m}), 4.90(0.5 \mathrm{H}, \mathrm{dd}, J=5.0,8.0 \mathrm{~Hz}), 5.00(0.5 \mathrm{H}, \mathrm{dd}, J=3.3,6.0 \mathrm{~Hz})$, $6.30(0.5 \mathrm{H}$, brs $), 6.35(0.5 \mathrm{H}$, brs $), 7.30(1 \mathrm{H}, \mathrm{brs}), 7.32(1 \mathrm{H}, \mathrm{brs}) ;{ }^{13} \mathrm{C}-\mathrm{NMR}\left(\mathrm{CDCl}_{3}\right) \delta$ : 5.0, -4.8, -4.6, -4.3, 18.2, 18.3, 25.9, 41.3, 42.3, 66.4, 66.7, 67.0, 67.3, 69.1, 71.0, 108.65, 108.69, 128.8, 138.8, 143.1, 143.2; IR (neat) $\mathrm{cm}^{-1}: 3381$; MS m/z $286\left(\mathrm{M}^{+}\right)$; HRMS Calcd for $\mathrm{C}_{14} \mathrm{H}_{26} \mathrm{O}_{4} \mathrm{Si}: 286.1600\left(\mathrm{M}^{+}\right)$, found: 286.1602 .

3-(3,4-Dihydroxy-1-triisopropylsilyloxybut-1-yl)furan (5b). According to the procedure for the synthesis of $\mathbf{5 a}$, the olefin $\mathbf{4 b}$ afforded the diol $\mathbf{5 b}(71 \%)$ as a colorless oil (ca. 1 : 1 mixture of diastereomers). ${ }^{1} \mathrm{H}-\mathrm{NMR}\left(\mathrm{CDCl}_{3}\right) \delta: 0.88-1.01(21 \mathrm{H}, \mathrm{m}), 1.59$ $1.65(1 \mathrm{H}, \mathrm{m}), 1.85-2.00$ (1H, m), 3.09-3.59 (4H, m), 3.86 (0.5H, brs), 4.00 (0.5H, brs), $5.00(0.5 \mathrm{H}, \mathrm{t}, J=6.6 \mathrm{~Hz}), 5.16(0.5 \mathrm{H}, \mathrm{t}, J=4.0 \mathrm{~Hz}), 6.31(0.5 \mathrm{H}, \mathrm{brs}), 6.36(0.5 \mathrm{H}, \mathrm{brs})$, 7.30 (1H, brs), 7.32 (1H, brs); ${ }^{13} \mathrm{C}-\mathrm{NMR}\left(\mathrm{CDCl}_{3}\right) \delta: 12.3,12.5,17.7,18.05,18.11,18.2$, 40.9, 42.6, 66.2, 66.8, 67.0, 67.4, 69.1, 70.0, 108.8, 128.4, 128.8, 138.9, 142.9, 143.1; IR (neat) $\mathrm{cm}^{-1}: 3409$; MS m/z $328\left(\mathrm{M}^{+}\right)$; HRMS Calcd for $\mathrm{C}_{17} \mathrm{H}_{32} \mathrm{O}_{4} \mathrm{Si}: 328.2070\left(\mathrm{M}^{+}\right)$, found: 328.2079 .

3-(1-tert-Butyldimethylsilyloxy-3-hydroxyprop-1-yl)furan (6a). Sodium periodate $(2.19 \mathrm{~g}, 10.2 \mathrm{mmol})$ was added to a stirred solution of the diol $\mathbf{5 a}(1.47 \mathrm{~g}, 5.12 \mathrm{mmol})$ in THF (12 ml) and $\mathrm{H}_{2} \mathrm{O}(12 \mathrm{ml})$ at room temperature. After vigorous stirring for $2 \mathrm{~h}$, sat. 
$\mathrm{NaHCO}_{3}$ and $10 \% \mathrm{Na}_{2} \mathrm{~S}_{2} \mathrm{O}_{3}$ were added, and the resulting mixture was extracted with $\mathrm{CH}_{2} \mathrm{Cl}_{2}$ and dried over $\mathrm{MgSO}_{4}$. The residue obtained by evaporation of the solvent was dissolved in $\mathrm{CH}_{2} \mathrm{Cl}_{2}(22 \mathrm{ml})$ and $\mathrm{MeOH}(2.2 \mathrm{ml})$, and sodium borohydride (581 $\mathrm{mg}$, $15.4 \mathrm{mmol}$ ) was added portionwise to the mixture at $0^{\circ} \mathrm{C}$. After stirring at room temperature for $1 \mathrm{~h}$, the reaction was stopped by adding sat. $\mathrm{NH}_{4} \mathrm{Cl}$, and the aqueous mixture was extracted with $\mathrm{CH}_{2} \mathrm{Cl}_{2}$. The organic layer was dried over $\mathrm{MgSO}_{4}$ and evaporated to leave a residue, which was chromatographed on silica gel (hexane : acetone $=50: 1)$ to afford the alcohol $\mathbf{6 a}(886 \mathrm{mg}, 68 \%)$ as a colorless oil. ${ }^{1} \mathrm{H}-\mathrm{NMR}$

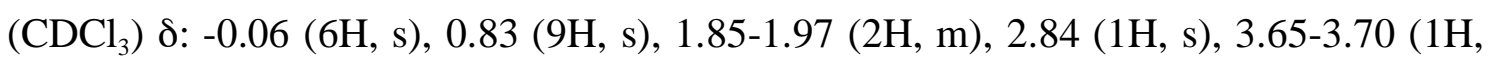
m), 3.74-3.79 (1H, m), $4.95(1 \mathrm{H}, \mathrm{dd}, J=4.7,6.4 \mathrm{~Hz}), 6.30$ (1H, brs), 7.30 (1H, brs), 7.34 (1H, brs); ${ }^{13} \mathrm{C}-\mathrm{NMR}\left(\mathrm{CDCl}_{3}\right) \delta:-5.1,-4.7,18.1,25.8,40.8,60.0,67.1,108.5,128.8$, 138.6, 142.9; IR (neat) $\mathrm{cm}^{-1}: 3378$; MS $\mathrm{m} / z 256\left(\mathrm{M}^{+}\right)$; HRMS Calcd for $\mathrm{C}_{13} \mathrm{H}_{24} \mathrm{O}_{3} \mathrm{Si}$ : 256.1495 $\left(\mathrm{M}^{+}\right)$, found: 256.1507 .

3-(3-Hydroxy-1-triisopropylsilyloxyprop-1-yl)furan (6b). According to the procedure for the synthesis of $\mathbf{6 a}$, the diol $\mathbf{5 b}$ afforded the alcohol $\mathbf{6 b}(52 \%)$ as a colorless oil. ${ }^{1} \mathrm{H}$ -

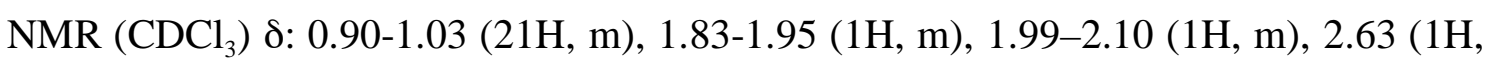
brs), 3.62 (1H, br), $3.76(1 \mathrm{H}, \mathrm{br}), 5.10(1 \mathrm{H}, \mathrm{t}, J=5.0 \mathrm{~Hz}), 6.36(1 \mathrm{H}, \mathrm{brs}), 7.34$ (2H, brs);

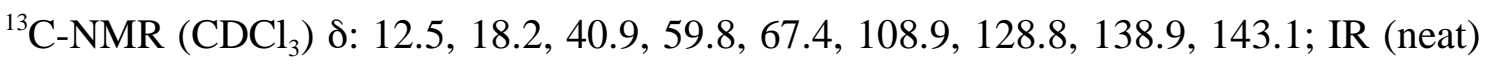
$\mathrm{cm}^{-1}$ : 3393; MS m/z $297\left(\mathrm{M}^{+}-1\right)$; HRMS Calcd for $\mathrm{C}_{16} \mathrm{H}_{29} \mathrm{O}_{3} \mathrm{Si}: 297.1886\left(\mathrm{M}^{+}-1\right)$, found: 297.1874 .

3-(3-Bromo-1-tert-butyldimethylsilyloxyprop-1-yl)furan (7a). A solution of the alcohol 6a (450 mg, $1.76 \mathrm{mmol}$ ), triphenylphosphine (506 mg, $1.93 \mathrm{mmol}$ ), and carbon tetrabromide $(639 \mathrm{mg}, 1.93 \mathrm{mmol})$ in anhydrous $\mathrm{CH}_{2} \mathrm{Cl}_{2}(7 \mathrm{ml})$ was stirred at room temperature for $30 \mathrm{~min}$. After addition of sat. $\mathrm{NaHCO}_{3}$, the mixture was extracted with $\mathrm{CH}_{2} \mathrm{Cl}_{2}$, and the organic layer was washed with brine and dried over $\mathrm{MgSO}_{4}$. Evaporation of the solvent gave a residue, which was subjected to silica gel column chromatography (hexane) to afford the bromide $7 \mathbf{a}(417 \mathrm{mg}, 75 \%)$ as a colorless oil. ${ }^{1} \mathrm{H}$ NMR $\left(\mathrm{CDCl}_{3}\right)$ \&: $-0.05(3 \mathrm{H}, \mathrm{s}), 0.09(3 \mathrm{H}, \mathrm{s}), 0.88(9 \mathrm{H}, \mathrm{s}), 2.02-2.13(1 \mathrm{H}, \mathrm{m}), 2.20-2.31$ $(1 \mathrm{H}, \mathrm{m}), 3.35-3.42(1 \mathrm{H}, \mathrm{m}), 3.50(1 \mathrm{H}, \mathrm{dd}, J=8.5,16 \mathrm{~Hz}), 4.80(1 \mathrm{H}, \mathrm{t}-\mathrm{like}, J=4.7 \mathrm{~Hz})$, 6.35 (1H, brs), 7.34 (1H, brs), $7.36(1 \mathrm{H}, \mathrm{brs}) ;{ }^{13} \mathrm{C}-\mathrm{NMR}\left(\mathrm{CDCl}_{3}\right)$ d: -4.6, -4.3, 18.4, 26.1, 30.5, 42.5, 65.7, 108.7, 128.8, 138.9, 143.2; IR (neat) $\mathrm{cm}^{-1}: 1592$; MS m/z 318, 320 $\left(\mathrm{M}^{+}\right)$; HRMS Calcd for $\mathrm{C}_{13} \mathrm{H}_{23}{ }^{81} \mathrm{BrO}_{2} \mathrm{Si}: 320.0630\left(\mathrm{M}^{+}\right)$, found: 320.0612 .

3-(3-Bromo-1-triisopropylsilyloxyprop-1-yl)furan (7b). According to the procedure 
for the synthesis of $\mathbf{7 a}$, the alcohol $\mathbf{6} \mathbf{b}$ afforded the bromide $\mathbf{7 b}(87 \%)$ as a colorless oil. ${ }^{1} \mathrm{H}-\mathrm{NMR}\left(\mathrm{CDCl}_{3}\right)$ \&: 0.90-1.00 $(21 \mathrm{H}, \mathrm{m}), 1.90-2.10(1 \mathrm{H}, \mathrm{m}), 2.20-2.30(1 \mathrm{H}, \mathrm{m}), 3.15$ $(1 \mathrm{H}, \mathrm{dd}, J=7.6,17 \mathrm{~Hz}), 3.40(1 \mathrm{H}, \mathrm{m}), 4.90(1 \mathrm{H}, \mathrm{t}, J=6.0 \mathrm{~Hz}), 6.30(1 \mathrm{H}, \mathrm{brs}), 7.30(2 \mathrm{H}$,

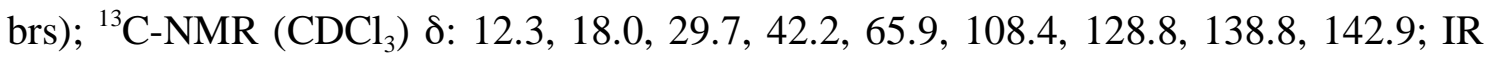
(neat) $\mathrm{cm}^{-1}: 1593$; MS m/z 361, $363\left(\mathrm{M}^{+}+1\right)$; HRMS Calcd for $\mathrm{C}_{16} \mathrm{H}_{30}{ }^{79} \mathrm{BrO}_{2} \mathrm{Si}: 361.1198$ $\left(\mathrm{M}^{+}+1\right)$, found: 361.1131 .

\section{1-[3-tert-Butyldimethylsilyloxy-3-(3-furyl)prop-1-yl]-4-methoxybenzocyclobutene-}

1-carbonitrile (8a). A solution of LDA $(1.71 \mathrm{mmol})$ in THF $(2.5 \mathrm{ml})$, prepared from diisopropylamine $(0.24 \mathrm{ml}, 1.71 \mathrm{mmol})$ and $n$-butyllithium $(1.6 \mathrm{M}$ in hexane, $1.07 \mathrm{ml}$, $1.71 \mathrm{mmol}$ ), was cooled to $-78^{\circ} \mathrm{C}$ and a solution of 4-methoxybenzocyclobutene-1carbonitrile (182 $\mathrm{mg}, 1.14 \mathrm{mmol})$ in THF $(1 \mathrm{ml})$ was added, and the mixture was allowed to react at $-78^{\circ} \mathrm{C}$ for $30 \mathrm{~min}$. To the mixture, a solution of the bromide $7 \mathbf{a}$ (364 $\mathrm{mg}, 1.14 \mathrm{mmol})$ in THF (1 ml) was added, and the cooling bath was removed to warm to $0^{\circ} \mathrm{C}$ over $30 \mathrm{~min}$. The reaction was quenched with sat. $\mathrm{NH}_{4} \mathrm{Cl}$, and the aqueous mixture was extracted with $\mathrm{Et}_{2} \mathrm{O}$. The organic layer was dried over $\mathrm{MgSO}_{4}$ and evaporated to leave a residue, which was chromatographed on silica gel (hexane : acetone $=100: 1)$ to afford the alkylated benzocyclobutene $8 \mathbf{a}(289 \mathrm{mg}, 64 \%)$ as a pale yellow oil. ${ }^{1} \mathrm{H}-\mathrm{NMR}\left(\mathrm{CDCl}_{3}\right)$ $\delta: 0.03(3 \mathrm{H}, \mathrm{s}), 0.06(3 \mathrm{H}, \mathrm{s}), 0.88(9 \mathrm{H}, \mathrm{s}), 1.90-2.05(4 \mathrm{H}$, m), $3.15(1 \mathrm{H}, \mathrm{d}, J=14 \mathrm{~Hz}), 3.60(1 \mathrm{H}, \mathrm{d}, J=14 \mathrm{~Hz}), 3.77(3 \mathrm{H}, \mathrm{s}), 4.80(1 \mathrm{H}, \mathrm{t}, J=5.0$ $\mathrm{Hz}), 6.30(1 \mathrm{H}, \mathrm{brs}), 6.70(1 \mathrm{H}, \mathrm{br}), 6.80(1 \mathrm{H}, \mathrm{dd}, J=2.0,8.0 \mathrm{~Hz}), 7.10(1 \mathrm{H}, \mathrm{d}, J=8.0$ $\mathrm{Hz}), 7.29(1 \mathrm{H}$, brs $), 7.34(1 \mathrm{H}$, brs $) ;{ }^{13} \mathrm{C}-\mathrm{NMR}\left(\mathrm{CDCl}_{3}\right) \delta:-4.9,-4.7,18.2,25.8,32.7$, 35.6, 41.8, 42.2, 55.4, 66.9, 108.4, 109.1, 114.8, 121.8, 122.6, 128.7, 135.1, 138.7, 141.8, 142.9, 160.9; IR (neat) $\mathrm{cm}^{-1}:$ 2231; MS m/z $397\left(\mathrm{M}^{+}\right)$; HRMS Calcd for $\mathrm{C}_{23} \mathrm{H}_{31} \mathrm{NO}_{3} \mathrm{Si}: 397.2073\left(\mathrm{M}^{+}\right)$, found: 397.2073.

\section{1-[3-(3-Furyl)-3-triisopropylsilyloxyprop-1-yl]-4-methoxybenzocyclobutene-1-}

carbonitrile (8b). According to the procedure for the synthesis of $\mathbf{8 a}$, the bromide $\mathbf{7 b}$ afforded the alkylated benzocyclobutene $\mathbf{8 b}(68 \%)$ as a pale yellow oil. ${ }^{1} \mathrm{H}-\mathrm{NMR}$

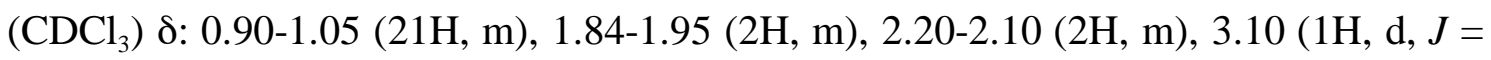
$14 \mathrm{~Hz}), 3.60(1 \mathrm{H}, \mathrm{d}, J=14 \mathrm{~Hz}), 3.80(3 \mathrm{H}, \mathrm{s}), 4.90(1 \mathrm{H}, \mathrm{br}), 6.30(1 \mathrm{H}, \mathrm{brs}), 6.72(1 \mathrm{H}, \mathrm{br})$, $6.80(1 \mathrm{H}, \mathrm{d}, J=8.0 \mathrm{~Hz}), 7.11(1 \mathrm{H}, \mathrm{d}, J=8.0 \mathrm{~Hz}), 7.30(1 \mathrm{H}, \mathrm{brs}), 7.34(1 \mathrm{H}, \mathrm{brs}) ;{ }^{13} \mathrm{C}-$ $\operatorname{NMR}\left(\mathrm{CDCl}_{3}\right) \delta: 12.5,18.2,32.5,36.0,42.0,42.4,55.6,67.1,108.7,109.4,115.0$, 122.0, 122.8, 128.9, 135.4, 139.0, 142.1, 143.1, 161.1; IR (neat) $\mathrm{cm}^{-1}: 2231$; MS m/z $439\left(\mathrm{M}^{+}\right)$; HRMS Calcd for $\mathrm{C}_{26} \mathrm{H}_{37} \mathrm{NO}_{3} \mathrm{Si}: 439.2543\left(\mathrm{M}^{+}\right)$, found: 439.2549 . 
Thermal Reaction (General Procedure) of 8a and 8b. Synthesis of 9a, 9b, and 10. A solution of the compound $\mathbf{8 a}$ or $\mathbf{8 b}(1 \mathrm{mmol})$ in $o$-dichlorobenzene $(30 \mathrm{ml})$ was refluxed for $2 \mathrm{~h}$ under Ar atmosphere. The solvent was evaporated in vacuo to leave a residue, which was subjected to silica gel column chromatography (hexane : acetone). The compound 8a afforded the tetracyclic products 9a (32\%) and $\mathbf{1 0}(26 \%)$ as colorless solids. The compound $\mathbf{8 b}$ afforded the tetracyclic products $\mathbf{9 b}(40 \%)$ and $\mathbf{1 0}(31 \%)$ as colorless solids. 9a: mp 160-162 ${ }^{\circ} \mathrm{C} ;{ }^{1} \mathrm{H}-\mathrm{NMR}\left(\mathrm{CDCl}_{3}\right) \delta: 0.07(6 \mathrm{H}, \mathrm{s}), 0.87(9 \mathrm{H}, \mathrm{s})$, 1.53-1.65 (1H, m), 1.90-1.94 (1H, m), 2.15-2.25 (1H, m), 2.90-2.97 $(1 \mathrm{H}, \mathrm{m}), 3.16(1 \mathrm{H}$, d, $J=15 \mathrm{~Hz}), 3.31(1 \mathrm{H}, \mathrm{d}, J=15 \mathrm{~Hz}), 3.76(1 \mathrm{H}, \mathrm{d}, J=11 \mathrm{~Hz}), 3.84(3 \mathrm{H}, \mathrm{s}), 4.30-4.38$ $(1 \mathrm{H}, \mathrm{m}), 5.32(1 \mathrm{H}, \mathrm{dd}, J=3.0,11 \mathrm{~Hz}), 5.95(1 \mathrm{H}, \mathrm{s}), 6.82-6.90(2 \mathrm{H}, \mathrm{m}), 7.24(1 \mathrm{H}, \mathrm{d}, J=$ $6.0 \mathrm{~Hz}) ;{ }^{13} \mathrm{C}-\mathrm{NMR}\left(\mathrm{CDCl}_{3}\right) \delta:-4.7,-4.6,18.5,26.0,30.6,31.2,34.5,35.5,52.4,55.4$, 67.8, 79.2, 112.9, 114.1, 115.7, 122.7, 123.2, 127.1, 137.1, 141.1, 159.5; IR (KBr) cm ${ }^{-1}$ : 2224; MS m/z $397\left(\mathrm{M}^{+}\right)$; HRMS Calcd for $\mathrm{C}_{23} \mathrm{H}_{31} \mathrm{NO}_{3} \mathrm{Si}: 397.2073\left(\mathrm{M}^{+}\right)$, found: 397.2043. 9b: ${ }^{1} \mathrm{H}-\mathrm{NMR}\left(\mathrm{CDCl}_{3}\right)$ \&: 0.90-1.14 (21H, m), 1.48-1.59 (1H, m), 1.98-2.00 $(1 \mathrm{H}, \mathrm{m}), 2.14(1 \mathrm{H}, \mathrm{dt}, J=2.5,14 \mathrm{~Hz}), 2.89(1 \mathrm{H}, \mathrm{d}, J=14 \mathrm{~Hz}), 3.14(1 \mathrm{H}, \mathrm{d}, J=15 \mathrm{~Hz})$, $3.28(1 \mathrm{H}, \mathrm{d}, J=15 \mathrm{~Hz}), 3.72(1 \mathrm{H}, \mathrm{d}, J=10 \mathrm{~Hz}), 3.80(3 \mathrm{H}, \mathrm{s}), 4.38(1 \mathrm{H}, \mathrm{dd}, J=5.2,11$ $\mathrm{Hz}), 5.28(1 \mathrm{H}, \mathrm{d}, J=10 \mathrm{~Hz}), 6.00(1 \mathrm{H}, \mathrm{s}), 6.81-6.90(2 \mathrm{H}, \mathrm{m}), 7.23(1 \mathrm{H}, \mathrm{d}, J=9.3 \mathrm{~Hz})$;

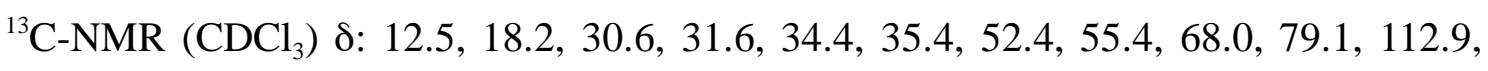
114.4, 115.7, 122.7, 123.2, 127.0, 137.1, 141.1, 159.5; IR (KBr) cm $\mathrm{cm}^{-1}: 2229$; MS m/z $439\left(\mathrm{M}^{+}\right)$; HRMS Calcd for $\mathrm{C}_{26} \mathrm{H}_{37} \mathrm{NO}_{3} \mathrm{Si}: 439.2543\left(\mathrm{M}^{+}\right)$, found: 439.2527. 10: $\mathrm{mp} 183$ -

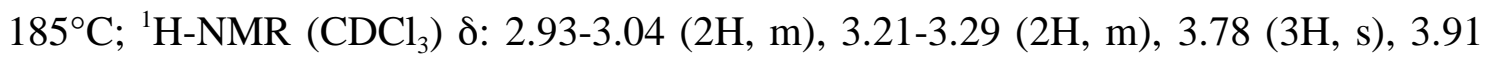
$(1 \mathrm{H}, \mathrm{d}, J=10 \mathrm{~Hz}), 5.28-5.36(1 \mathrm{H}, \mathrm{m}), 5.43-5.49(1 \mathrm{H}, \mathrm{m}), 6.00(1 \mathrm{H}, \mathrm{dd}, J=2.3,9.8 \mathrm{~Hz})$, $6.11(1 \mathrm{H}, \mathrm{s}), 6.74(1 \mathrm{H}, \mathrm{dd}, J=2.0,8.5 \mathrm{~Hz}), 6.80(1 \mathrm{H}, \mathrm{s}), 7.04(1 \mathrm{H}, \mathrm{d}, J=8.5 \mathrm{~Hz}) ;{ }^{13} \mathrm{C}-$ NMR $\left(\mathrm{CDCl}_{3}\right) \delta: 32.2,34.5,35.2,49.1,55.4,79.2,109.7,112.0,115.5,118.6,120.8$, 122.1, 123.9, 126.1, 136.8, 143.1, 159.4; IR (KBr) cm $\mathrm{cm}^{-1}: 2231,1612$; MS m/z $265\left(\mathrm{M}^{+}\right)$; HRMS Calcd for $\mathrm{C}_{17} \mathrm{H}_{15} \mathrm{NO}_{2}: 265.1103\left(\mathrm{M}^{+}\right)$, found: 265.1070 .

Desilylation of the Compound 9a. Synthesis of 9c. To a stirred solution of the compound 9a (60 mg, $0.136 \mathrm{mmol})$ in anhydrous THF (3 ml), tetra- $n$-butylammonium fluoride ( $1 \mathrm{M}$ in THF, $0.15 \mathrm{ml}, 0.15 \mathrm{mmol})$ was added at $0^{\circ} \mathrm{C}$ under Ar atmosphere. After stirring at room temperature for $1 \mathrm{~h}$, sat. $\mathrm{NH}_{4} \mathrm{Cl}$ was added to the reaction mixture and the resulting aqueous solution was extracted with $\mathrm{CHCl}_{3}$. The organic layer was dried over $\mathrm{MgSO}_{4}$ and evaporated to leave a residue, which was chromatographed on silica gel (hexane : acetone $=10: 1)$ to afford the alcohol 9c $(33 \mathrm{mg}, 86 \%)$ as a colorless 


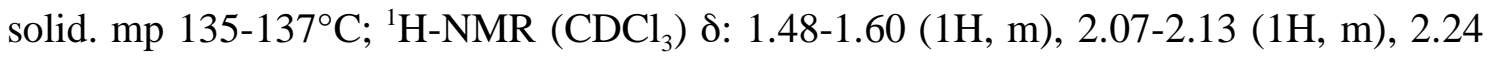
$(1 \mathrm{H}, \mathrm{dt}, J=3.0,15 \mathrm{~Hz}), 3.00(1 \mathrm{H}, \mathrm{d}, J=15 \mathrm{~Hz}), 3.20(1 \mathrm{H}, \mathrm{d}, J=16 \mathrm{~Hz}), 3.35(1 \mathrm{H}, \mathrm{d}, J$ $=16 \mathrm{~Hz}), 3.80(1 \mathrm{H}, \mathrm{d}, J=10 \mathrm{~Hz}), 3.90(3 \mathrm{H}, \mathrm{s}), 4.40(1 \mathrm{H}, \mathrm{m}), 5.35(1 \mathrm{H}, \mathrm{d}, J=10 \mathrm{~Hz})$, 6.00 (1H, brs), 6.81-6.90 (2H, m), $7.29(1 \mathrm{H}, \mathrm{d}, J=9.3 \mathrm{~Hz}) ;{ }^{13} \mathrm{C}-\mathrm{NMR}\left(\mathrm{CDCl}_{3}\right)$ $\delta: 30.5$, 30.8, 34.5, 35.5, 52.3, 55.5, 67.1, 79.1, 113.0, 113.9, 115.9, 122.5, 123.1, 127.0, 137.1, 140.5, 159.6; IR (KBr) cm $\mathrm{cm}^{-1}$ 3437, 2229; MS m/z $283\left(\mathrm{M}^{+}\right)$; HRMS Calcd for $\mathrm{C}_{17} \mathrm{H}_{17} \mathrm{NO}_{3}: 283.1208\left(\mathrm{M}^{+}\right)$, found: 283.1224 .

4-Methoxy-1-(oxiranylmethyl)benzocyclobutene-1-carbonitrile (12). According to the procedure for the synthesis of 8a, 4-methoxybenzocyclobutene-1-carbonitrile (500 $\mathrm{mg}, 3.14 \mathrm{mmol}$ ) was treated with LDA and glycidyl tosylate $(716 \mathrm{mg}, 3.14 \mathrm{mmol})$, successively, to afford the alkylated benzocyclobutene 12 (368 mg, 55\%) as a colorless oil (ca. $1: 1$ mixture of diastereomers). ${ }^{1} \mathrm{H}-\mathrm{NMR}\left(\mathrm{CDCl}_{3}\right) \delta: 2.00(0.5 \mathrm{H}, \mathrm{dd}, J=7.0,14$ Hz), $2.09(0.5 \mathrm{H}, \mathrm{dd}, J=6.3,14 \mathrm{~Hz}), 2.22(0.5 \mathrm{H}, \mathrm{dd}, J=5.0,14 \mathrm{~Hz}), 2.36(0.5 \mathrm{H}, \mathrm{dd}, J=$ 4.4, $14 \mathrm{~Hz}), 2.58-2.61(1 \mathrm{H}, \mathrm{m}), 2.83-2.90(1 \mathrm{H}, \mathrm{m}), 3.13-3.40(0.5 \mathrm{H}, \mathrm{m}), 3.40-3.45(0.5 \mathrm{H}$, m), $3.37(0.5 \mathrm{H}, \mathrm{d}, J=14 \mathrm{~Hz}), 3.43(0.5 \mathrm{H}, \mathrm{d}, J=14 \mathrm{~Hz}), 3.72(0.5 \mathrm{H}, \mathrm{d}, J=14 \mathrm{~Hz}), 3.74$ $(0.5 \mathrm{H}, \mathrm{d}, J=14 \mathrm{~Hz}), 3.79(3 \mathrm{H}, \mathrm{s}), 6.73(1 \mathrm{H}, \mathrm{brs}), 6.81-6.88(1 \mathrm{H}, \mathrm{m}), 7.12(0.5 \mathrm{H}, \mathrm{d}, J=$ $8.2 \mathrm{~Hz}), 7.21(0.5 \mathrm{H}, \mathrm{d}, J=8.2 \mathrm{~Hz}) ;{ }^{13} \mathrm{C}-\mathrm{NMR}\left(\mathrm{CDCl}_{3}\right) \delta: 39.87,39.92,40.1,40.3,42.2$, 42.4, 46.3, 46.6, 49.1, 49.2, 55.6, 109.1, 109.2, 115.2, 121.4, 121.5, 122.9, 123.6, 127.9, 130.0, 134.1, 134.4, 141.7, 141.9, 161.19, 161.22; IR (neat) $\mathrm{cm}^{-1}: 2232$; MS m/z 215 $\left(\mathrm{M}^{+}\right)$; HRMS Calcd for $\mathrm{C}_{13} \mathrm{H}_{13} \mathrm{NO}_{2}: 215.0946\left(\mathrm{M}^{+}\right)$, found: 215.0933 .

\section{1-[3-(3-Furyl)-2-hydroxyprop-1-yl]-4-methoxybenzocyclobutene-1-carbonitrile (13).}

$n$-Butyllithium (1.4 M in hexane, $4.0 \mathrm{ml}, 5.6 \mathrm{mmol}$ ) was added to a solution of 3bromofuran $(0.51 \mathrm{ml}, 5.51 \mathrm{mmol})$ in anhydrous $\mathrm{Et}_{2} \mathrm{O}(26 \mathrm{ml})$ at $-78^{\circ} \mathrm{C}$ and the mixture was stirred at the same temperature for 30min. A solution of the epoxide 12 (790 $\mathrm{mg}$, $3.67 \mathrm{mmol})$ and trifluoroborane etherate $(0.47 \mathrm{ml}, 3.67 \mathrm{mmol})$ in anhydrous $\mathrm{Et}_{2} \mathrm{O}(5 \mathrm{ml})$ was added dropwise to the mixture, and then allowed to warm to $0^{\circ} \mathrm{C}$ over $30 \mathrm{~min}$. The reaction was quenched with sat. $\mathrm{NH}_{4} \mathrm{Cl}$, and the mixture was extracted with $\mathrm{CH}_{2} \mathrm{Cl}_{2}$. The organic layer was dried over $\mathrm{MgSO}_{4}$ and evaporated to leave a residue, which was chromatographed on silica gel (hexane : acetone $=8: 1$ ) to afford the alcohol 13 (641 $\mathrm{mg}, 61 \%)$ as a colorless oil (ca. $1: 1$ mixture of diastereomers). ${ }^{1} \mathrm{H}-\mathrm{NMR}\left(\mathrm{CDCl}_{3}\right) \delta$ : $1.67(1 \mathrm{H}, \mathrm{br}), 1.96-2.03(1 \mathrm{H}, \mathrm{m}), 2.14-2.24(1 \mathrm{H}, \mathrm{m}), 2.59$ (1H, dd, $J=8.0,14 \mathrm{~Hz}), 2.64-$ $2.75(1 \mathrm{H}, \mathrm{m}), 3.29(0.5 \mathrm{H}, \mathrm{d}, J=14 \mathrm{~Hz}), 3.48(0.5 \mathrm{H}, \mathrm{d}, J=14 \mathrm{~Hz}), 3.72(1 \mathrm{H}, \mathrm{d}, J=14$ $\mathrm{Hz}), 3.78(1.5 \mathrm{H}, \mathrm{s}), 3.79(1.5 \mathrm{H}, \mathrm{s}), 4.15-4.23(1 \mathrm{H}, \mathrm{m}), 6.33(1 \mathrm{H}, \mathrm{brs}), 6.71(1 \mathrm{H}, \mathrm{dd}, J=$ 
$1.4,9.3 \mathrm{~Hz}), 6.79-6.84(1 \mathrm{H}, \mathrm{m}), 7.13(0.5 \mathrm{H}, \mathrm{d}, J=8.2 \mathrm{~Hz}), 7.21(1 \mathrm{H}, \mathrm{d}, J=8.0 \mathrm{~Hz})$,

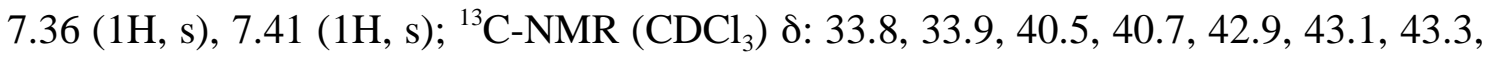
44.1, 55.7, 69.7, 69.7, 108.9, 109.3, 111.3, 115.1, 120.2, 120.3, 122.1, 122.2, 122.9, $124.7,134.9,135.6,140.38,140.43,142.0,142.5,143.4,143.5,161.0,161.2$; IR (neat) $\mathrm{cm}^{-1}: 3480,2232$; MS $\mathrm{m} / \mathrm{z}, 283\left(\mathrm{M}^{+}\right)$; HRMS Calcd for $\mathrm{C}_{17} \mathrm{H}_{17} \mathrm{NO}_{3}: 283.1208\left(\mathrm{M}^{+}\right)$, found: 283.1208 .

Thermal Reaction of 13. Synthesis of 14 and 15. According to the general procedure, the compound 13 afforded the tetracyclic product $14(41 \%)$ and the pentacyclic product $15(29 \%)$ as colorless solids. 14: mp 160-162 ${ }^{\circ}$; ${ }^{1} \mathrm{H}-\mathrm{NMR}\left(\mathrm{CDCl}_{3}\right) \delta: 1.82(1 \mathrm{H}, \mathrm{br})$, $1.93(1 \mathrm{H}, \mathrm{ddd}, J=1.7,11,15 \mathrm{~Hz}), 2.07(1 \mathrm{H}, \mathrm{dd}, J=12,14 \mathrm{~Hz}), 2.57(1 \mathrm{H}, \mathrm{ddd}, J=1.3$, $5.1,12 \mathrm{~Hz}), 3.05-3.12(2 \mathrm{H}, \mathrm{m}), 3.26(1 \mathrm{H}, \mathrm{dd}, J=3.4,16 \mathrm{~Hz}), 3.63(1 \mathrm{H}, \mathrm{d}, J=11 \mathrm{~Hz})$, 3.74-3.79 (1H, m), $3.80(3 \mathrm{H}, \mathrm{s}), 5.27(1 \mathrm{H}, \mathrm{ddd}, J=2.1,3.4,11 \mathrm{~Hz}), 5.90(1 \mathrm{H}, \mathrm{s}), 6.88-$

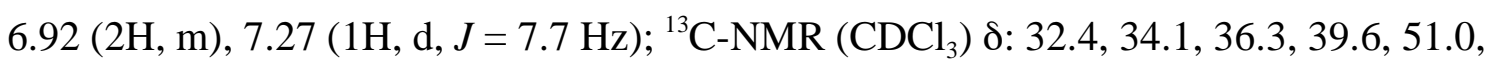
55.2, 64.6, 78.2, 107.2, 112.7, 115.6, 121.8, 123.4, 126.7, 136.7, 142.2, 159.6; IR (KBr) $\mathrm{cm}^{-1}:$ 3450, 2223; MS m/z $283\left(\mathrm{M}^{+}\right)$; HRMS Calcd for $\mathrm{C}_{17} \mathrm{H}_{17} \mathrm{NO}_{3}: 283.1208\left(\mathrm{M}^{+}\right)$, found: 283.1179. 15: $\mathrm{mp} 160-162{ }^{\circ} \mathrm{C} ;{ }^{1} \mathrm{H}-\mathrm{NMR}\left(\mathrm{CDCl}_{3}\right) \delta: 1.97(1 \mathrm{H}, \mathrm{d}, J=16 \mathrm{~Hz}), 2.09$ $2.14(1 \mathrm{H}, \mathrm{m}), 2.51(1 \mathrm{H}, \mathrm{dd}, J=1.3,5.1 \mathrm{~Hz}), 2.85(1 \mathrm{H}, \mathrm{d}, J=13 \mathrm{~Hz}), 2.96-3.02(2 \mathrm{H}, \mathrm{m})$, 3.08-3.12 (1H, m), $3.29(1 \mathrm{H}, \mathrm{dd}, J=7.7,16 \mathrm{~Hz}), 3.80(3 \mathrm{H}, \mathrm{s}), 4.38(1 \mathrm{H}, \mathrm{t}, J=5.3 \mathrm{~Hz})$, $4.64(1 \mathrm{H}$, q-like, $J=8.1 \mathrm{~Hz}), 5.69(1 \mathrm{H}, \mathrm{d}, J=3.4 \mathrm{~Hz}), 6.73(1 \mathrm{H}, \mathrm{d}, J=2.6 \mathrm{~Hz}), 6.82$

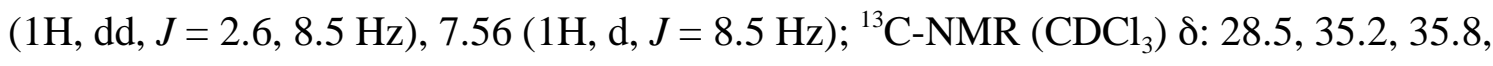
43.6, 44.5, 44.8, 55.3, 73.3, 78.7, 108.6, 112.5, 114.6, 125.4, 127.1, 127.3, 134.0, 159.6; IR (KBr) cm $\mathrm{cm}^{-1}: 2223$; MS m/z $283\left(\mathrm{M}^{+}\right)$; HRMS Calcd for $\mathrm{C}_{17} \mathrm{H}_{17} \mathrm{NO}_{3}: 283.1208\left(\mathrm{M}^{+}\right)$, found: 283.1194.

\section{1-[3-(3-Furyl)-2-(methoxymethoxy)prop-1-yl]-4-methoxybenzocyclobutene-1-}

carbonitrile (16). A solution of the alcohol $13(50 \mathrm{mg}, 0.176 \mathrm{mmol})$, chloromethyl methyl ether ( $43 \mu \mathrm{l}, 0.53 \mathrm{mmol})$, and $N, N$-diisopropylethylamine $(0.12 \mathrm{ml}, 0.71 \mathrm{mmol})$ was refluxed for $3 \mathrm{~h}$ under Ar atmosphere. After evaporation of the solvent, the residue was chromatographed on silica gel (hexane : acetone $=30: 1$ ) to afford the MOM ether $16(38 \mathrm{mg}, 66 \%)$ as a colorless oil (ca. $1: 1$ mixture of diastereomers). ${ }^{1} \mathrm{H}-\mathrm{NMR}$

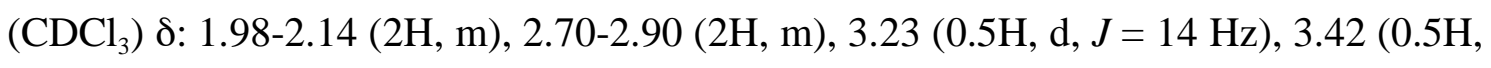
$\mathrm{d}, J=14 \mathrm{~Hz}), 3.43(1.5 \mathrm{H}, \mathrm{s}), 3.47(1.5 \mathrm{H}, \mathrm{s}), 3.67(0.5 \mathrm{H}, \mathrm{d}, J=14 \mathrm{~Hz}), 3.69(0.5 \mathrm{H}, \mathrm{d}, J$ $=14 \mathrm{~Hz}), 3.78(3 \mathrm{H}, \mathrm{s}), 4.05-4.19(1 \mathrm{H}, \mathrm{m}), 4.73-4.81(2 \mathrm{H}, \mathrm{m}), 6.30(1 \mathrm{H}, \mathrm{brs}), 6.69(1 \mathrm{H}$, brs), $6.81(1 \mathrm{H}, \mathrm{dd}, J=1.3,8.2 \mathrm{~Hz}), 7.12(1 \mathrm{H}, \mathrm{d}, J=8.2 \mathrm{~Hz}), 7.26-7.28(1 \mathrm{H}, \mathrm{m}), 7.34-$ 
$7.37(1 \mathrm{H}, \mathrm{m}) ;{ }^{13} \mathrm{C}-\mathrm{NMR}\left(\mathrm{CDCl}_{3}\right) \delta: 30.6,40.3,41.0,41.6,42.9,44.2,55.7,56.3,56.5$, 75.8, 76.2, 96.4, 96.6, 109.0, 109.3, 111.57, 111.62, 115.1, 115.2, 120.1, 120.3, 122.1, 123.0, 124.0, 135.1, 135.8, 140.19, 140.24, 142.0, 142.4, 143.0, 161.1, 161.3; IR (neat) $\mathrm{cm}^{-1}: 2231$; MS m/z $327\left(\mathrm{M}^{+}\right)$; HRMS Calcd for $\mathrm{C}_{19} \mathrm{H}_{21} \mathrm{NO}_{4}: 327.1471\left(\mathrm{M}^{+}\right)$, found: 327.1458 .

Thermal Reaction of 16. Synthesis of 17 and 18. According to the general procedure, the compound 16 afforded the tetracyclic products 17 (19\%) as a pale yellow oil and 18 $(14 \%)$ as a colorless solid. 17: ${ }^{1} \mathrm{H}-\mathrm{NMR}\left(\mathrm{CDCl}_{3}\right) \delta: 1.98(1 \mathrm{H}, \mathrm{t}, J=12 \mathrm{~Hz}), 2.12(1 \mathrm{H}$, dd, $J=12,14 \mathrm{~Hz}), 2.60(1 \mathrm{H}, \mathrm{dd}, J=5.1,12 \mathrm{~Hz}), 3.08-3.16(2 \mathrm{H}, \mathrm{m}), 3.27(1 \mathrm{H}, \mathrm{dd}, J=3.4$, $16 \mathrm{~Hz}), 3.43(3 \mathrm{H}, \mathrm{s}), 3.61-3.70(2 \mathrm{H}, \mathrm{m}), 3.81(3 \mathrm{H}, \mathrm{s}), 4.71(2 \mathrm{H}, \mathrm{s}), 5.27(1 \mathrm{H}, \mathrm{ddd}, J=$ 3.0, 5.6, $11 \mathrm{~Hz}), 5.91(1 \mathrm{H}, \mathrm{s}), 6.82(1 \mathrm{H}, \mathrm{d}, J=2.6 \mathrm{~Hz}), 6.85(1 \mathrm{H}, \mathrm{dd}, J=2.6,8.5 \mathrm{~Hz})$, $7.29(1 \mathrm{H}, \mathrm{d}, J=8.5 \mathrm{~Hz}) ;{ }^{13} \mathrm{C}-\mathrm{NMR}\left(\mathrm{CDCl}_{3}\right) \delta: 32.2,34.2,35.6,36.2,51.5,55.4,55.8$, 69.7, 78.6, 94.7, 106.0, 111.8, 114.7, 122.9, 124.2, 129.3, 136.0, 142.1, 159.4; MS m/z $327\left(\mathrm{M}^{+}\right)$; HRMS Calcd for $\mathrm{C}_{19} \mathrm{H}_{21} \mathrm{NO}_{4}: 327.1471\left(\mathrm{M}^{+}\right)$, found: 327.1460. 18: ${ }^{1} \mathrm{H}-\mathrm{NMR}$

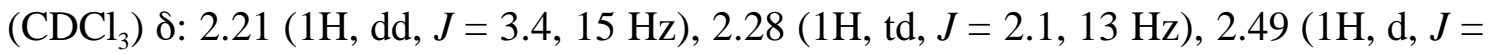
$15 \mathrm{~Hz}), 3.10-3.19(2 \mathrm{H}, \mathrm{m}), 3.25(3 \mathrm{H}, \mathrm{s}), 3.25-3.30(1 \mathrm{H}, \mathrm{m}), 3.60(1 \mathrm{H}, \mathrm{d}, J=10 \mathrm{~Hz})$, $3.80(3 \mathrm{H}, \mathrm{s}), 4.11(1 \mathrm{H}, \mathrm{dd}, J=2.1,3.4 \mathrm{~Hz}), 4.51(1 \mathrm{H}, \mathrm{d}, J=6.8 \mathrm{~Hz}), 4.56(1 \mathrm{H}, \mathrm{d}, J=6.8$ $\mathrm{Hz}), 5.26(1 \mathrm{H}, \mathrm{td}, J=3.0,10 \mathrm{~Hz}), 5.98(1 \mathrm{H}, \mathrm{s}), 6.76-6.80(2 \mathrm{H}, \mathrm{m}), 7.51(1 \mathrm{H}, \mathrm{d}, J=9.4$ $\mathrm{Hz}) ;{ }^{13} \mathrm{C}-\mathrm{NMR}\left(\mathrm{CDCl}_{3}\right)$ ठ: 30.4, 34.4, 36.6, 37.9, 51.4, 55.5, 55.8, 70.8, 78.5, 95.9, 107.3, 113.0, 115.9, 122.0, 123.6, 126.9, 136.9, 142.2, 159.6; MS m/z $327\left(\mathrm{M}^{+}\right)$; HRMS Calcd for $\mathrm{C}_{19} \mathrm{H}_{21} \mathrm{NO}_{4}: 327.1471\left(\mathrm{M}^{+}\right)$, found: 327.1484 .

Hydrogenation of the Compound 1. Synthesis of 19. A solution of the compound 1 $(85 \mathrm{mg}, 0.26 \mathrm{mmol})$ in $\mathrm{MeOH}(8 \mathrm{ml})$ was vigorously stirred in the presence of $20 \%$ $\mathrm{Pd}(\mathrm{OH})_{2} / \mathrm{C}(3.2 \mathrm{mg})$ under $\mathrm{H}_{2}$ atmosphere at room temperature for 5 days. The catalyst was filtered off and the filtrate was concentrated in vacuo. The residue was purified by silica gel column chromatography (hexane : acetone $=20: 1$ ) to afford the hydrogenated product $19(51 \mathrm{mg}, 60 \%)$ as a colorless solid. mp $135-137^{\circ} \mathrm{C} ;{ }^{1} \mathrm{H}-\mathrm{NMR}\left(\mathrm{CDCl}_{3}\right) \delta: 1.73$ $1.77(1 \mathrm{H}, \mathrm{m}), 1.84(1 \mathrm{H}, \mathrm{dt}, J=3.0,12 \mathrm{~Hz}), 2.38(1 \mathrm{H}, \mathrm{dt}, J=3.4,12 \mathrm{~Hz}), 2.60$ (1H, ddd, $J=2.8,6.6,15 \mathrm{~Hz}), 2.68(1 \mathrm{H}, \mathrm{q}, J=8.1 \mathrm{~Hz}), 3.05-3.12(2 \mathrm{H}, \mathrm{m}), 3.17-3.24(2 \mathrm{H}, \mathrm{m})$, $3.66(1 \mathrm{H}, \mathrm{t}, J=8.1 \mathrm{~Hz}), 3.82(3 \mathrm{H}, \mathrm{s}), 3.92-4.03(4 \mathrm{H}, \mathrm{m}), 4.61(1 \mathrm{H}, \mathrm{dt}, J=3.0,4.5 \mathrm{~Hz})$, 6.81-6.84 (2H, m), $7.32(1 \mathrm{H}, \mathrm{d}, J=8.5 \mathrm{~Hz}) ;{ }^{13} \mathrm{C}-\mathrm{NMR}\left(\mathrm{CDCl}_{3}\right)$ ठ: 27.7, 30.8, 35.2, 35.8, 47.3, 55.3, 64.3, 65.0, 69.7, 77.7, 107.4, 112.6, 115.7, 123.1, 125.28, 125.30, 137.9, 159.4; IR (KBr) cm $\mathrm{cm}^{-1}: 2228$; MS m/z $327\left(\mathrm{M}^{+}\right)$; HRMS Calcd for $\mathrm{C}_{19} \mathrm{H}_{21} \mathrm{NO}_{4}: 327.1471$ 
$\left(\mathrm{M}^{+}\right)$, found: 327.1452 .

Deacetalization of the Compound 19. Synthesis of 20. A mixture of the compound 19 $(51 \mathrm{mg}, 0.16 \mathrm{mmol})$ and $p$-toluenesulfonic acid $(30 \mathrm{mg}, 0.16 \mathrm{mmol})$ in acetone $(10 \mathrm{ml})$ was refluxed for $40 \mathrm{~h}$. The reaction mixture was diluted with sat. $\mathrm{NaHCO}_{3}$, extracted with $\mathrm{CH}_{2} \mathrm{Cl}_{2}$, and dried over $\mathrm{MgSO}_{4}$. The residue obtained by evaporation of the solvent was chromatographed on silica gel (hexane : acetone $=5: 1$ ) to afford the ketone 20 (37 $\mathrm{mg}, 83 \%)$ as a colorless solid. mp $167-169^{\circ} \mathrm{C} ;{ }^{1} \mathrm{H}-\mathrm{NMR}\left(\mathrm{CDCl}_{3}\right)$ $\delta: 2.24-2.35(2 \mathrm{H}, \mathrm{m})$, 2.37-2.45 (1H, m), 2.50-2.58 (2H, m), $2.67(1 \mathrm{H}, \mathrm{td}, J=8.1,16 \mathrm{~Hz}), 2.98(1 \mathrm{H}, \mathrm{dd}, J=$ 4.7, $16 \mathrm{~Hz}), 3.09$ (1H, dd, $J=5.5,16 \mathrm{~Hz}), 3.81(3 \mathrm{H}, \mathrm{s}), 3.81-3.86(1 \mathrm{H}, \mathrm{m}), 3.94-3.99$ $(1 \mathrm{H}, \mathrm{m}), 4.19-4.23(1 \mathrm{H}, \mathrm{m}), 6.80(1 \mathrm{H}, \mathrm{d}, J=2.5 \mathrm{~Hz}), 6.85(1 \mathrm{H}, \mathrm{dd}, J=2.5,8.5 \mathrm{~Hz})$, $7.49(1 \mathrm{H}, \mathrm{d}, J=8.5 \mathrm{~Hz}) ;{ }^{13} \mathrm{C}-\mathrm{NMR}\left(\mathrm{CDCl}_{3}\right)$ d: 31.9, 33.9, 35.3, 37.9, 47.9, 55.4, 63.8, $67.8,80.5,113.0,115.6,120.6,123.1,126.8,135.5,160.0,215.5$; IR $(\mathrm{KBr}) \mathrm{cm}^{-1}: 2226$, 1712; MS $m / z 283\left(\mathrm{M}^{+}\right)$; HRMS Calcd for $\mathrm{C}_{17} \mathrm{H}_{17} \mathrm{NO}_{3}: 283.1208\left(\mathrm{M}^{+}\right)$, found: 283.1178.

4-Hydroxybenzocyclobutene-1-carbonitrile (22). A mixture of the benzocyclobutene 11 (500 $\mathrm{mg}, 3.14 \mathrm{mmol})$ and iodotrimethylsilane $(1.79 \mathrm{ml}, 12.6 \mathrm{mmol})$ in anhydrous $\mathrm{MeCN}(10 \mathrm{ml})$ was refluxed for $15 \mathrm{~h}$ under Ar atmosphere. After addition of dil. $\mathrm{HCl}$, the aqueous solution was extracted with $\mathrm{Et}_{2} \mathrm{O}$, and the organic layer was dried over $\mathrm{MgSO}_{4}$. The solvent was evaporated off to leave a residue, which was chromatographed on silica gel (hexane : acetone $=5: 1)$ to afford the alcohol $22(434 \mathrm{mg}, 95 \%)$ as a pale yellow solid. mp 110-112 ${ }^{\circ} \mathrm{C} ;{ }^{1} \mathrm{H}-\mathrm{NMR}\left(\mathrm{CDCl}_{3}\right) \delta: 3.42(1 \mathrm{H}, \mathrm{dd}, J=2.1,14 \mathrm{~Hz}), 3.57$ $(1 \mathrm{H}, \mathrm{dd}, J=5.5,14 \mathrm{~Hz}), 4.14(1 \mathrm{H}, \mathrm{dd}, J=2.1,5.5 \mathrm{~Hz}), 6.64(1 \mathrm{H}, \mathrm{d}, J=1.7 \mathrm{~Hz}), 6.76$ $(1 \mathrm{H}, \mathrm{dd}, J=2.1,8.1 \mathrm{~Hz}), 7.02(1 \mathrm{H}, \mathrm{d}, J=8.1 \mathrm{~Hz}) ;{ }^{13} \mathrm{C}-\mathrm{NMR}\left(\mathrm{CDCl}_{3}\right) \delta: 27.8,35.5$, 110.6, 115.9, 119.9, 123.6, 129.5, 143.6, 157.2; IR (KBr) cm $\mathrm{cm}^{-1}: 3334,2250$; MS m/z 145 $\left(\mathrm{M}^{+}\right)$; HRMS Calcd for $\mathrm{C}_{9} \mathrm{H}_{7} \mathrm{NO}: 145.0528\left(\mathrm{M}^{+}\right)$, found: 145.0526 .

\section{4-Hydroxy-1-[3-(tetrahydropyran-2-yloxy)prop-1-yl]benzocyclobutene-1-}

carbonitrile (23). According to the procedure for the synthesis of $\mathbf{8 a}$, the compound 22 (255 mg, $1.76 \mathrm{mmol}$ ) was treated with LDA (2 equiv.) and 1-bromo-3-(tetrahydropyran2-yloxy)propane (393 mg, $1.76 \mathrm{mmol}$ ), successively, to afford the alkylated

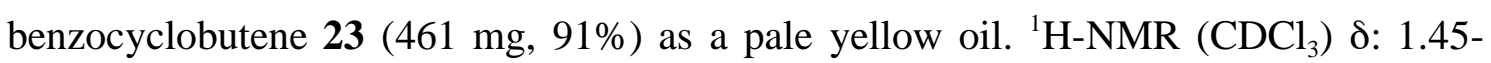
1.60 (4H, m), 1.70-1.82 (2H, m), 1.85-2.08 (4H, m), 3.17 (1H, dd, J=3.0, 14 Hz), 3.45$3.57(2 \mathrm{H}, \mathrm{m}), 3.60(1 \mathrm{H}, \mathrm{d}, J=14 \mathrm{~Hz}), 3.80-3.92(2 \mathrm{H}, \mathrm{m}), 4.60(1 \mathrm{H}, \mathrm{dd}, J=2.1,3.1 \mathrm{~Hz})$, $6.62(1 \mathrm{H}, \mathrm{s}), 6.70(1 \mathrm{H}, \mathrm{d}, J=8.1 \mathrm{~Hz}), 6.99(1 \mathrm{H}, \mathrm{dd}, J=5.6,8.1 \mathrm{~Hz}) ;{ }^{13} \mathrm{C}-\mathrm{NMR}\left(\mathrm{CDCl}_{3}\right)$

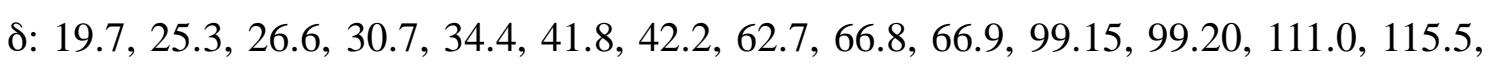


121.9, 122.8, 134.4, 142.0, 157.5; IR (neat) $\mathrm{cm}^{-1}: 3364,2234$; MS $m / z 287\left(\mathrm{M}^{+}\right)$; HRMS Calcd for $\mathrm{C}_{17} \mathrm{H}_{21} \mathrm{NO}_{3}: 287.1521\left(\mathrm{M}^{+}\right)$, found: 287.1577.

\section{4-tert-Butyldimethylsilyloxy-1-[3-(tetrahydropyran-2-yloxy)prop-1-}

yl]benzocyclobutene-1-carbonitrile (24). To a solution of the alcohol 23 (360 $\mathrm{mg}, 1.25$ mmol) in anhydrous $\mathrm{CH}_{2} \mathrm{Cl}_{2}(10 \mathrm{ml})$, triethylamine $(0.21 \mathrm{ml}, 1.50 \mathrm{mmol})$ and tertbutyldimethylsilyl trifluoromethanesulfonate $(0.32 \mathrm{ml}, 1.38 \mathrm{mmol})$ were added successively at $0^{\circ} \mathrm{C}$ under $\mathrm{Ar}$ atmosphere. The mixture was stirred at room temperature for $1.5 \mathrm{~h}$, and then diluted with $\mathrm{Et}_{2} \mathrm{O}$. The solution was washed with $3 \% \mathrm{HCl}$, sat. $\mathrm{NaHCO}_{3}$, and brine, successively, and the organic layer was dried over $\mathrm{MgSO}_{4}$. The residue obtained by evaporation of the solvent was subjected to silica gel column chromatography (hexane $:$ acetone $=50: 1)$ to afford the silyl ether $\mathbf{2 4}(476 \mathrm{mg}, 95 \%)$ as a colorless oil. ${ }^{1} \mathrm{H}-\mathrm{NMR}\left(\mathrm{CDCl}_{3}\right) \delta: 0.17(6 \mathrm{H}, \mathrm{s}), 0.96(9 \mathrm{H}, \mathrm{s}), 1.50-1.56(4 \mathrm{H}, \mathrm{m})$, 1.67-1.72 (1H, m), 1.72-1.82 (1H, m), 1.89-1.97 (2H, m), 1.98-2.10 (2H, m), $3.21(1 \mathrm{H}$, $\mathrm{d}, J=14 \mathrm{~Hz}), 3.44-3.51(2 \mathrm{H}, \mathrm{m}), 3.64(1 \mathrm{H}, \mathrm{d}, J=14 \mathrm{~Hz}), 3.79-3.86(2 \mathrm{H}, \mathrm{m}), 4.57(1 \mathrm{H}$, brs), $6.63(1 \mathrm{H}, \mathrm{d}, J=2.1 \mathrm{~Hz}), 6.73(1 \mathrm{H}, \mathrm{dd}, J=2.1,8.1 \mathrm{~Hz}), 7.06(1 \mathrm{H}, \mathrm{d}, J=8.1 \mathrm{~Hz})$;

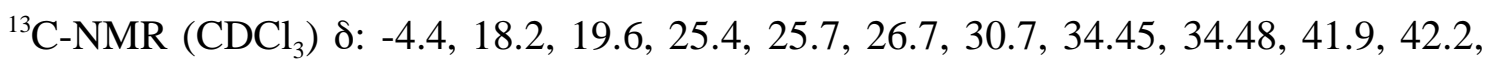
$62.3,66.5,98.8,115.6,120.3,121.8,122.8,135.8,141.7,156.8$; IR (neat) $\mathrm{cm}^{-1}: 2231$; MS $m / z, 401\left(\mathrm{M}^{+}\right)$; HRMS Calcd for $\mathrm{C}_{23} \mathrm{H}_{35} \mathrm{NO}_{3} \mathrm{Si}: 401.2386\left(\mathrm{M}^{+}\right)$, found: 401.2412.

\section{4-tert-Butyldimethylsilyloxy-1-(3-hydroxyprop-1-yl)benzocyclobutene-1-}

carbonitrile (25). A mixture of the THP ether $24(250 \mathrm{mg}, 0.623 \mathrm{mmol})$ and pyridinium p-toluenesulfonate $(31 \mathrm{mg}, 0.125 \mathrm{mmol})$ in $\mathrm{EtOH}(5 \mathrm{ml})$ was heated at $60^{\circ} \mathrm{C}$ for $3.5 \mathrm{~h}$. The mixture was diluted with sat. $\mathrm{NaHCO}_{3}$, and the resulting solution was extracted with $\mathrm{CH}_{2} \mathrm{Cl}_{2}$ and then dried over $\mathrm{MgSO}_{4}$. The residue obtained by evaporation of the solvent was subjected to silica gel column chromatography (hexane : acetone $=20: 1$ ) to afford the alcohol $25(182 \mathrm{mg}, 93 \%)$ as a colorless oil. ${ }^{1} \mathrm{H}-\mathrm{NMR}\left(\mathrm{CDCl}_{3}\right) \delta: 0.17(6 \mathrm{H}$, s), $0.96(9 \mathrm{H}, \mathrm{s}), 1.81-1.91(2 \mathrm{H}, \mathrm{m}), 1.93-2.06(2 \mathrm{H}, \mathrm{m}), 2.13(1 \mathrm{H}, \mathrm{br}), 3.19(1 \mathrm{H}, \mathrm{d}, J=14$ $\mathrm{Hz}), 3.62(1 \mathrm{H}, \mathrm{d}, J=14 \mathrm{~Hz}), 3.67(2 \mathrm{H}, \mathrm{t}, J=6.2 \mathrm{~Hz}), 6.63(1 \mathrm{H}, \mathrm{d}, J=2.1 \mathrm{~Hz}), 6.72(1 \mathrm{H}$, $\mathrm{dd}, J=2.1,8.1 \mathrm{~Hz}), 7.15(1 \mathrm{H}, \mathrm{d}, J=8.1 \mathrm{~Hz}) ;{ }^{13} \mathrm{C}-\mathrm{NMR}\left(\mathrm{CDCl}_{3}\right) \delta:-4.4,18.2,25.7,29.4$, 34.0, 41.8, 42.3, 61.8, 115.6, 120.4, 121.9, 122.7, 135.7, 141.7, 156.8; IR (neat) $\mathrm{cm}^{-1}$ : 3442, 2234; MS m/z $317\left(\mathrm{M}^{+}\right)$; HRMS Calcd for $\mathrm{C}_{18} \mathrm{H}_{27} \mathrm{NO}_{2} \mathrm{Si}: 317.1811\left(\mathrm{M}^{+}\right)$, found: 317.1792 .

\section{4-tert-Butyldimethylsilyloxy-1-[3-(3-furyl)-3-hydroxyprop-1-yl]benzocyclobutene-}

1-carbonitrile (26). To a solution of the alcohol $25(595 \mathrm{mg}, 1.87 \mathrm{mmol})$ in anhydrous 
$\mathrm{CH}_{2} \mathrm{Cl}_{2}(10 \mathrm{ml})$ was added pyridinium dichromate $(2.1 \mathrm{~g}, 5.6 \mathrm{mmol})$ at room temperature. The reaction mixture was stirred for $3 \mathrm{~h}$ under Ar atmosphere, and then diluted with $\mathrm{Et}_{2} \mathrm{O}$. After filtration through Celite pad, the filtrate was concentrated to leave a residue, which was chromatographed on silica gel (hexane : acetone $=20: 1$ ) to afford the corresponding aldehyde $(355 \mathrm{mg})$. The product was checked by a ${ }^{1} \mathrm{H}-\mathrm{NMR}$ spectrum and used for the next reaction without further characterization due to its instability. ${ }^{1} \mathrm{H}-\mathrm{NMR}\left(\mathrm{CDCl}_{3}\right) \delta: 0.20(6 \mathrm{H}, \mathrm{s}), 0.98(9 \mathrm{H}, \mathrm{s}), 2.15-2.39(2 \mathrm{H}, \mathrm{m}), 2.78-2.87$ $(2 \mathrm{H}, \mathrm{m}), 3.20-3.26(1 \mathrm{H}, \mathrm{m}), 3.67-3.70(1 \mathrm{H}, \mathrm{m}), 6.65(1 \mathrm{H}, \mathrm{s}), 6.74-6.80(1 \mathrm{H}, \mathrm{m}), 7.04-$ $7.07(1 \mathrm{H}, \mathrm{m}), 9.85(1 \mathrm{H}, \mathrm{s})$. A solution of 3-lithiofuran $(1.69 \mathrm{mmol})$ in $\mathrm{Et}_{2} \mathrm{O}(10 \mathrm{ml})$ was prepared according to the procedure for the synthesis of $\mathbf{1 3}$, and the aldehyde (355 $\mathrm{mg}$, $1.13 \mathrm{mmol})$ in anhydrous $\mathrm{Et}_{2} \mathrm{O}(6 \mathrm{ml})$ was added to the solution at $-78^{\circ} \mathrm{C}$. The reaction mixture was warmed to $-10^{\circ} \mathrm{C}$ over $30 \mathrm{~min}$, and sat. $\mathrm{NH}_{4} \mathrm{Cl}$ was added. The resulting aqueous solution was extracted with $\mathrm{CH}_{2} \mathrm{Cl}_{2}$, and the organic layer was dried over $\mathrm{MgSO}_{4}$ and then concentrated. The residue was purified by silica gel column chromatography (hexane : acetone $=30: 1)$ to afford the alcohol $26(238 \mathrm{mg}, 33 \%$ in 2 steps) as a colorless oil. ${ }^{1} \mathrm{H}-\mathrm{NMR}\left(\mathrm{CDCl}_{3}\right) \delta: 0.18(6 \mathrm{H}, \mathrm{s}), 0.97(9 \mathrm{H}, \mathrm{s}), 1.86-2.14(4 \mathrm{H}$, m), $3.17(1 \mathrm{H}, \mathrm{d}, J=14 \mathrm{~Hz}), 3.63(1 \mathrm{H}, \mathrm{d}, J=14 \mathrm{~Hz}), 4.70(1 \mathrm{H}, \mathrm{t}, J=6.2 \mathrm{~Hz}), 6.39(1 \mathrm{H}$, d, $J=5.1 \mathrm{~Hz}), 6.63(1 \mathrm{H}, \mathrm{s}), 6.73(1 \mathrm{H}, \mathrm{d}, J=8.1 \mathrm{~Hz}), 7.04(1 \mathrm{H}, \mathrm{d}, J=8.1 \mathrm{~Hz}), 7.40(2 \mathrm{H}$,

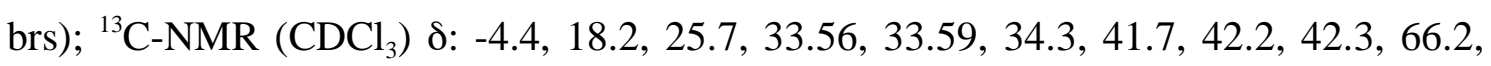
66.3, 108.2, 115.7, 120.5, 121.8, 122.7, 122.8, 128.4, 135.6, 135.7, 139.0, 141.7, 143.4, 156.9; IR (neat) $\mathrm{cm}^{-1}: 3449,2234$; MS $m / z 383\left(\mathrm{M}^{+}\right)$; HRMS Calcd for $\mathrm{C}_{22} \mathrm{H}_{29} \mathrm{NO}_{3} \mathrm{Si}$ : $383.1917\left(\mathrm{M}^{+}\right)$, found: 383.1960 .

\section{4-tert-Butyldimethylsilyloxy-1-[3-(3-furyl)-3-oxo-prop-1-yl]benzocyclobutene-1-}

carbonitrile (27). According to the procedure for oxidation of 25, the alcohol 26 (238 $\mathrm{mg}, 0.62 \mathrm{mmol}$ ) and pyridinium dichromate $(467 \mathrm{mg}, 1.24 \mathrm{mmol})$ afforded the ketone

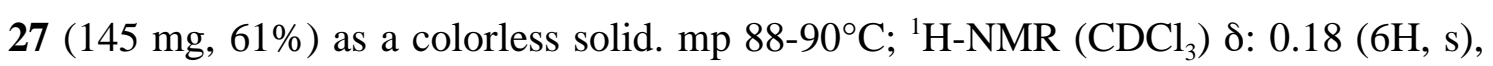
$0.97(9 \mathrm{H}, \mathrm{s}), 2.30-2.45(2 \mathrm{H}, \mathrm{m}), 3.06(2 \mathrm{H}, \mathrm{t}, J=7.9 \mathrm{~Hz}), 3.24(1 \mathrm{H}, \mathrm{d}, J=14 \mathrm{~Hz}), 3.67$ $(1 \mathrm{H}, \mathrm{d}, J=14 \mathrm{~Hz}), 6.65(1 \mathrm{H}, \mathrm{s}), 6.75(1 \mathrm{H}, \mathrm{dd}, J=1.2,8.1 \mathrm{~Hz}), 6.77(1 \mathrm{H}, \mathrm{d}, J=1.2 \mathrm{~Hz})$, $7.05(1 \mathrm{H}, \mathrm{d}, J=8.1 \mathrm{~Hz}), 7.46(1 \mathrm{H}, \mathrm{s}), 8.08(1 \mathrm{H}, \mathrm{s}) ;{ }^{13} \mathrm{C}-\mathrm{NMR}\left(\mathrm{CDCl}_{3}\right)$ 8: -4.4, 18.2, 25.6, 31.5, 36.8, 41.2, 42.1, 108.4, 115.7, 120.6, 121.4, 122.7, 127.2, 135.1, 141.6, 144.2, 147.1, 157.0, 192.3; IR (KBr) $\mathrm{cm}^{-1}: 2232,1679$; MS m/z $381\left(\mathrm{M}^{+}\right)$; HRMS Calcd for $\mathrm{C}_{22} \mathrm{H}_{27} \mathrm{NO}_{3} \mathrm{Si}: 381.1760\left(\mathrm{M}^{+}\right)$, found: 381.1821 .

\section{4-tert-Butyldimethylsilyloxy-1-[3-(3-furyl)-3-oxo-prop-1-yl]benzocyclobutene-1-}


carbonitrile Ethylene Ketal (28). A solution of the ketone 27 (300 mg, $0.79 \mathrm{mmol}$ ), ethylene glycol $(0.17 \mathrm{ml}, 3.15 \mathrm{mmol})$, and $p$-toluenesulfonic acid (15 mg, $0.079 \mathrm{mmol})$ in anhydrous benzene (40 ml) was refluxed using Dean-Stark apparatus for $15 \mathrm{~h}$. The solution was washed with sat. $\mathrm{NaHCO}_{3}$ and brine, dried over $\mathrm{MgSO}_{4}$, and then evaporated. The residue was chromatographed on silica gel (hexane : acetone $=50: 1$ ) to afford the ketal $28(327 \mathrm{mg}, 92 \%)$ as a colorless oil. ${ }^{1} \mathrm{H}-\mathrm{NMR}\left(\mathrm{CDCl}_{3}\right)$ ס: $0.17(6 \mathrm{H}, \mathrm{s})$, $0.96(9 \mathrm{H}, \mathrm{s}), 2.00-2.06(2 \mathrm{H}, \mathrm{m}), 2.12-2.25(2 \mathrm{H}, \mathrm{m}), 3.16(1 \mathrm{H}, \mathrm{d}, J=14 \mathrm{~Hz}), 3.60(1 \mathrm{H}, \mathrm{d}$, $J=14 \mathrm{~Hz}), 3.87-3.89(2 \mathrm{H}, \mathrm{m}), 3.96-3.98(2 \mathrm{H}, \mathrm{m}), 6.32(1 \mathrm{H}, \mathrm{s}), 6.60(1 \mathrm{H}, \mathrm{s}), 6.72(1 \mathrm{H}, \mathrm{d}$, $J=8.1 \mathrm{~Hz}), 7.00(1 \mathrm{H}, \mathrm{d}, J=8.1 \mathrm{~Hz}), 7.35(1 \mathrm{H}, \mathrm{s}), 7.36(1 \mathrm{H}, \mathrm{s}) ;{ }^{13} \mathrm{C}-\mathrm{NMR}\left(\mathrm{CDCl}_{3}\right) \delta$ : 4.4, 18.2, 25.6, 31.6, 36.1, 41.5, 42.1, 64.7, 106.7, 108.4, 115.6, 120.4, 121.6, 122.6, 127.1, 135.6, 139.8, 141.6, 143.3, 156.8; IR (neat) $\mathrm{cm}^{-1}: 2232$; MS $\mathrm{m} / z 425\left(\mathrm{M}^{+}\right)$; HRMS Calcd for $\mathrm{C}_{24} \mathrm{H}_{31} \mathrm{NO}_{4} \mathrm{Si}: 425.2022\left(\mathrm{M}^{+}\right)$, found: 425.2003 .

Thermal Reaction of 28. Synthesis of 29a. According to the general procedure, the compound 28 afforded the tetracyclic product 29a (61\%) as a colorless solid. mp $156^{\circ} \mathrm{C}$;

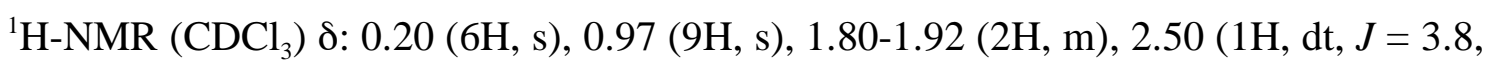
$14 \mathrm{~Hz}), 2.84(1 \mathrm{H}, \mathrm{dd}, J=3.0,14 \mathrm{~Hz}), 3.06(1 \mathrm{H}, \mathrm{dd}, J=1.7,16 \mathrm{~Hz}), 3.23(1 \mathrm{H}, \mathrm{d}, J=16$ $\mathrm{Hz}), 3.82-3.93(4 \mathrm{H}, \mathrm{m}), 3.94-4.00(1 \mathrm{H}, \mathrm{m}), 5.25-5.29(1 \mathrm{H}, \mathrm{m}), 6.00(1 \mathrm{H}, \mathrm{d}, J=1.7 \mathrm{~Hz})$, 6.73-6.78 (2H, m), $7.15(1 \mathrm{H}, \mathrm{d}, J=8.1 \mathrm{~Hz}) ;{ }^{13} \mathrm{C}-\mathrm{NMR}\left(\mathrm{CDCl}_{3}\right) \delta:-4.3,18.2,25.6,29.7$, 31.3, 33.9, 35.2, 51.1, 63.6, 65.2, 79.6, 104.5, 110.2, 118.4, 121.8, 122.2, 123.2, 126.6, 136.6, 142.8, 155.6; IR (KBr) $\mathrm{cm}^{-1}: 2230$; MS m/z $425\left(\mathrm{M}^{+}\right)$; HRMS Calcd for $\mathrm{C}_{24} \mathrm{H}_{31} \mathrm{NO}_{4} \mathrm{Si}: 425.2022\left(\mathrm{M}^{+}\right)$, found: 425.2020 .

Desilylation of the Compound 29a. Synthesis of 29b. According to the procedure for the synthesis of $\mathbf{9 c}$, the compound $29 \mathbf{a}(220 \mathrm{mg}, 0.52 \mathrm{mmol})$ was treated with TBAF $(0.57 \mathrm{mmol})$ to afford the desilylated tetracyclic product $29 \mathrm{~b}(140 \mathrm{mg}, 87 \%)$ as a colorless solid. mp $156{ }^{\circ} \mathrm{C} ;{ }^{1} \mathrm{H}-\mathrm{NMR}\left(\mathrm{CDCl}_{3}\right.$-DMSO- $\left.d_{6}\right) \delta: 1.60-1.72(2 \mathrm{H}, \mathrm{m}), 2.28(1 \mathrm{H}$, $\mathrm{dt}, J=3.8,14 \mathrm{~Hz}), 2.60-2.68(1 \mathrm{H}, \mathrm{m}), 2.86(1 \mathrm{H}, \mathrm{dd}, J=2.4,16 \mathrm{~Hz}), 3.00(1 \mathrm{H}, \mathrm{dd}, J=$ $3.4,16 \mathrm{~Hz}), 3.65-3.75(4 \mathrm{H}, \mathrm{m}), 3.79-3.83(1 \mathrm{H}, \mathrm{m}), 5.06-5.11(1 \mathrm{H}, \mathrm{m}), 5.82(1 \mathrm{H}, \mathrm{d}, J=$ $2.1 \mathrm{~Hz}), 6.56-6.60(2 \mathrm{H}, \mathrm{m}), 6.93(1 \mathrm{H}, \mathrm{d}, J=9.4 \mathrm{~Hz}), 8.85(1 \mathrm{H}, \mathrm{s}) ;{ }^{13} \mathrm{C}-\mathrm{NMR}\left(\mathrm{CDCl}_{3^{-}}\right.$ DMSO- $\left.d_{6}\right) \delta: 29.2,30.7,33.4,34.6,50.6,63.2$, 64.8, 79.2, 104.1, 109.9, 113.9, 117.0, 120.6, 122.1, 126.3, 136.2, 142.5, 157.1; IR ( $\mathrm{KBr}) \mathrm{cm}^{-1}: 3294,2228$; MS m/z $311\left(\mathrm{M}^{+}\right)$; HRMS Calcd for $\mathrm{C}_{18} \mathrm{H}_{17} \mathrm{NO}_{4}: 311.1158\left(\mathrm{M}^{+}\right)$, found: 311.1129 .

Synthesis of 29c. According to the procedure for the synthesis of $\mathbf{4 b}$, the alcohol $\mathbf{2 9 b}$ (30 mg, $0.1 \mathrm{mmol})$ was reacted with triisopropylsilyl trifluoromethanesulfonate $(0.11$ 
mmol) and triethylamine $(0.12 \mathrm{mmol})$ to afford the TIPS derivative $29 \mathrm{c}(45 \mathrm{mg}, 96 \%)$ as a colorless oil. ${ }^{1} \mathrm{H}-\mathrm{NMR}\left(\mathrm{CDCl}_{3}\right) \delta: 1.02-1.15(18 \mathrm{H}, \mathrm{m}), 1.20-1.32(3 \mathrm{H}, \mathrm{m}), 1.80-1.95$ $(2 \mathrm{H}, \mathrm{m}), 2.51(1 \mathrm{H}, \mathrm{dt}, J=4.4,15 \mathrm{~Hz}), 2.85(1 \mathrm{H}, \mathrm{td}, J=3.3,15 \mathrm{~Hz}), 3.06(1 \mathrm{H}, \mathrm{dd}, J=$ 2.5, $16 \mathrm{~Hz}), 3.25(1 \mathrm{H}, \mathrm{dd}, J=3.6,16 \mathrm{~Hz}), 3.84-3.95(4 \mathrm{H}, \mathrm{m}), 3.97-4.05(1 \mathrm{H}, \mathrm{m}), 5.28$ $(1 \mathrm{H}, \mathrm{ddd}, J=2.5,3.6,11 \mathrm{~Hz}), 6.00(1 \mathrm{H}, \mathrm{d}, J=1.7 \mathrm{~Hz}), 6.75-6.81(2 \mathrm{H}, \mathrm{m}), 7.14(1 \mathrm{H}, \mathrm{d}$, $J=8.8 \mathrm{~Hz}) ;{ }^{13} \mathrm{C}-\mathrm{NMR}\left(\mathrm{CDCl}_{3}\right) \delta: 12.9,18.2,30.0,31.5,34.2,35.5,51.4,63.9,65.5$, 79.9, 104.8, 110.4, 118.6, 122.0, 122.5, 123.1, 126.8, 136.8, 143.0, 156.2; IR (neat) $\mathrm{cm}^{-}$ 1: 2230; MS m/z $467\left(\mathrm{M}^{+}\right)$; HRMS Calcd for $\mathrm{C}_{27} \mathrm{H}_{37} \mathrm{NO}_{4} \mathrm{Si}: 467.2483\left(\mathrm{M}^{+}\right)$, found: 467.2520.

\section{1-[3-(3-Furyl)-3-oxo-prop-1-yl]benzocyclobutene-1-carbonitrile Ethylene Ketal}

(32). According to the procedure for the synthesis of 8a, benzocyclobutene-1carbonitrile $30(557 \mathrm{mg}, 4.31 \mathrm{mmol})$ and the bromide 31 (1.07 g, $4.31 \mathrm{mmol})$ afforded the alkylated benzocyclobutene $32(396 \mathrm{mg}, 31 \%)$ as a colorless oil. ${ }^{1} \mathrm{H}-\mathrm{NMR}\left(\mathrm{CDCl}_{3}\right)$

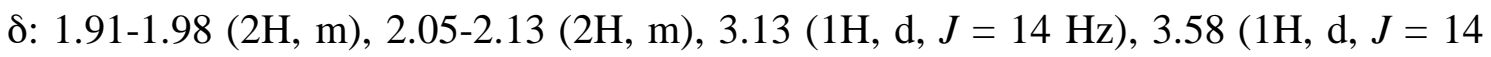
Hz), 3.77-3.92 (4H, m), 6.20 (1H, s), 7.00-7.07 (2H, m), 7.12-7.17 (2H, m), 7.19-7.26

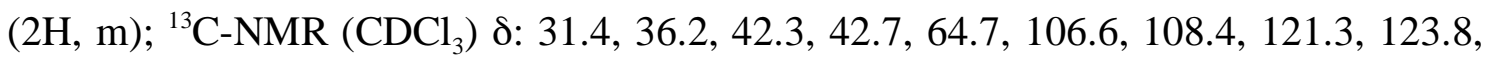
127.1, 127.9, 129.4, 139.9, 141.1, 143.3, 143.4; IR (neat) $\mathrm{cm}^{-1}: 2233$; MS $m / z 295\left(\mathrm{M}^{+}\right)$; HRMS Calcd for $\mathrm{C}_{18} \mathrm{H}_{17} \mathrm{NO}_{3}: 295.1208\left(\mathrm{M}^{+}\right)$, found: 295.1200 .

Thermal Reaction of 32. Synthesis of 33. According to the general procedure, the compound 32 afforded the tetracyclic product $33(78 \%)$ as a colorless solid. mp 154-

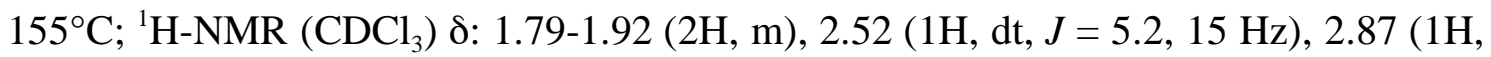
$\mathrm{dt}, J=3.3,15 \mathrm{~Hz}), 3.10(1 \mathrm{H}, \mathrm{dd}, J=2.2,16 \mathrm{~Hz}), 3.22(1 \mathrm{H}, \mathrm{dd}, J=3.3,16 \mathrm{~Hz}), 3.76-$ $3.98(5 \mathrm{H}, \mathrm{m}), 5.27(1 \mathrm{H}, \mathrm{td}, J=2.7,11 \mathrm{~Hz}), 5.96(1 \mathrm{H}, \mathrm{brs}), 7.22-7.35(4 \mathrm{H}, \mathrm{m}) ;{ }^{13} \mathrm{C}-\mathrm{NMR}$

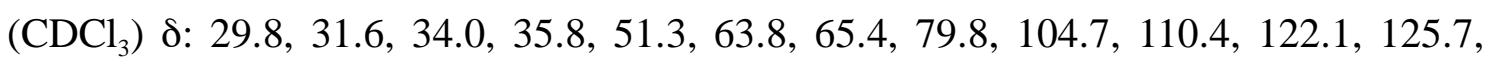
127.4, 128.6, 130.5, 130.9, 135.4, 143.1; IR (KBr) $\mathrm{cm}^{-1}: 2229$; MS m/z $295\left(\mathrm{M}^{+}\right)$; HRMS Calcd for $\mathrm{C}_{18} \mathrm{H}_{17} \mathrm{NO}_{3}: 295.1208\left(\mathrm{M}^{+}\right)$, found: 295.1186 .

\section{Procedure for Anti-viral Assay}

Virus: Hemagglutinating virus of Japan (HVJ) W strain was propagated in the allantoic cavity of 10-day-old embryonated hen eggs for $72 \mathrm{~h}$ at $35^{\circ} \mathrm{C}$. The infected allantoic fluids were collected and then stored in small portions at $-80^{\circ} \mathrm{C}$ after clarification at $1,000 \mathrm{x} g$ for $20 \mathrm{~min}$.

Cells: LLC-MK2 cells, a rhesus monkey kidney cell line, obtained from Dai-Nippon 
Pharmaceutical Company (Osaka, Japan), were grown in Eagle's minimum essential medium (MEM) supplemented with $8 \%$ heat-inactivated $\left(56^{\circ} \mathrm{C}\right.$ for $\left.30 \mathrm{~min}\right)$ fetal bovine serum (FBS) in a humidified atmosphere containing $5 \% \mathrm{CO}_{2}$ at $37^{\circ} \mathrm{C}$.

Drugs: The tested drugs were initially dissolved in dimethyl sulfoxide (DMSO) and then diluted with MEM supplemented with 4\% FBS (maintenance medium: MM) to become a final concentration of DMSO to less than $1 \%$.

Cytotoxic assay: The cytotoxic activity of drugs was examined by the 3-(4,5-dimethyl2-thiazoly)-2,5-diphenyl-2-tetrazolium bromide (MTT) assay, a sensitive method for cytotoxicity based on the detection of mitochondrial enzymatic activity reacting with a chromogenic substrate, of which the color development is read at an optical density (OD) of $570 \mathrm{~nm} \cdot{ }^{[9]}$ In brief, the cells were inoculated at a density of $10^{3}$ cells/well in a 96-well plate and cultured overnight at $37^{\circ} \mathrm{C}$. Thereafter, the culture medium was replaced to $100 \mu \mathrm{l}$ of $\mathrm{MM}$ containing various doses of drugs. After a 24-h culture, the cells were processed to MTT assay. The MM with $1 \%$ DMSO was used as a control. Triplicate cultures were used for each experimental point to statistical analysis by Students's t test.

Virus growth assay and therapeutic index: A confluent monolayer of LLC-MK2 cells in a 24-well plate was washed once with MM and then infected with $0.2 \mathrm{ml}$ of 10-fold diluted virus stock solution. After adsorption for $1 \mathrm{~h}$ at room temperature, the cells were washed three times with MM to remove unabsorbed viruses and then further cultured in $0.5 \mathrm{ml}$ of MM containing drugs at various doses at $37^{\circ} \mathrm{C}$. This time was designated $0 \mathrm{~h}$ post infection. MM containing 1\% DMSO was used as a control. At $24 \mathrm{~h}$ post infection, the cultured supernatants were collected at $500 \mathrm{x} \mathrm{g}$ for $10 \mathrm{~min}$ to determine hemagglunation (HA) titers as described previously. ${ }^{[8]}$ In this connection, the 0 -h supernatants were less than 4 HA titers in all samples. Therapeutic index was calculated by the formula of $\alpha / \beta$, where $\alpha$ is the minimum dose giving HA titer of less than 4 in virus growth assay, and $\beta$ is the maximum dose without a significant difference from the control in MTT assay. 


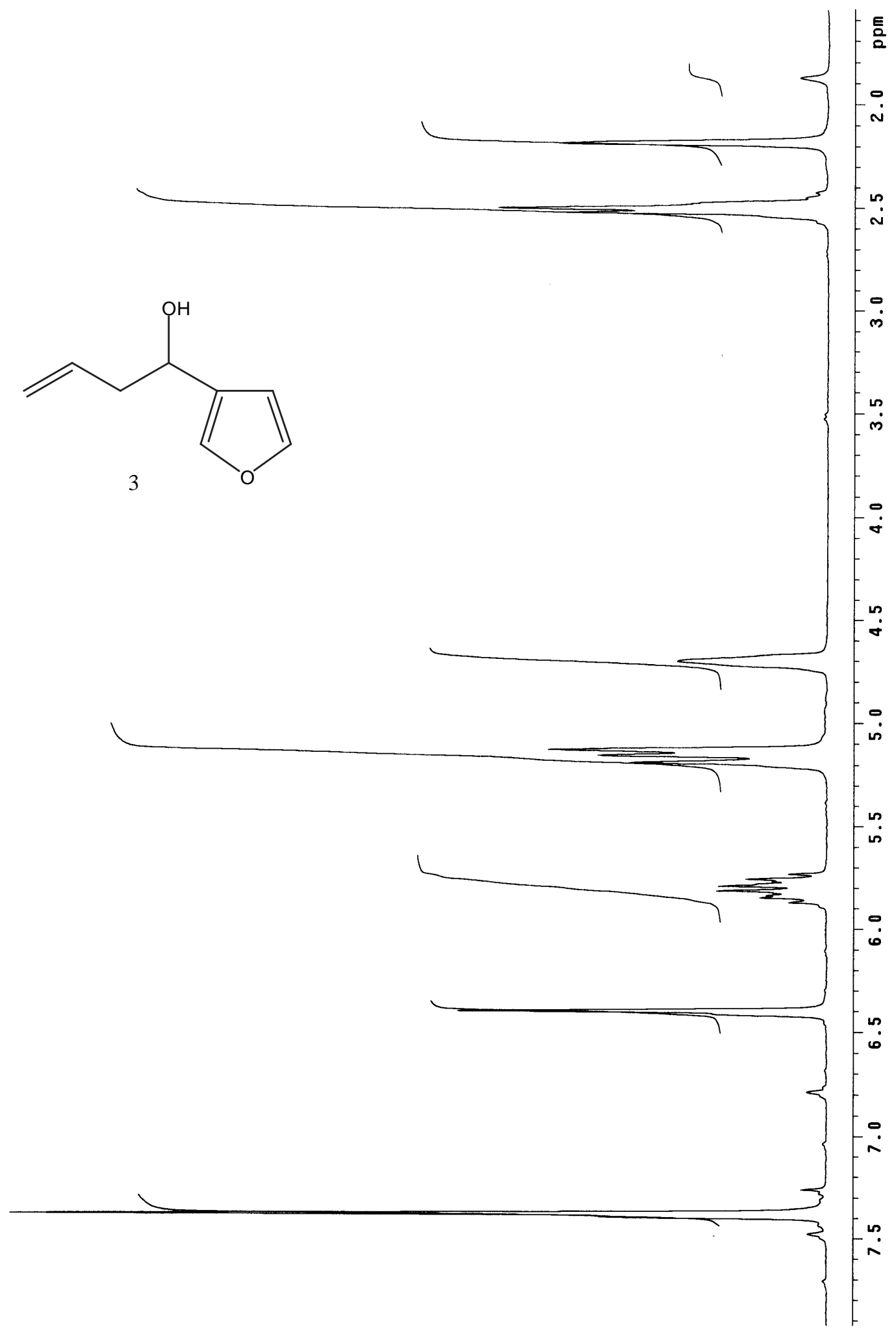



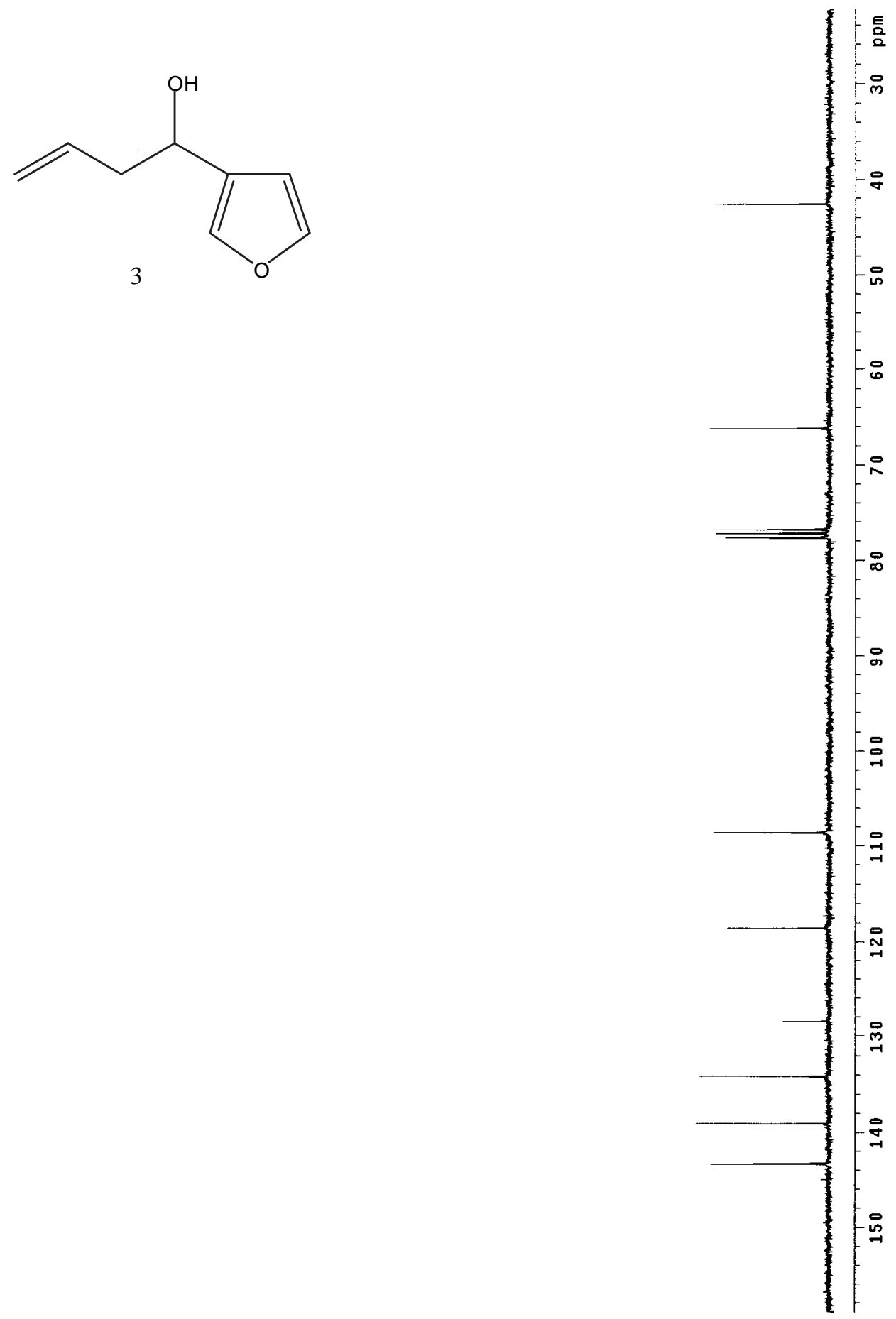


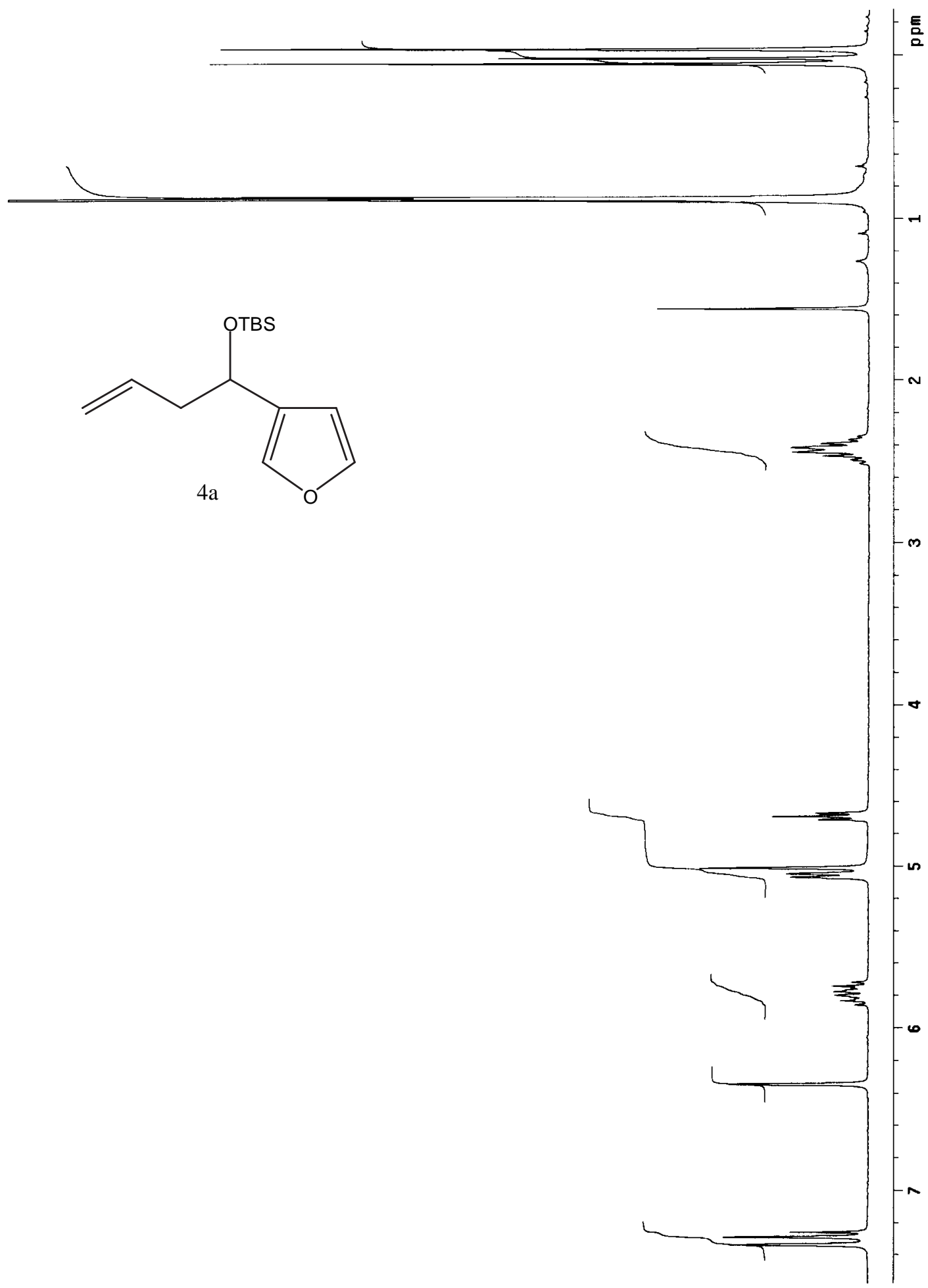




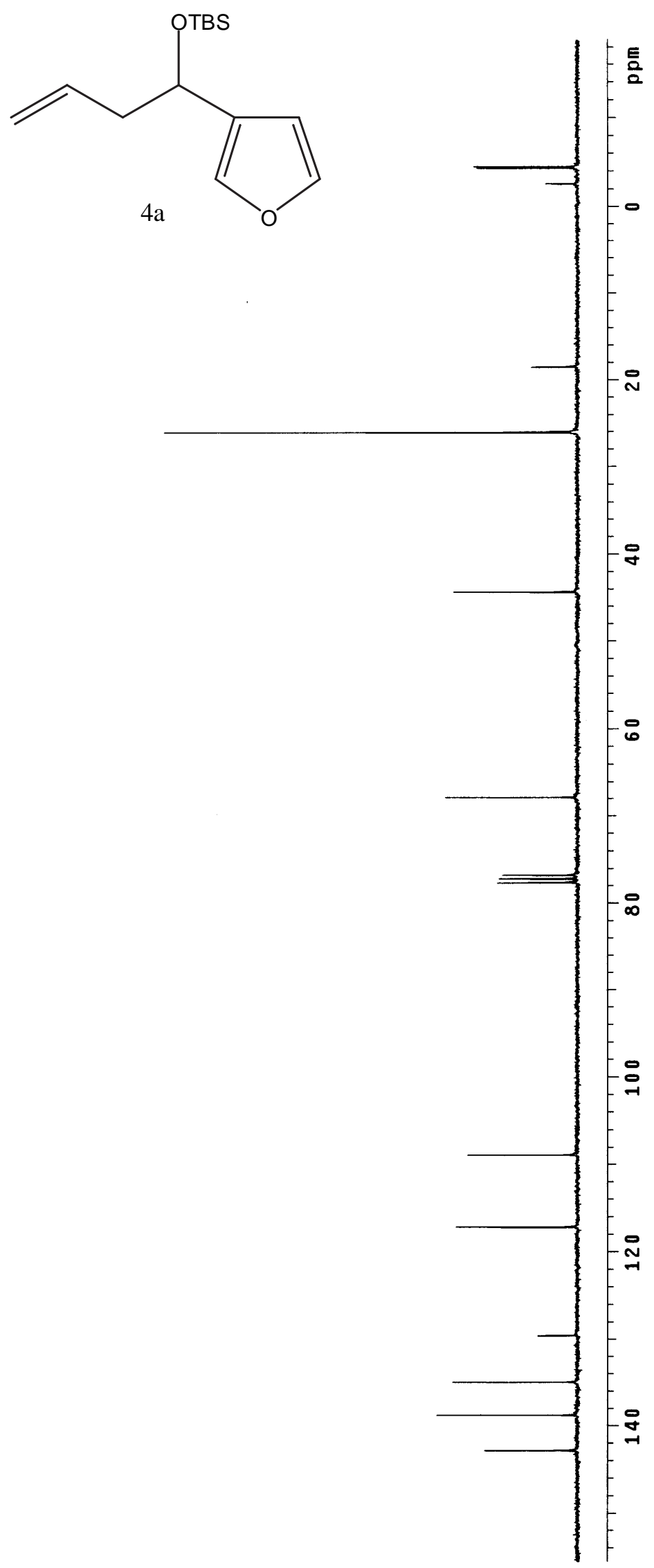




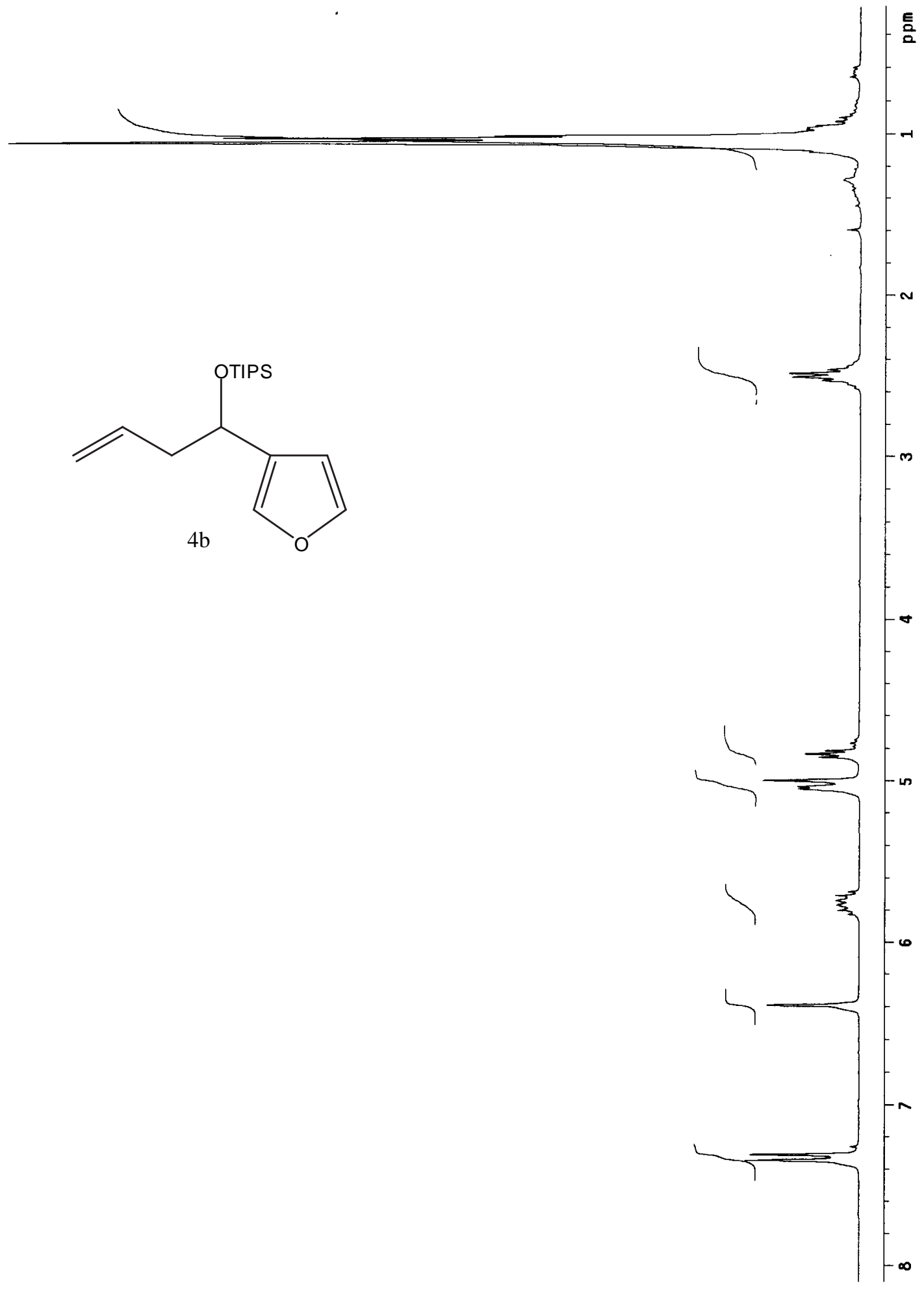




$$
" 1
$$




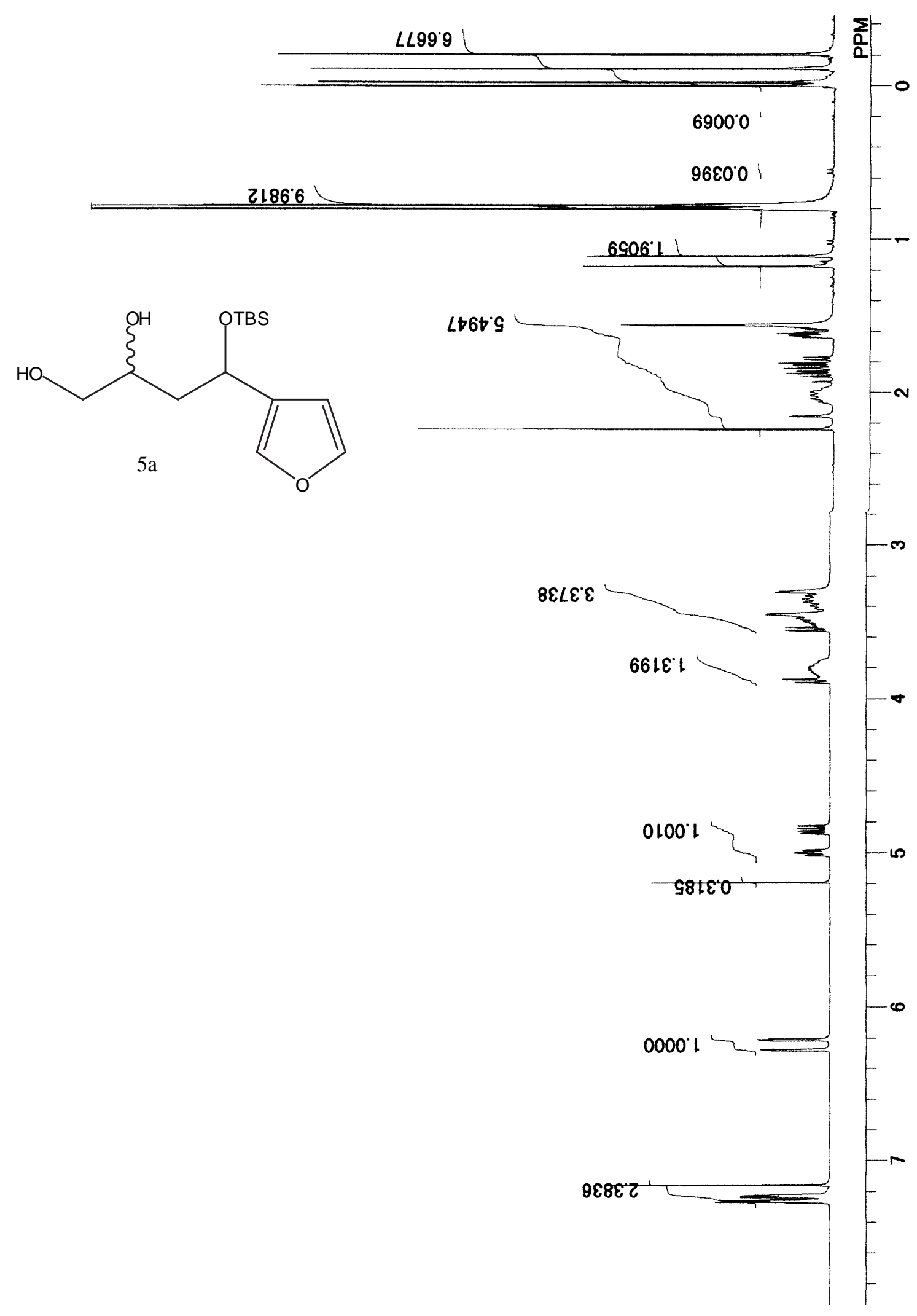




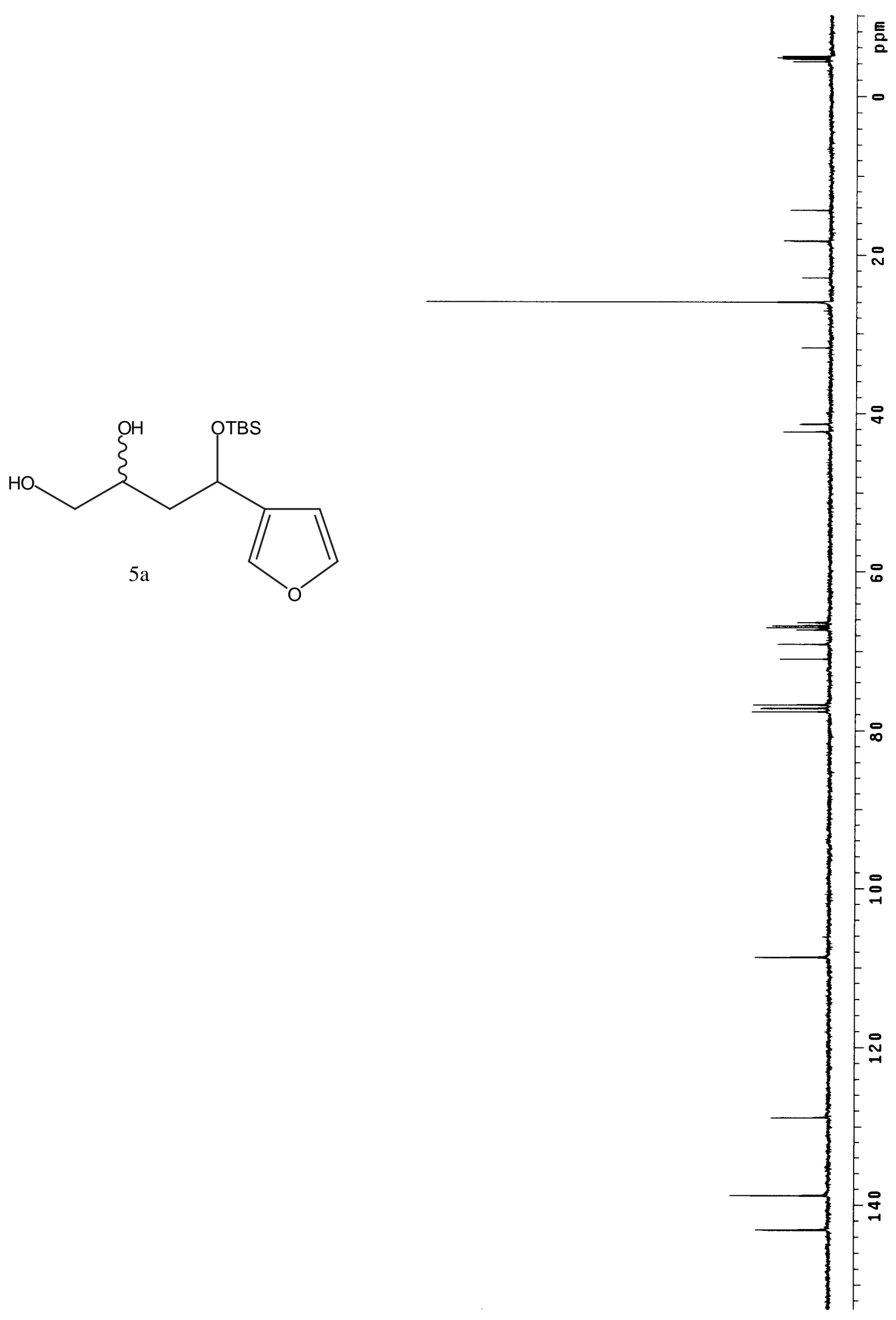




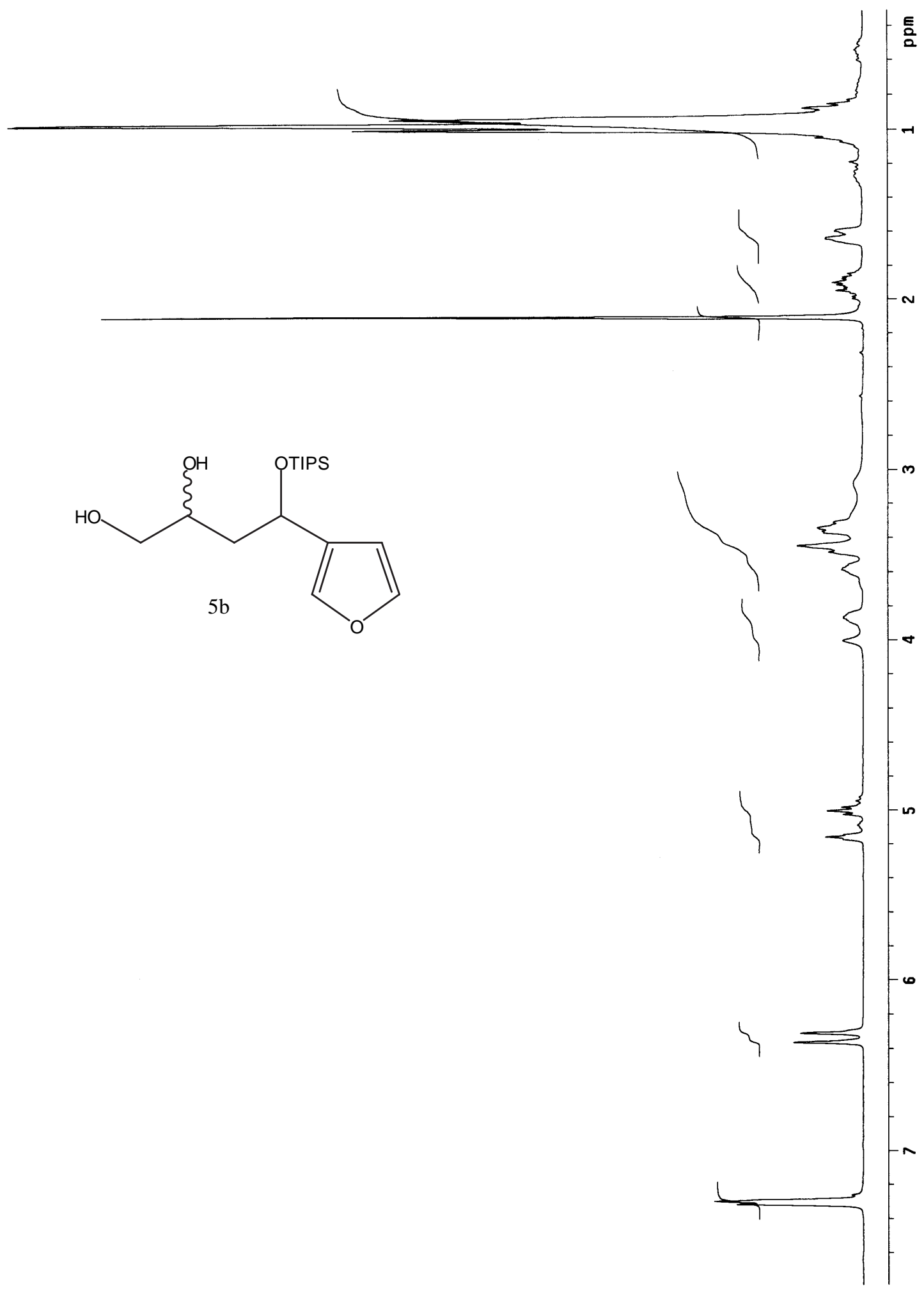



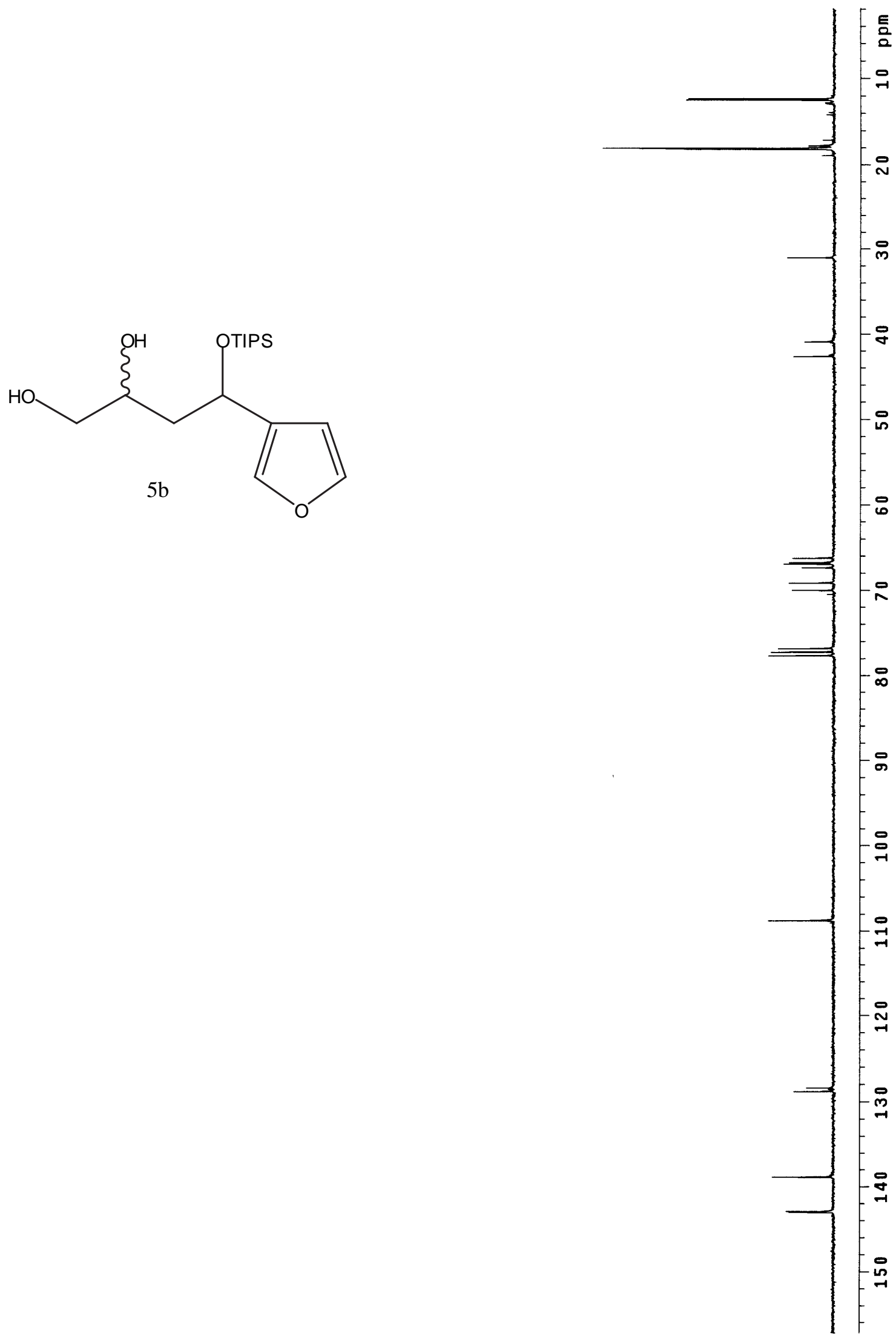


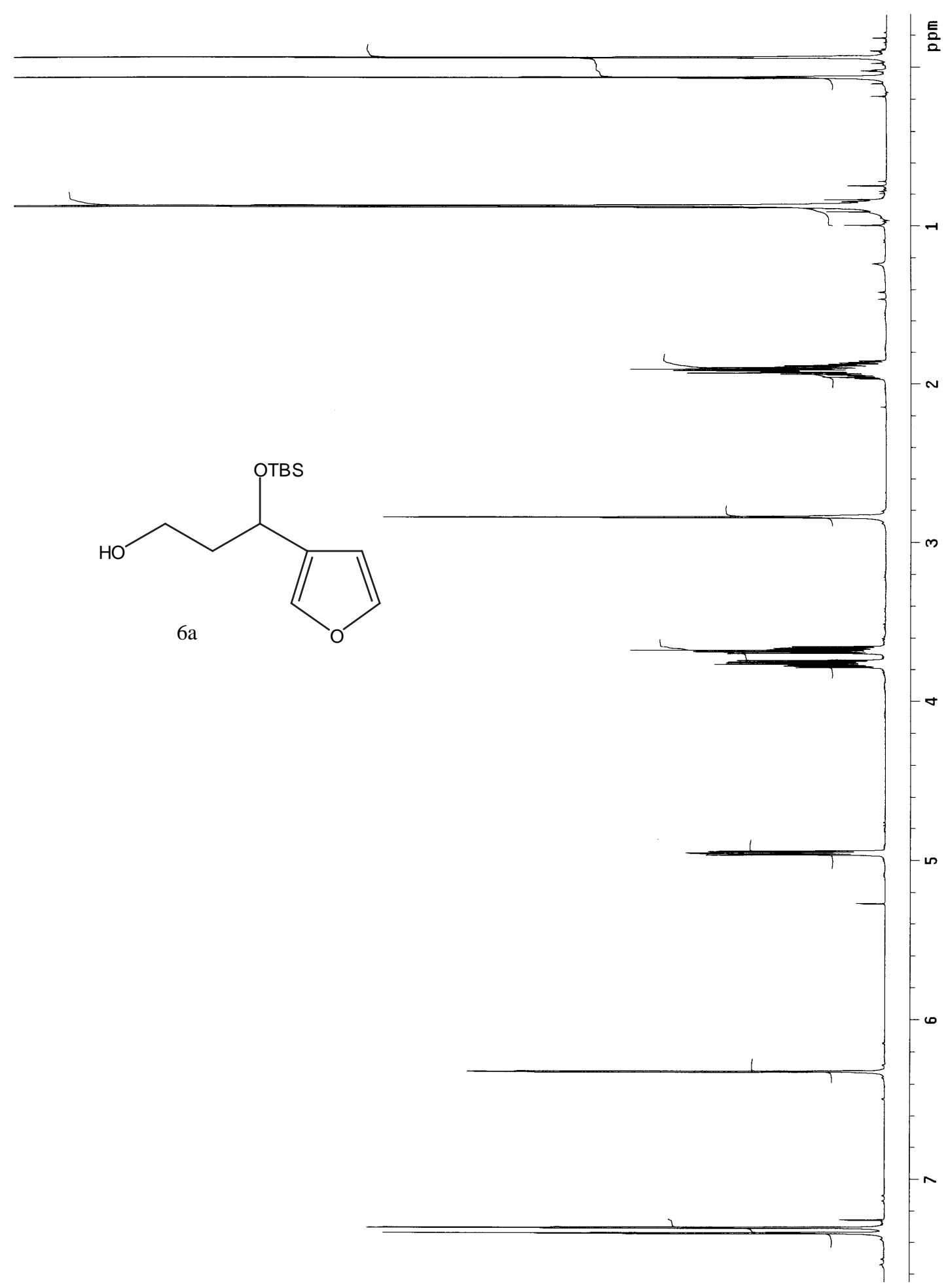



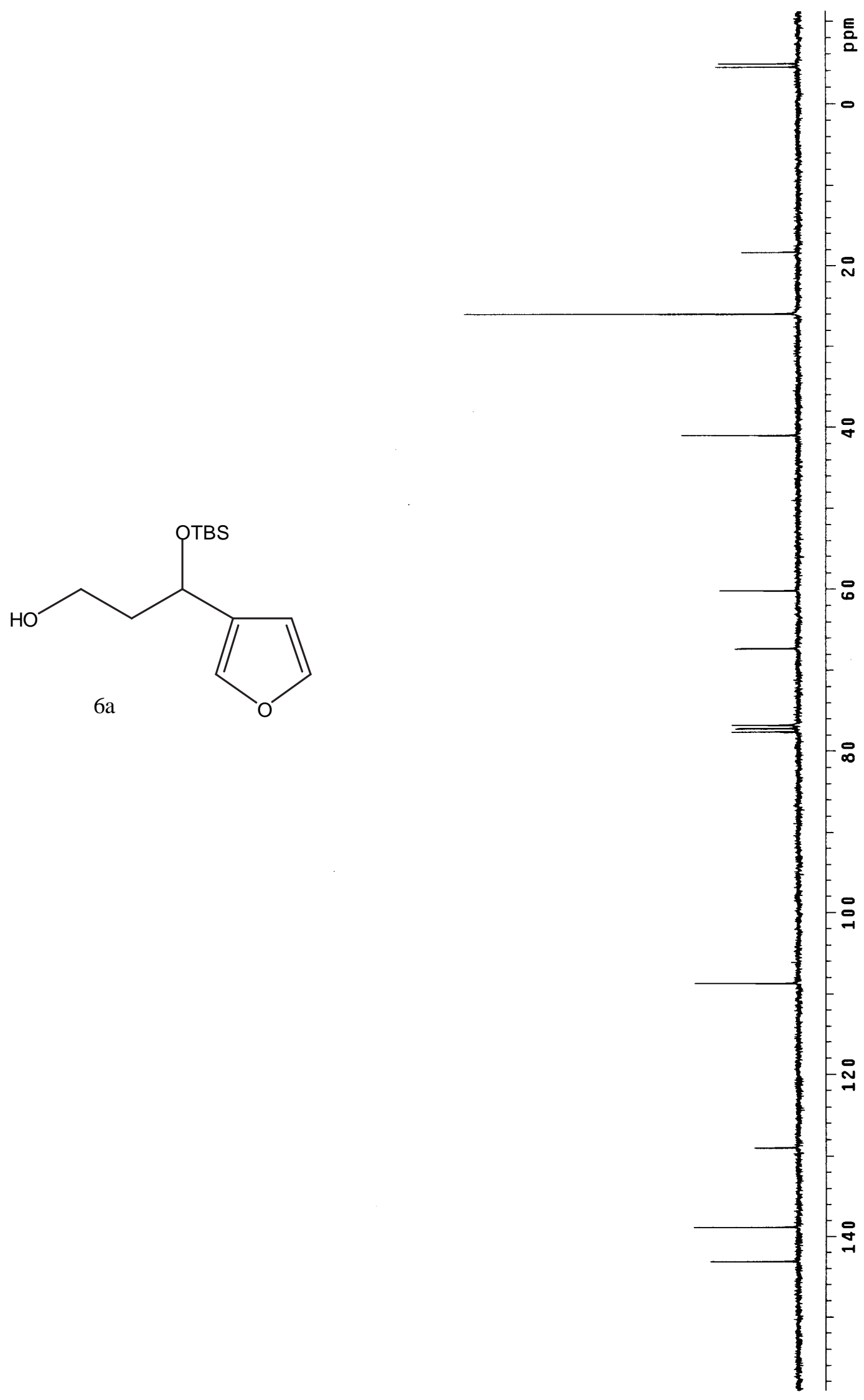


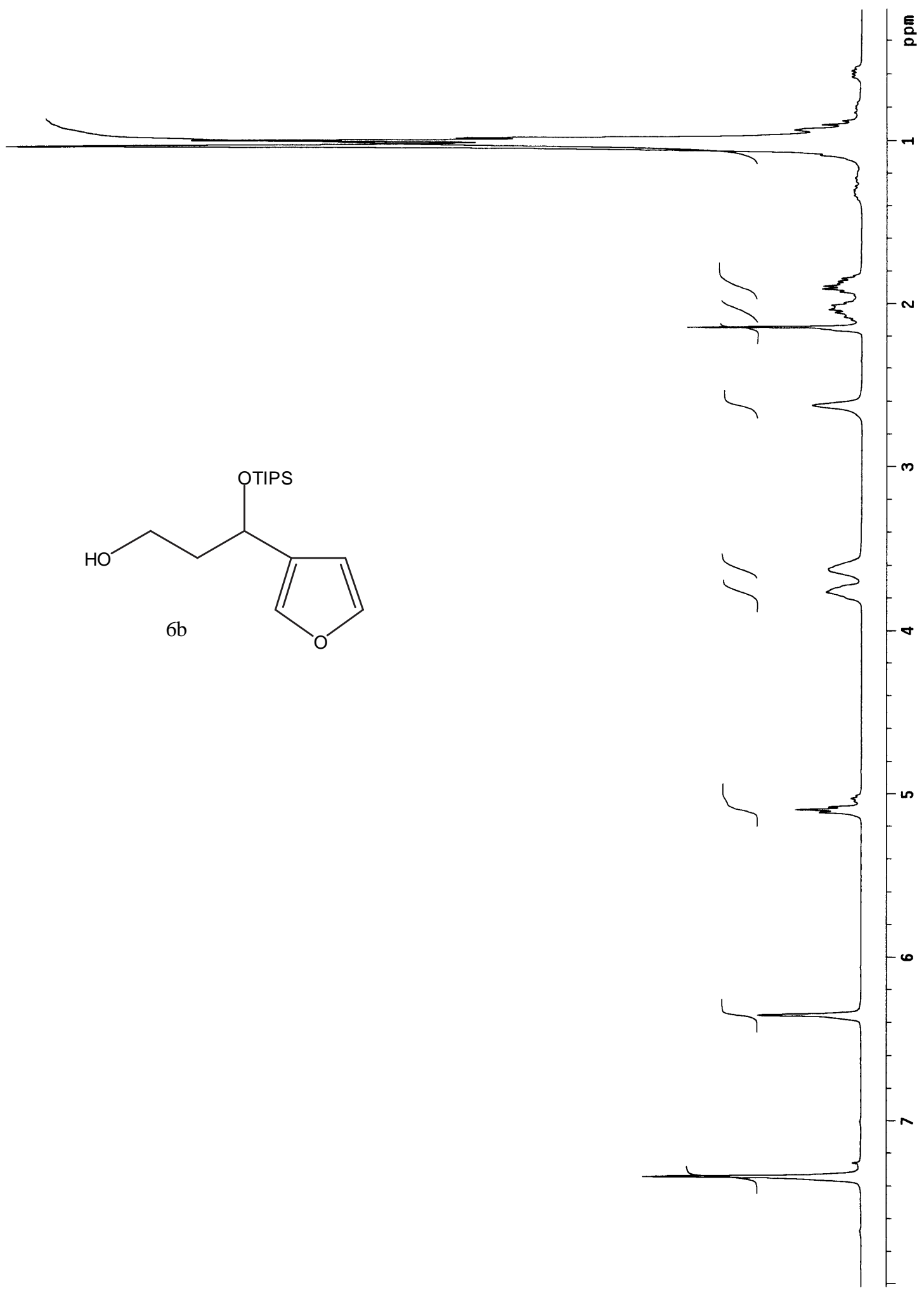



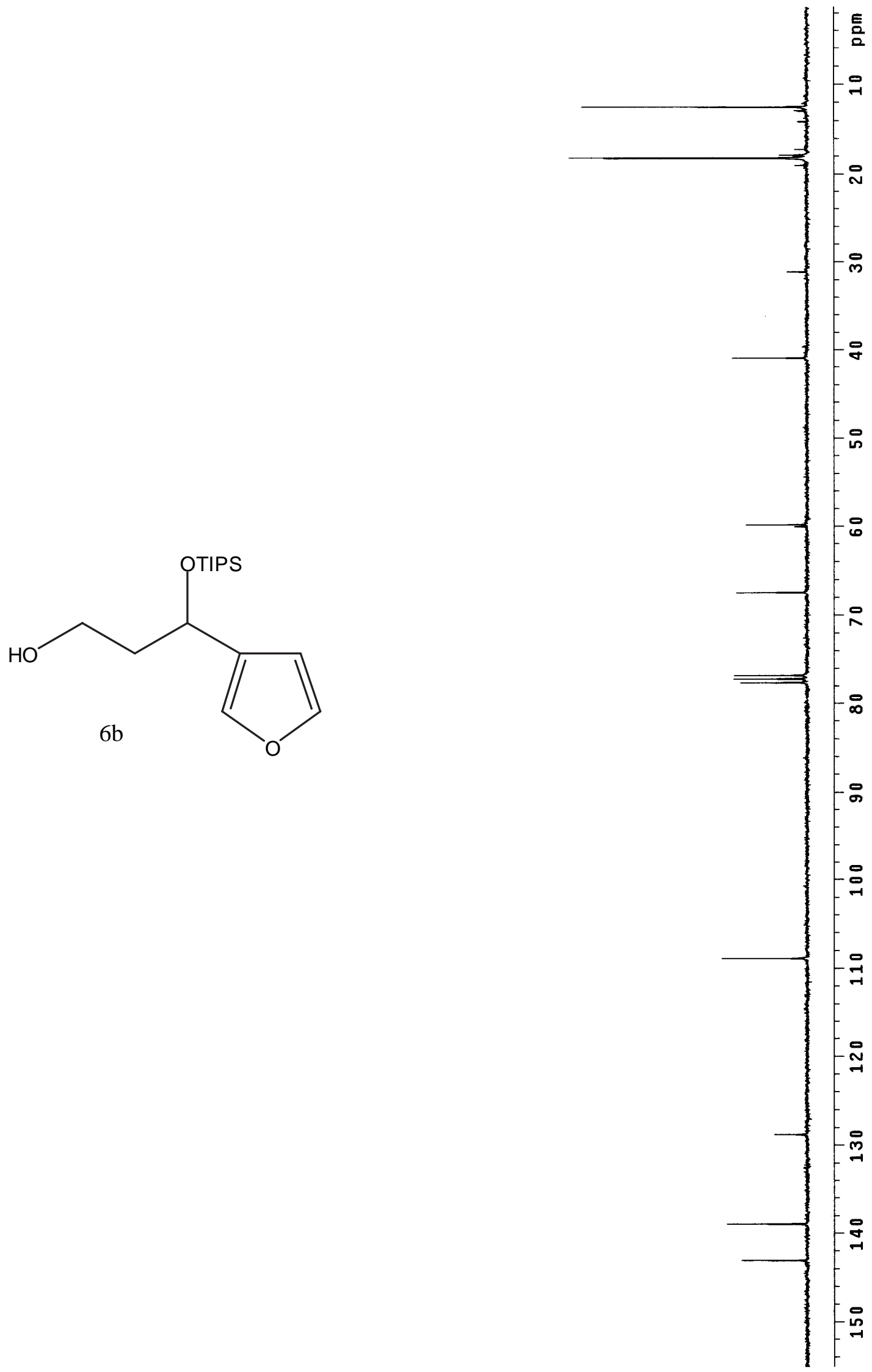


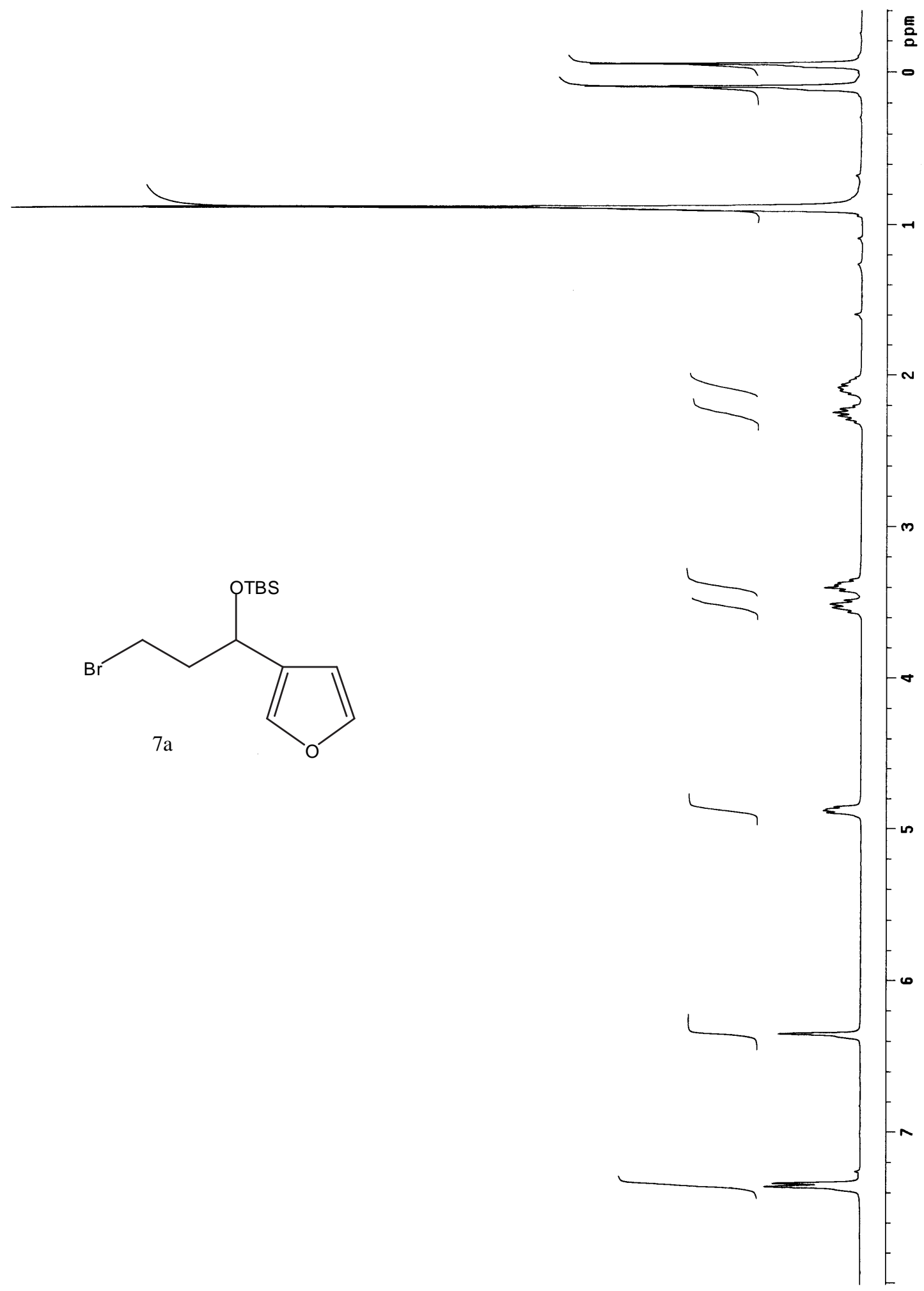




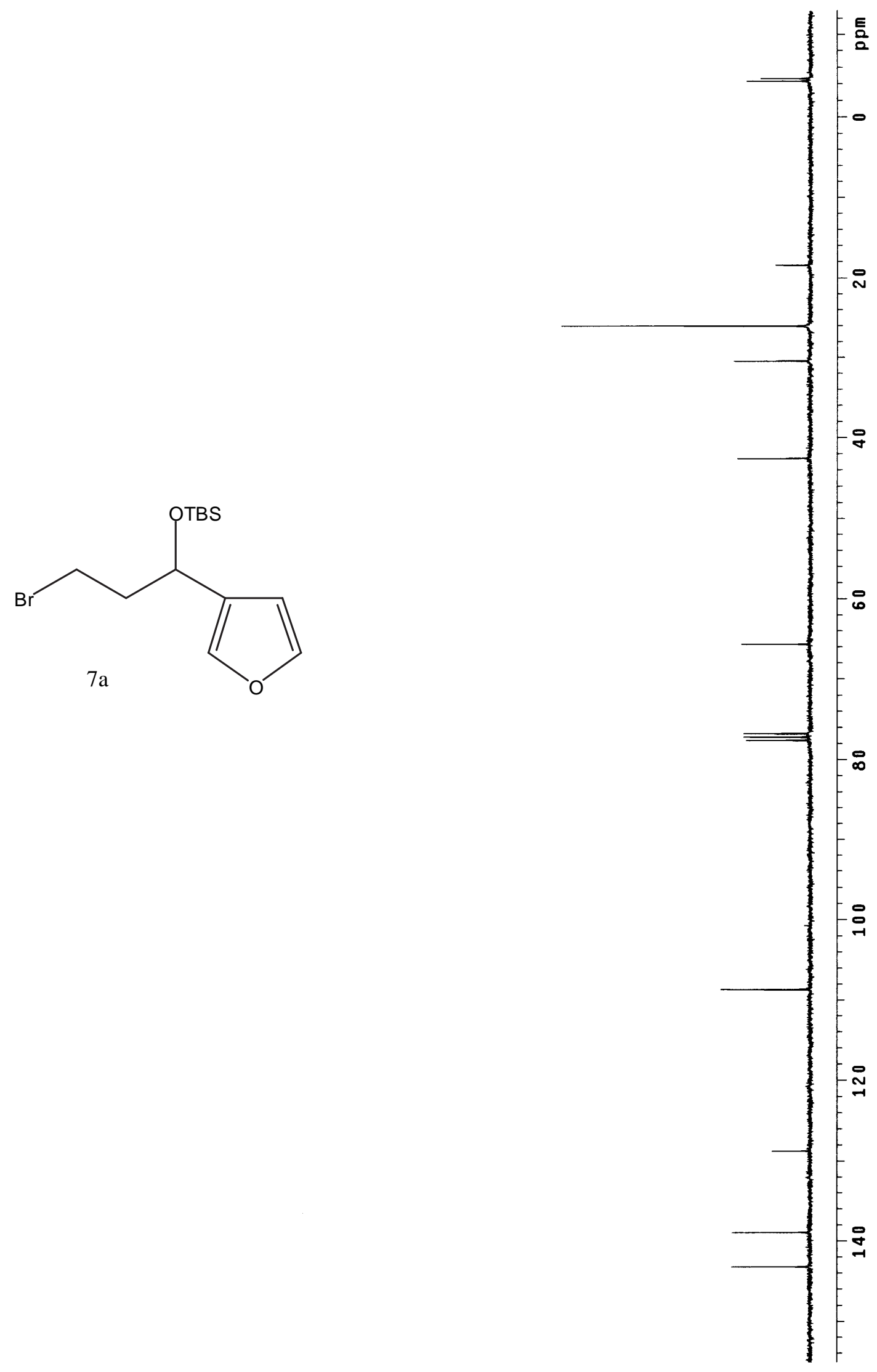




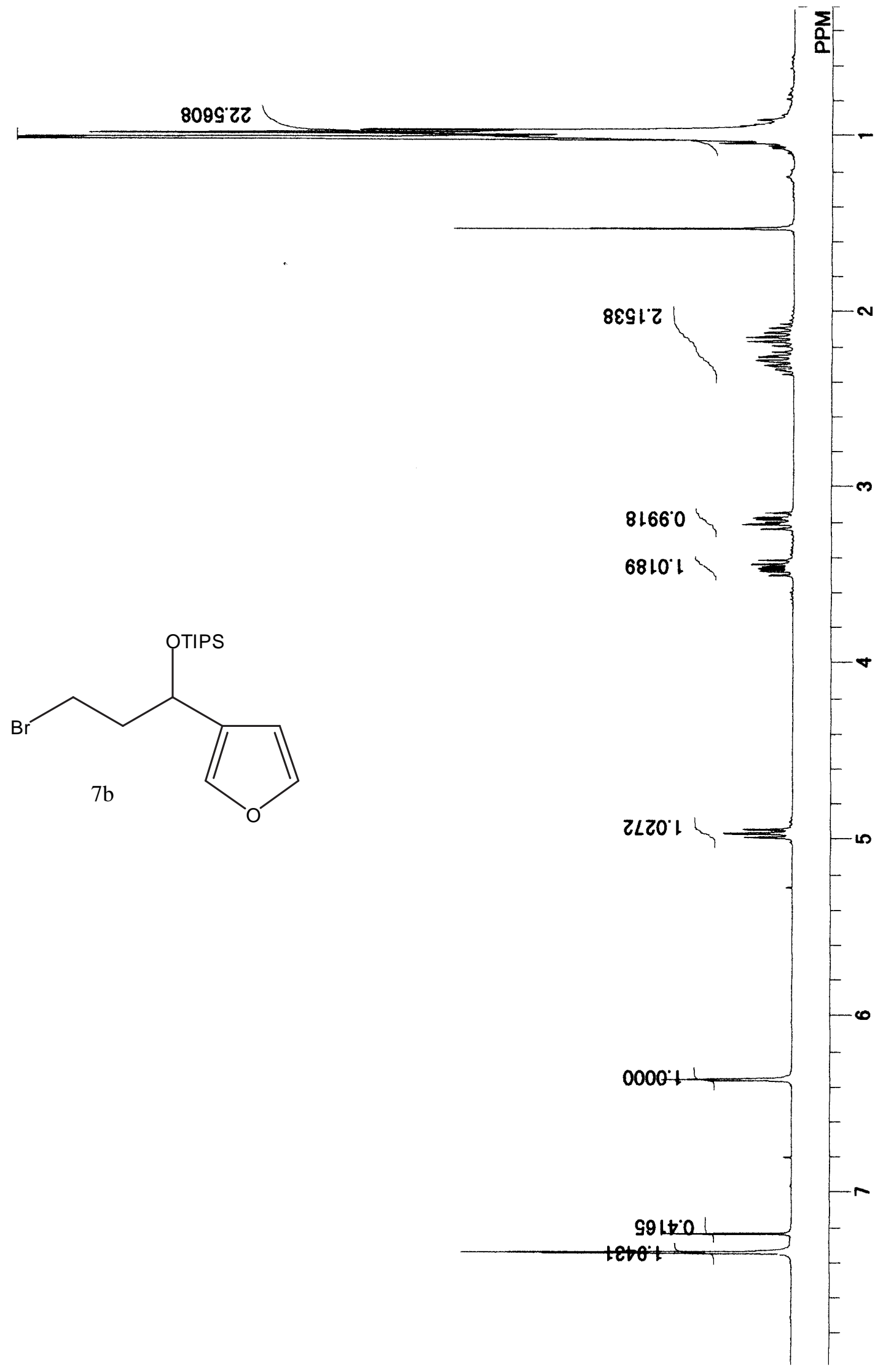



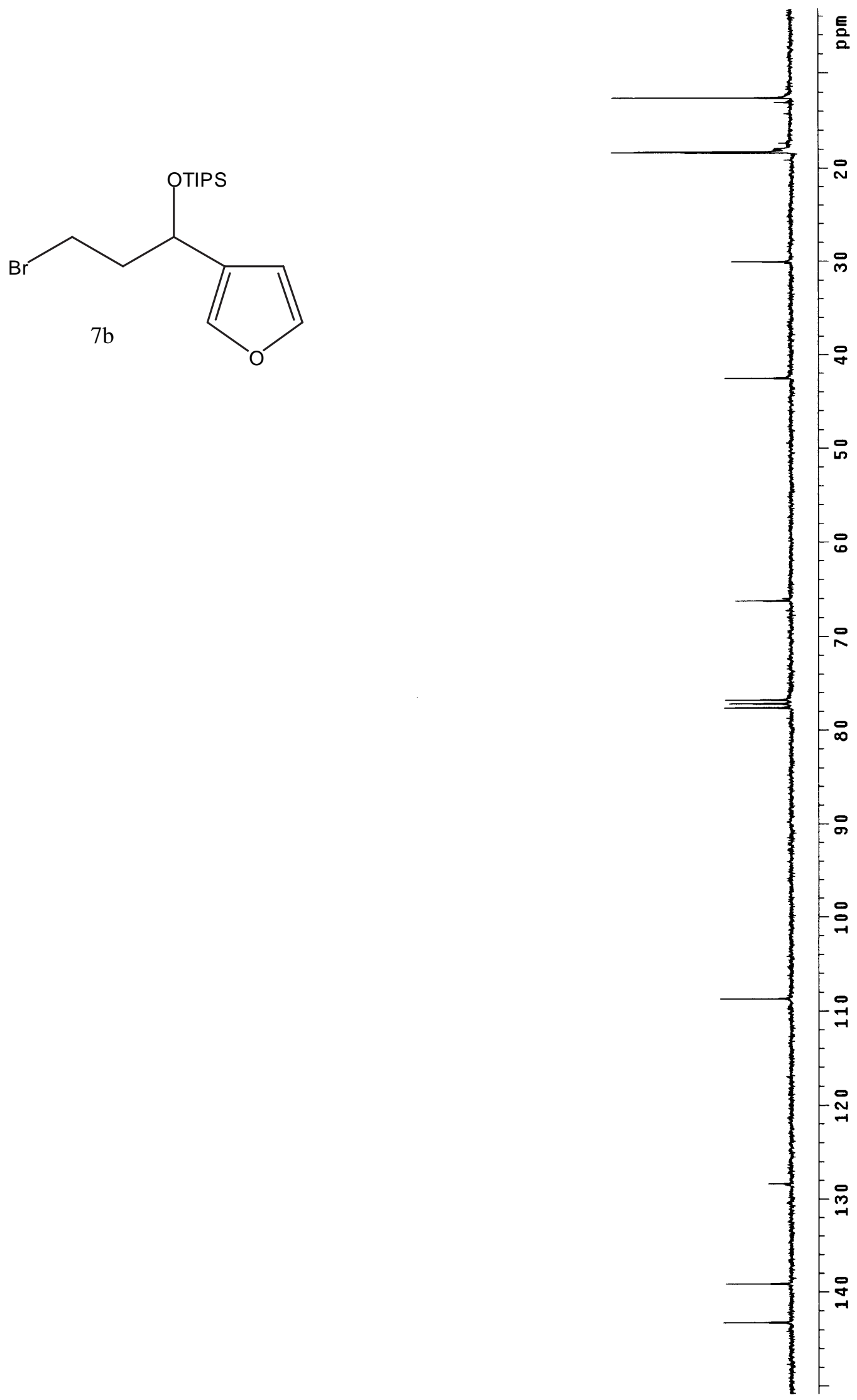


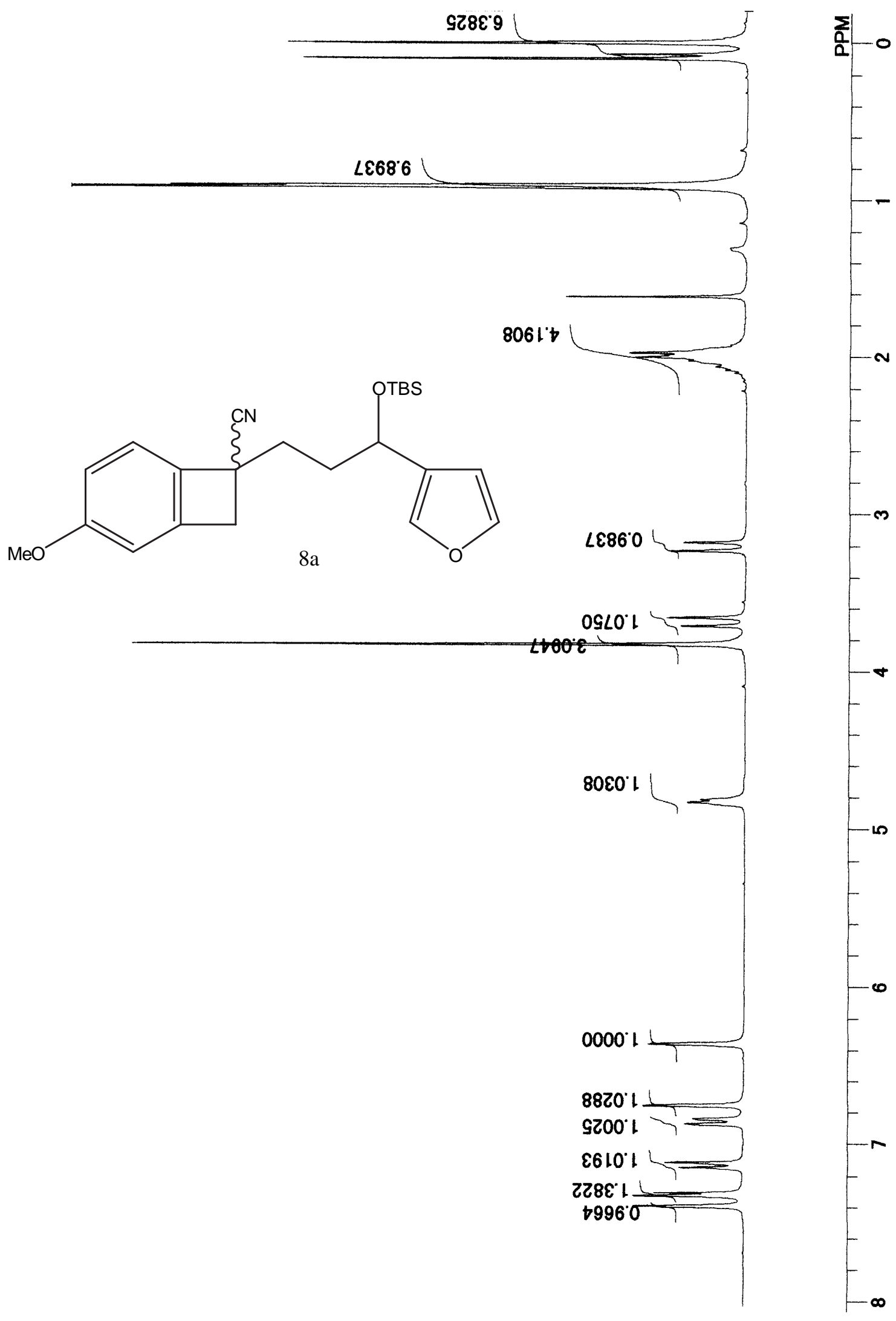



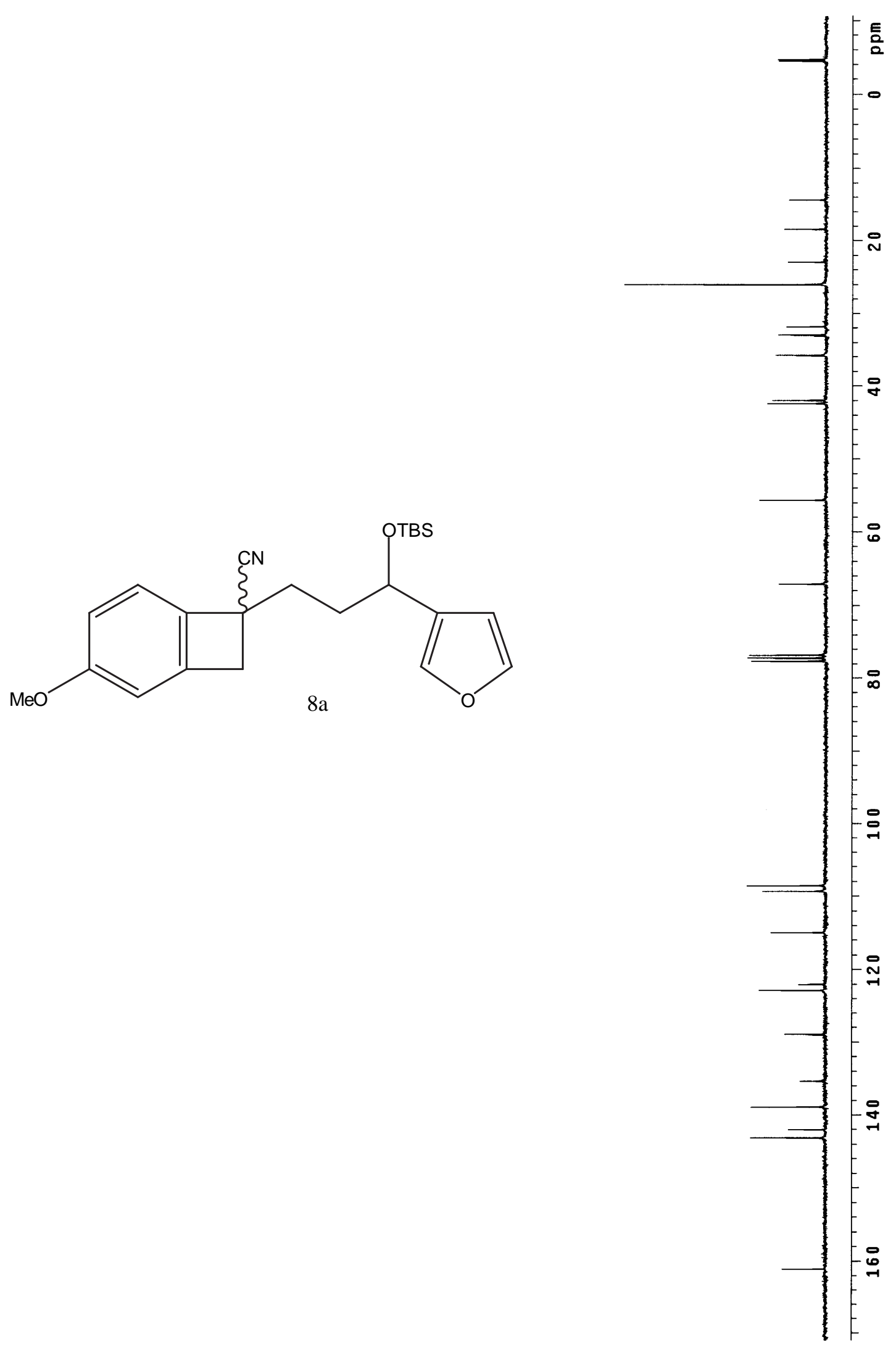


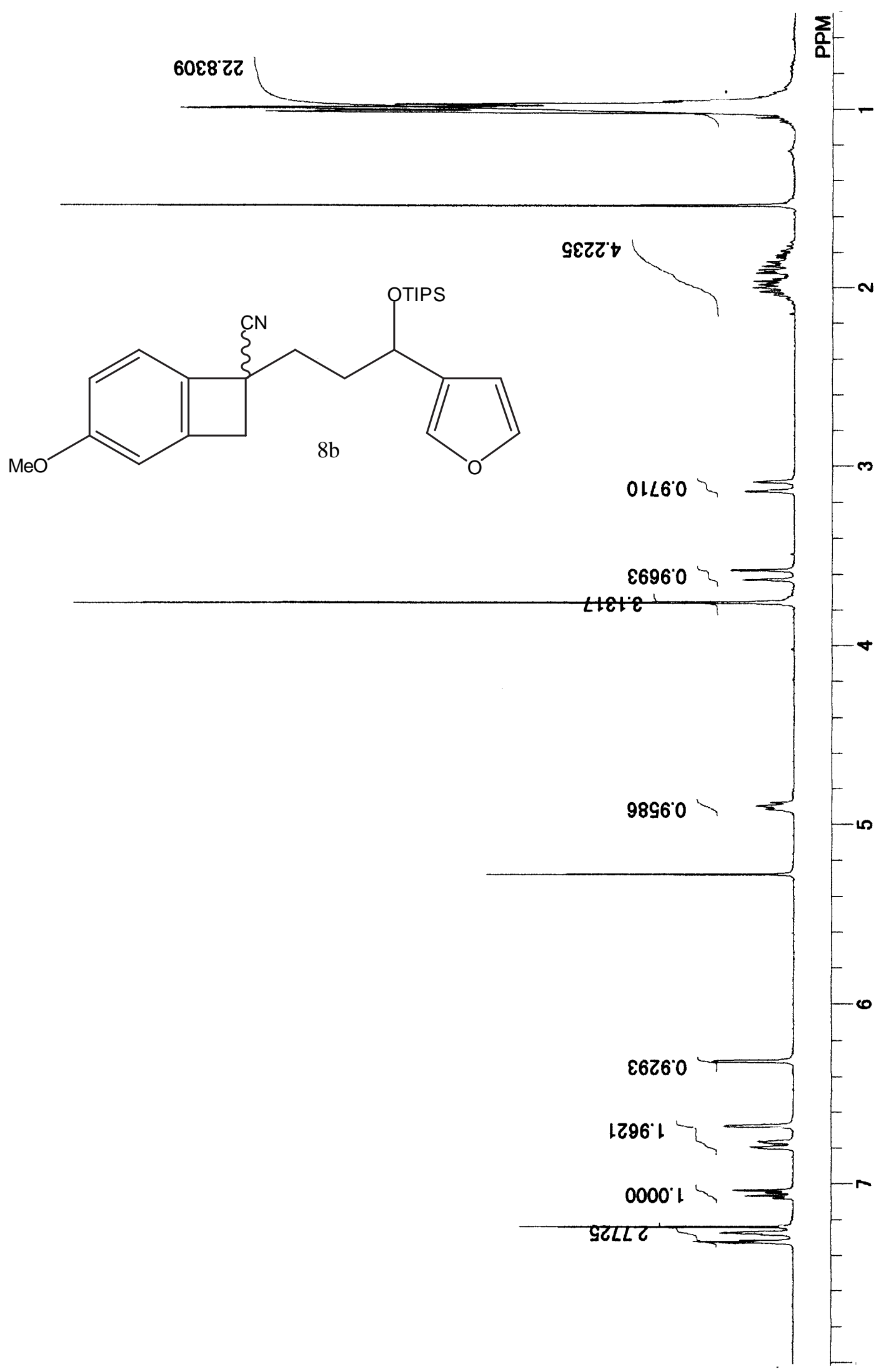



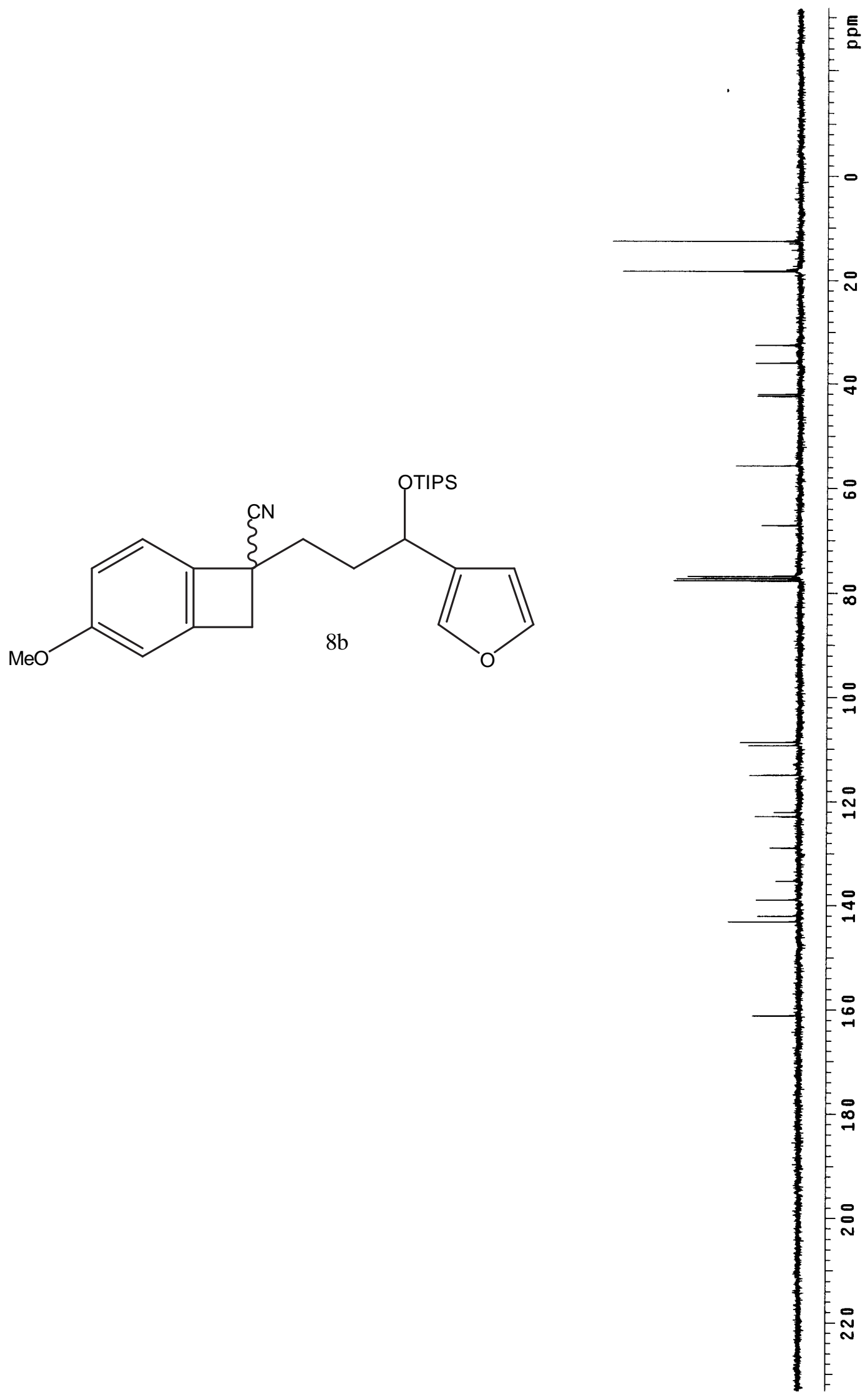


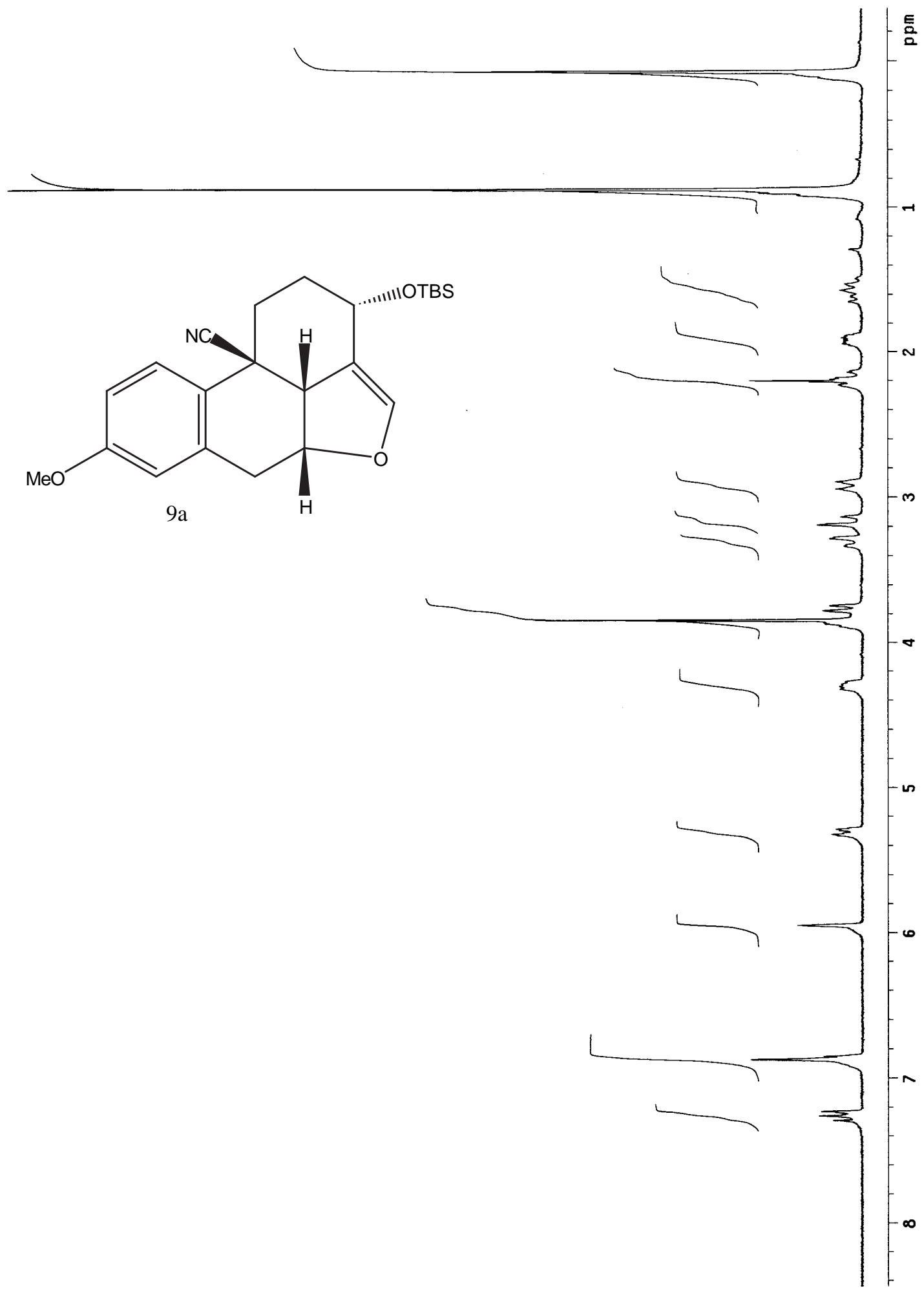



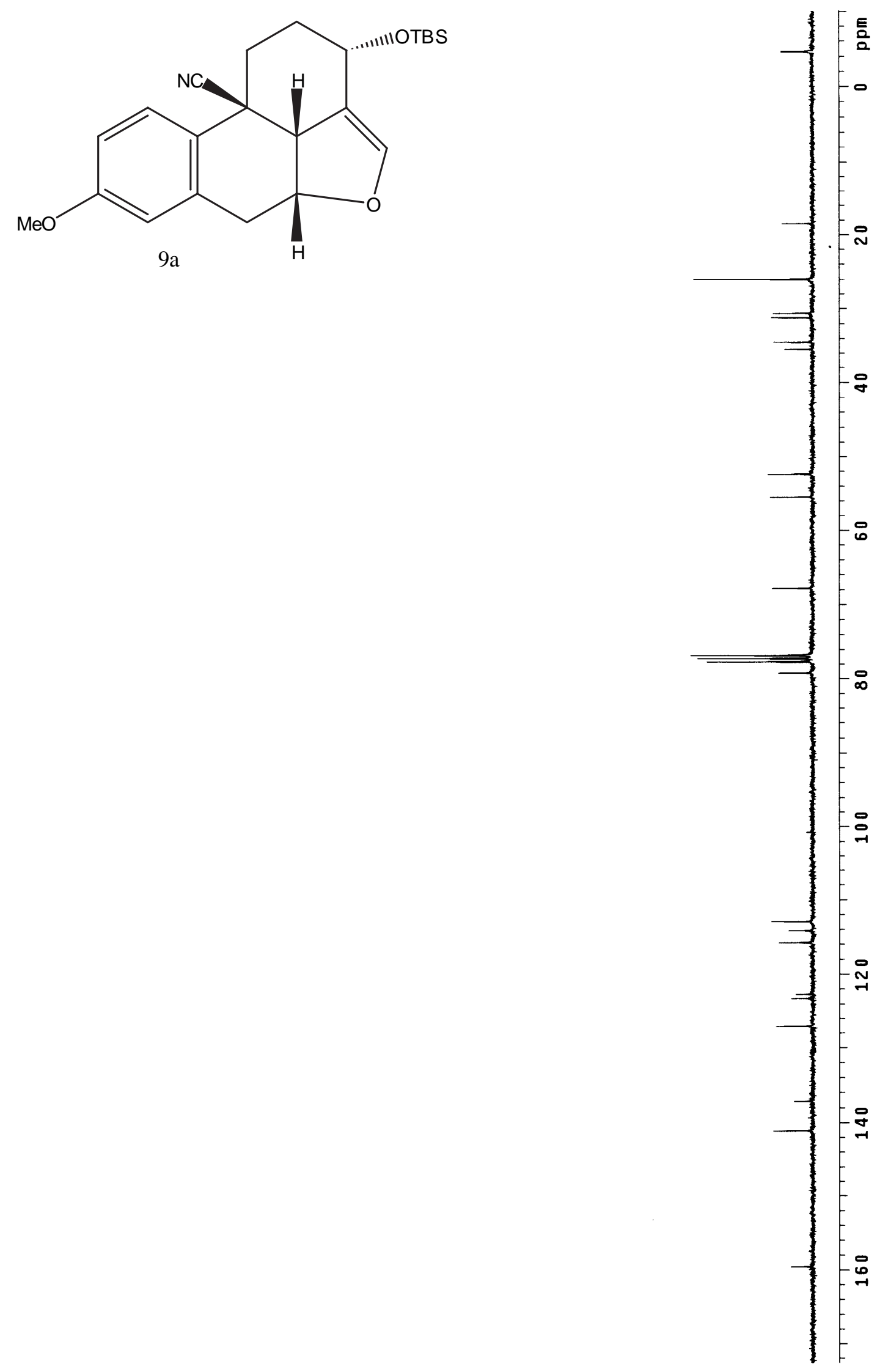


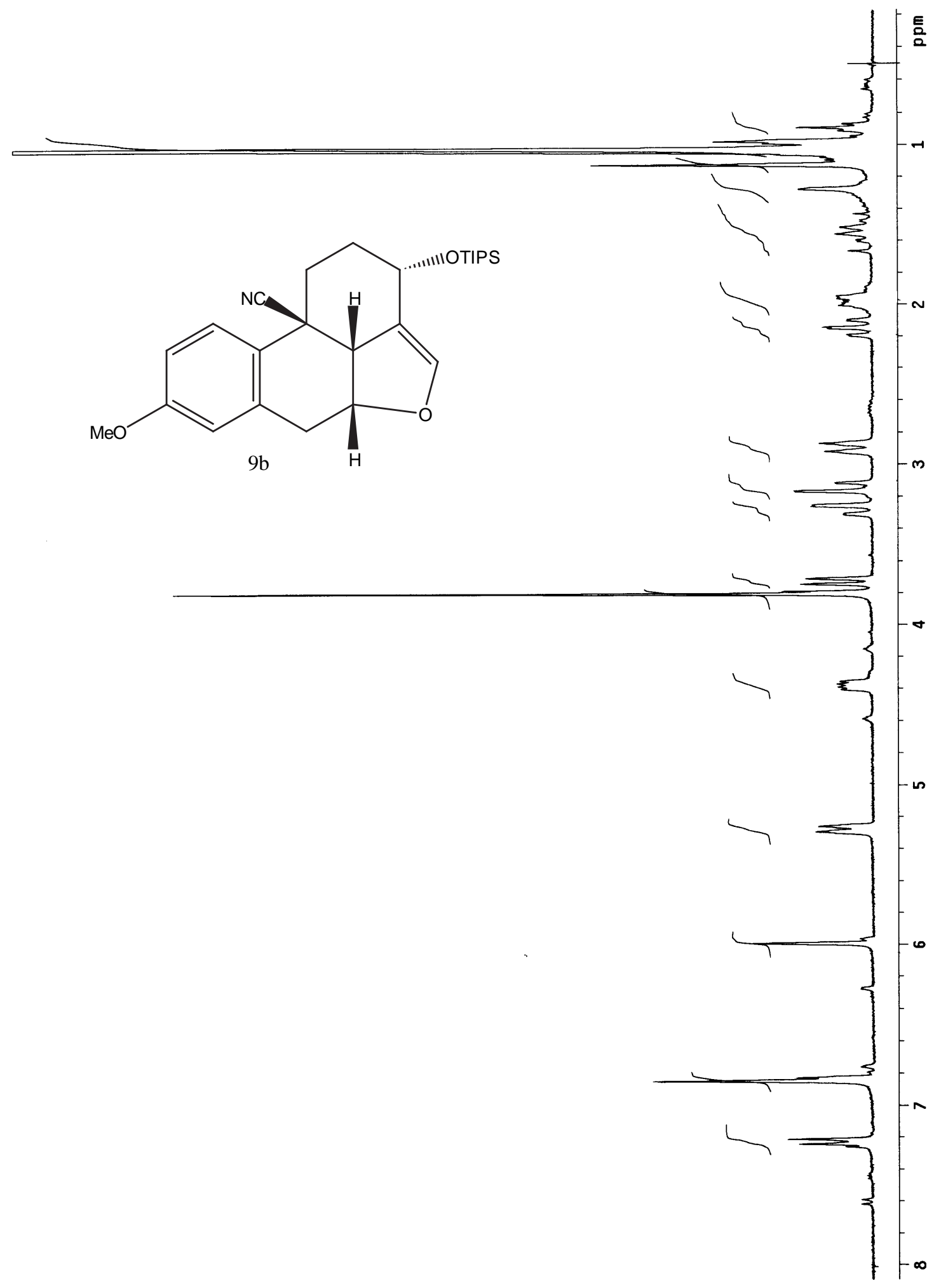



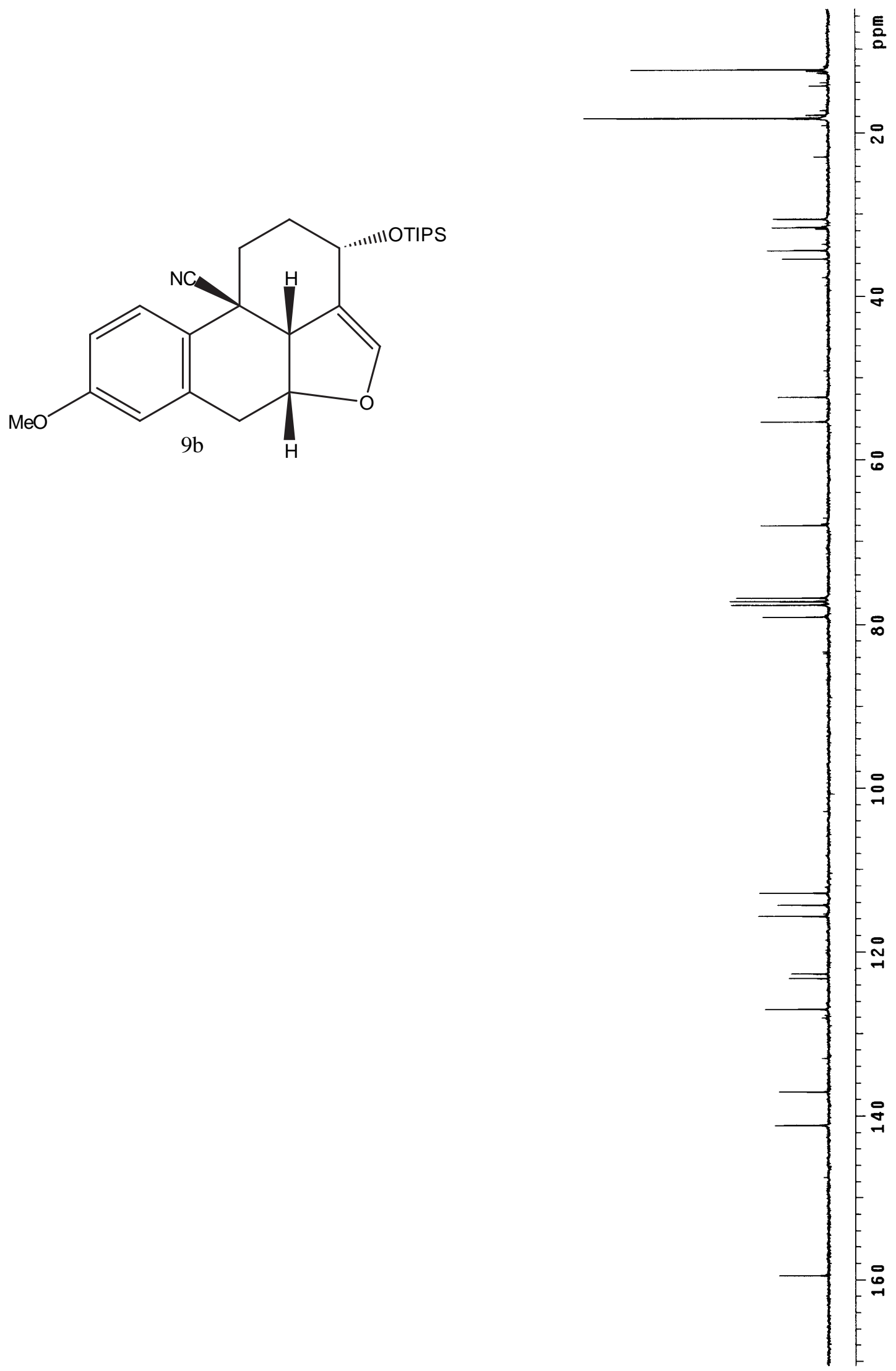


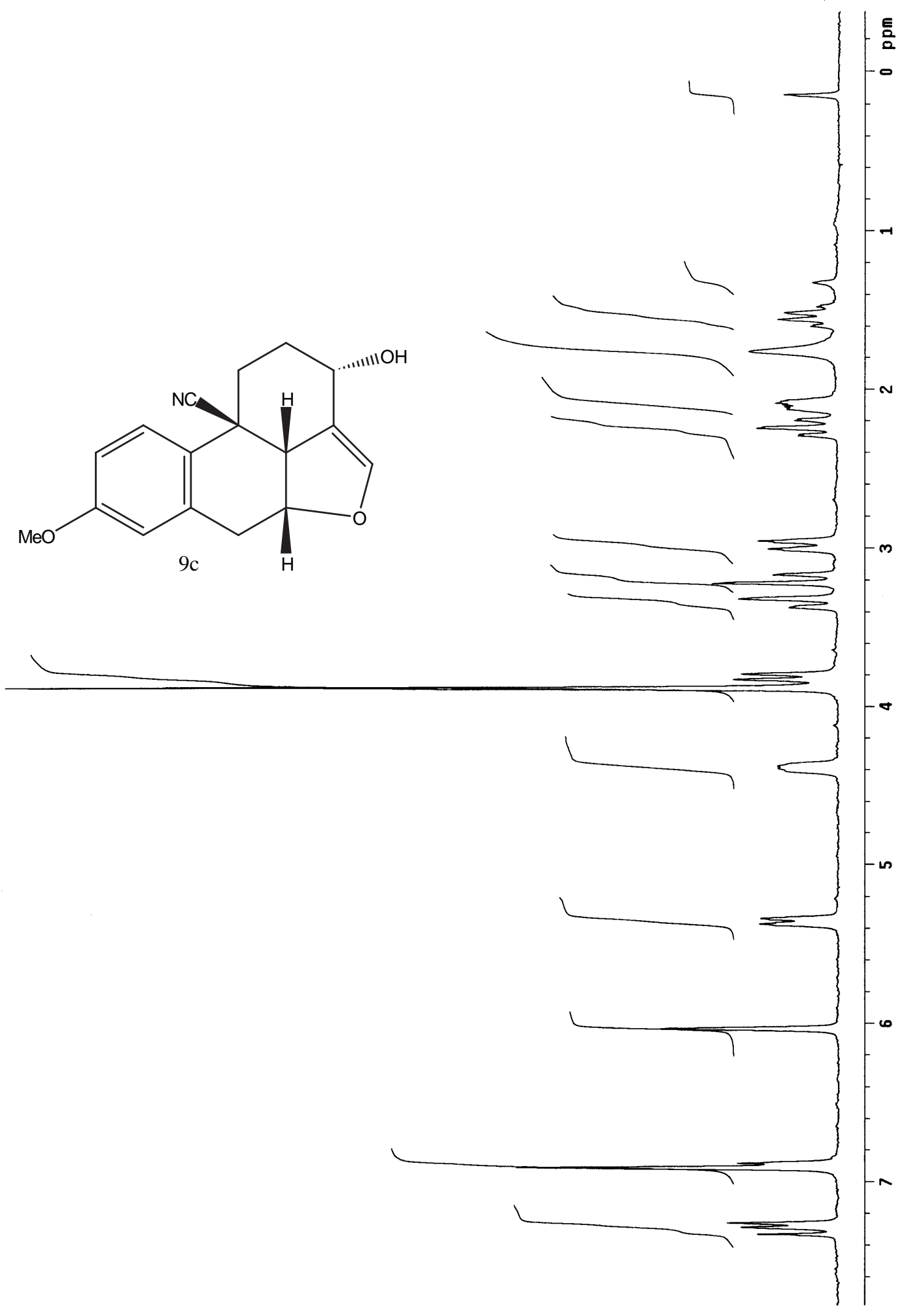



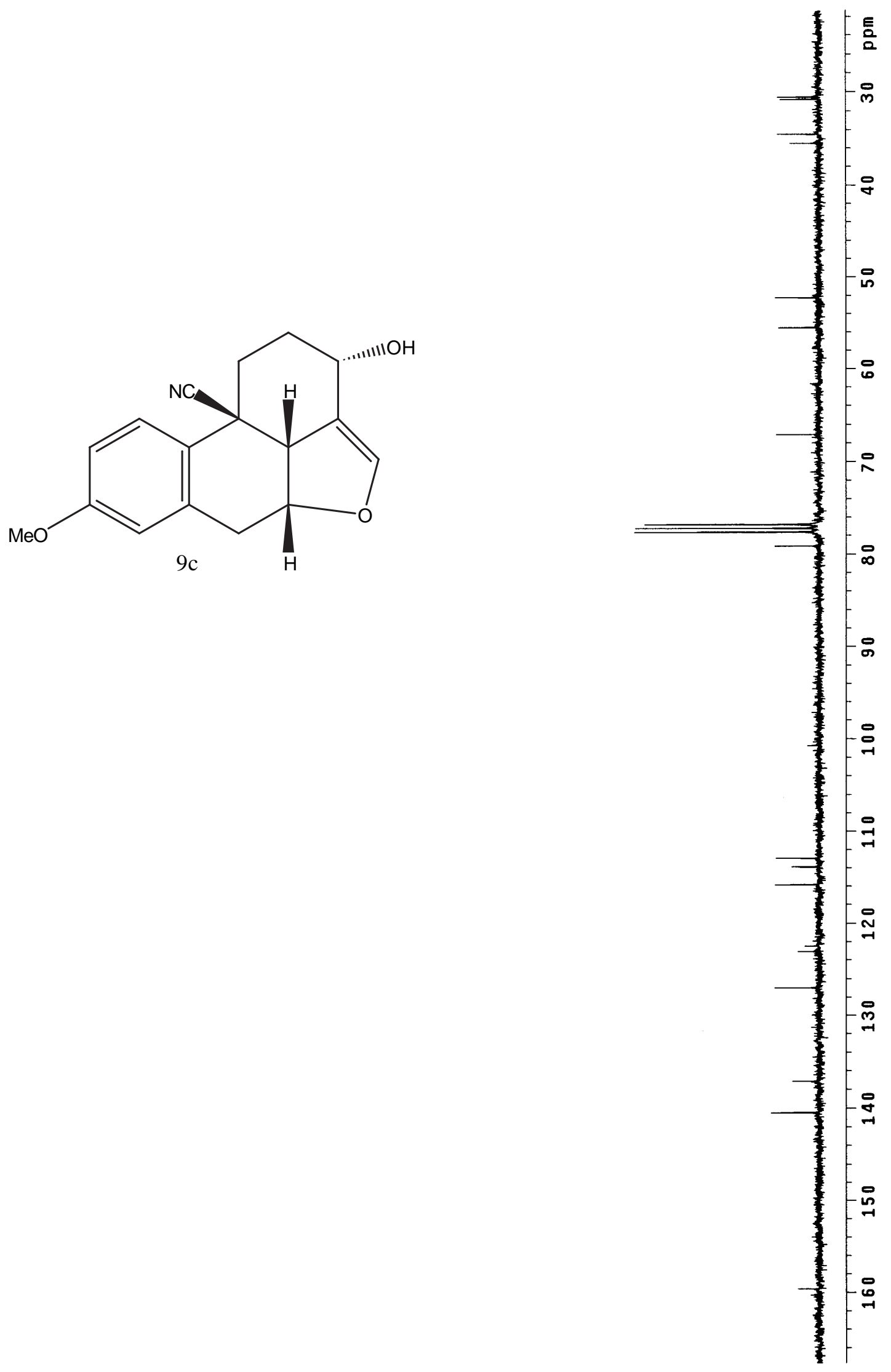


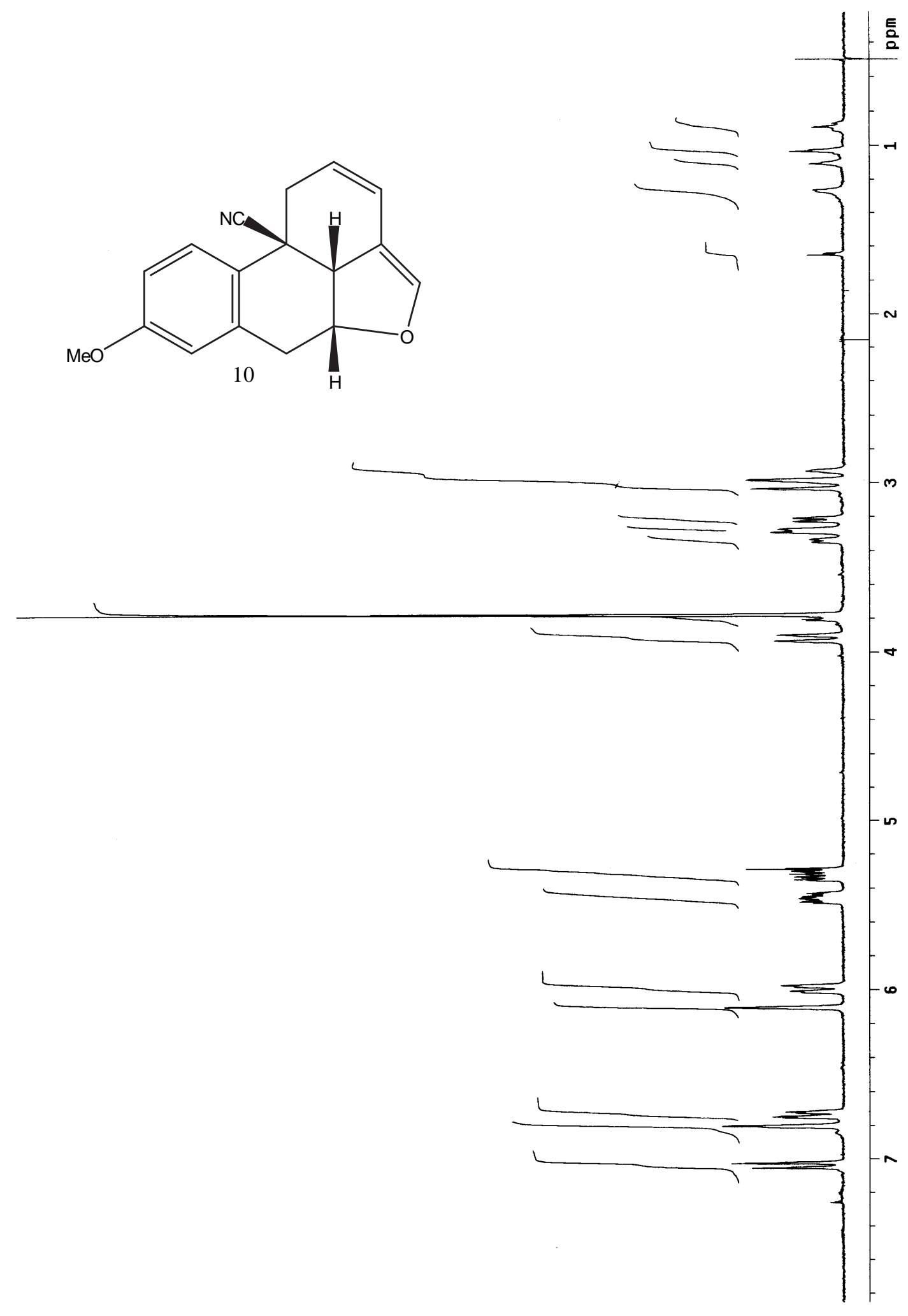



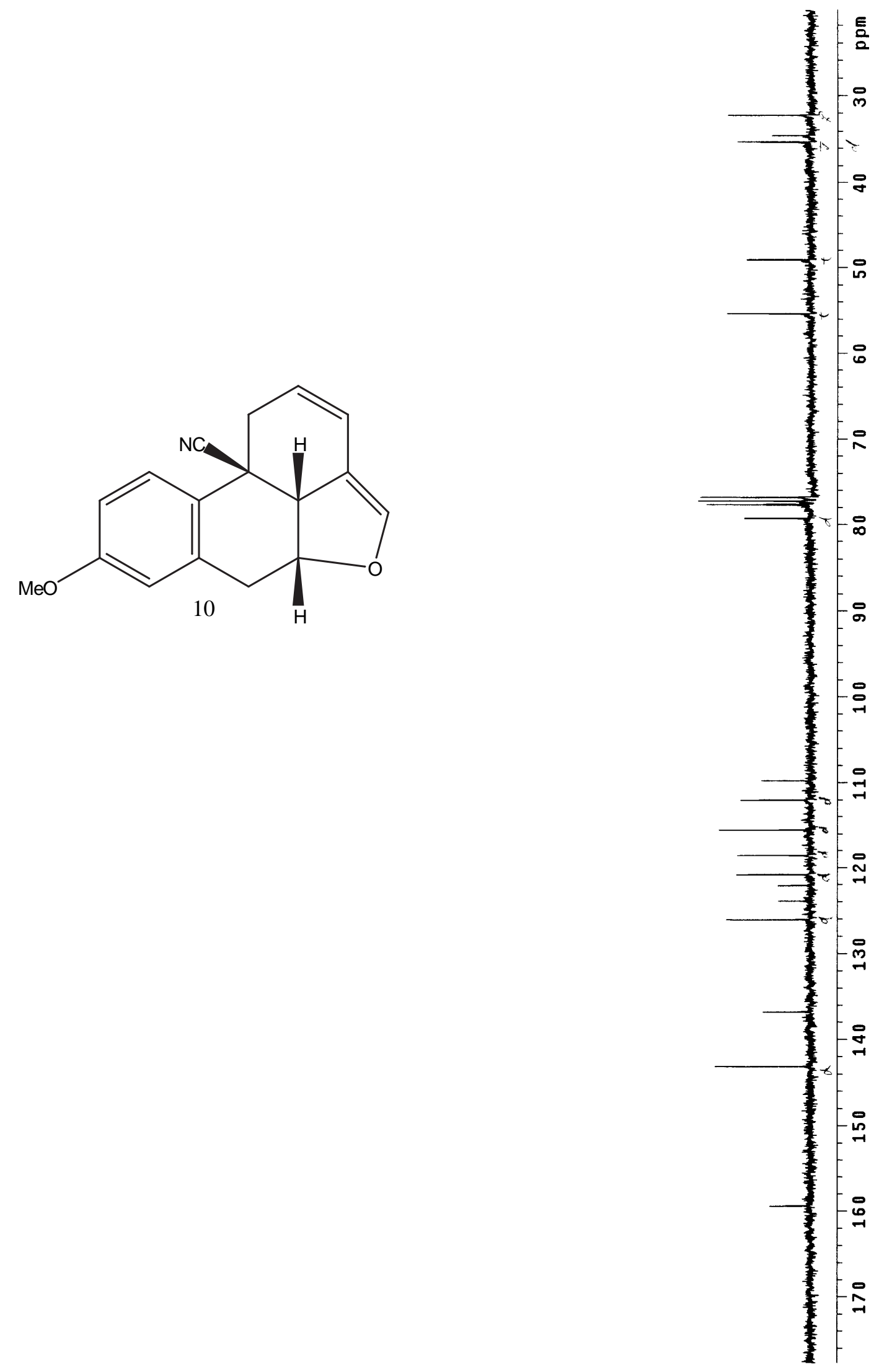

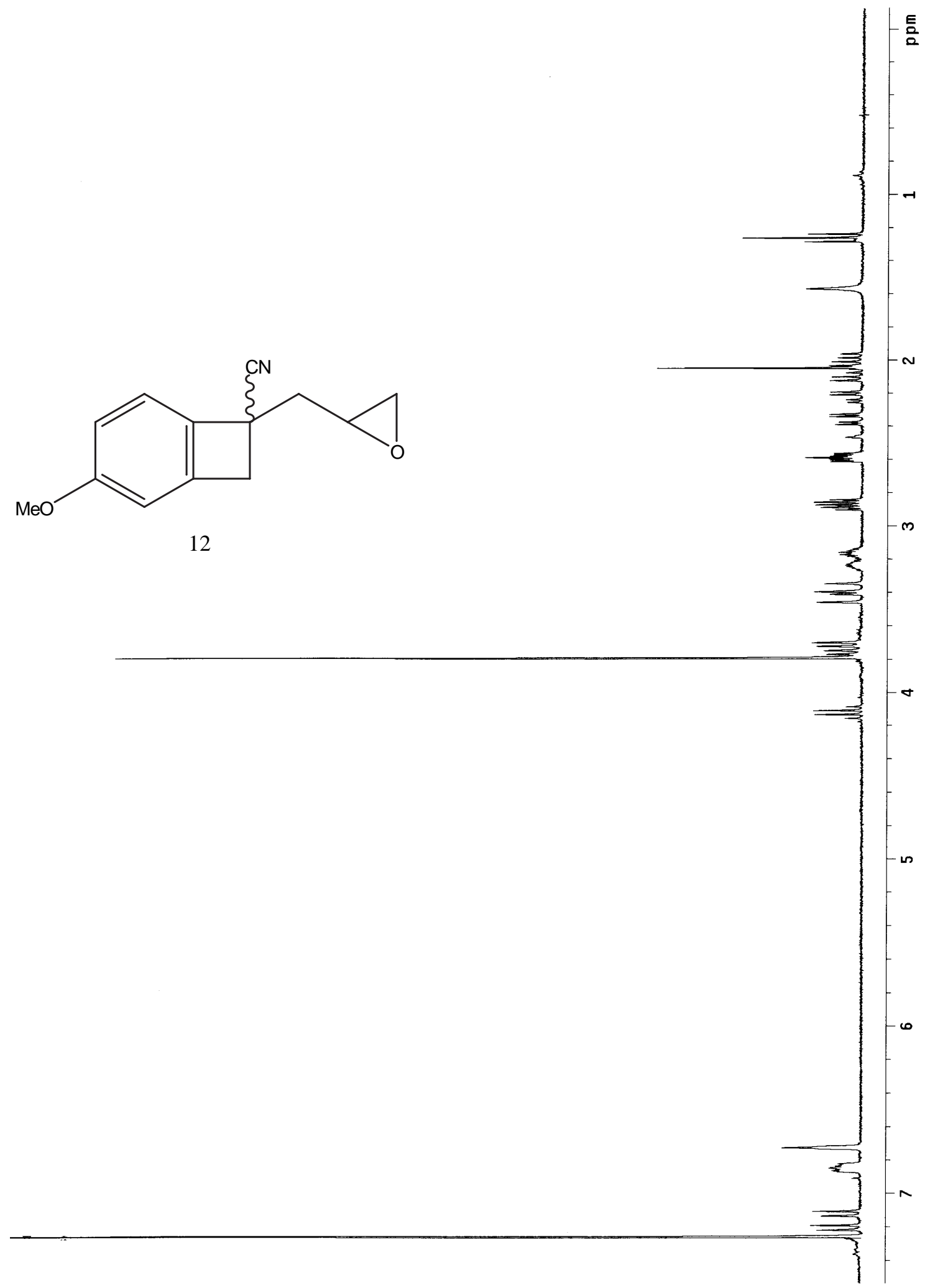


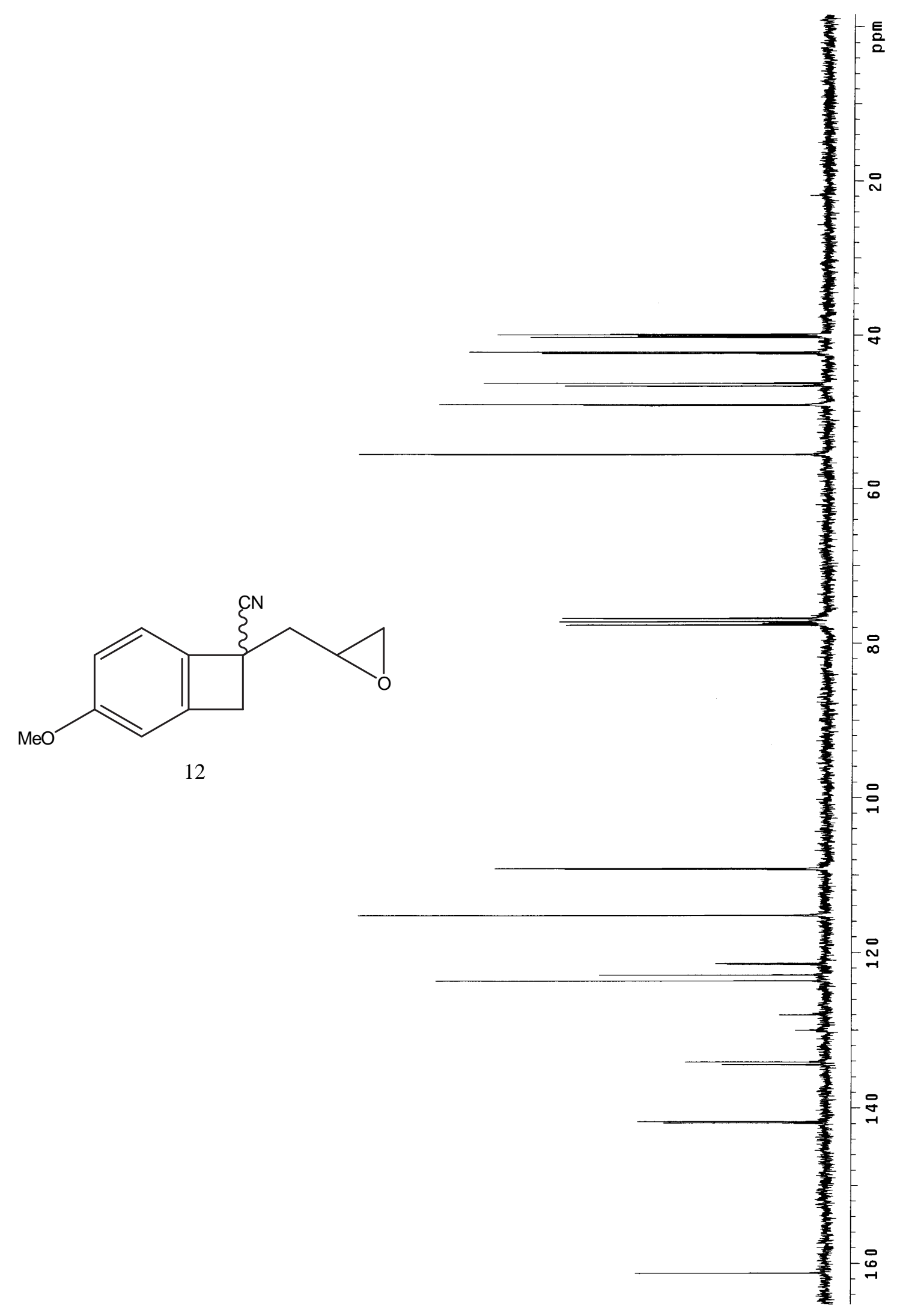



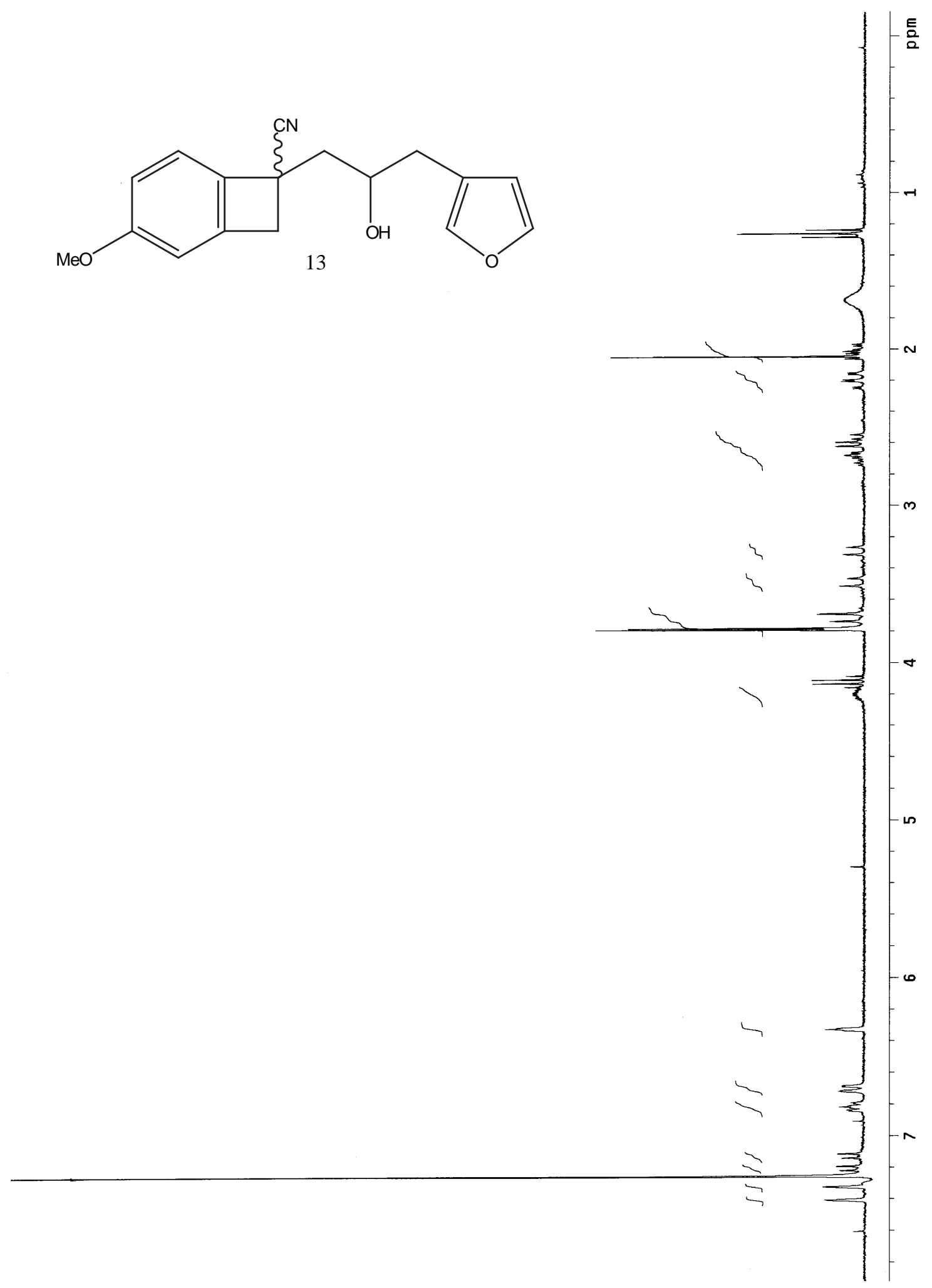


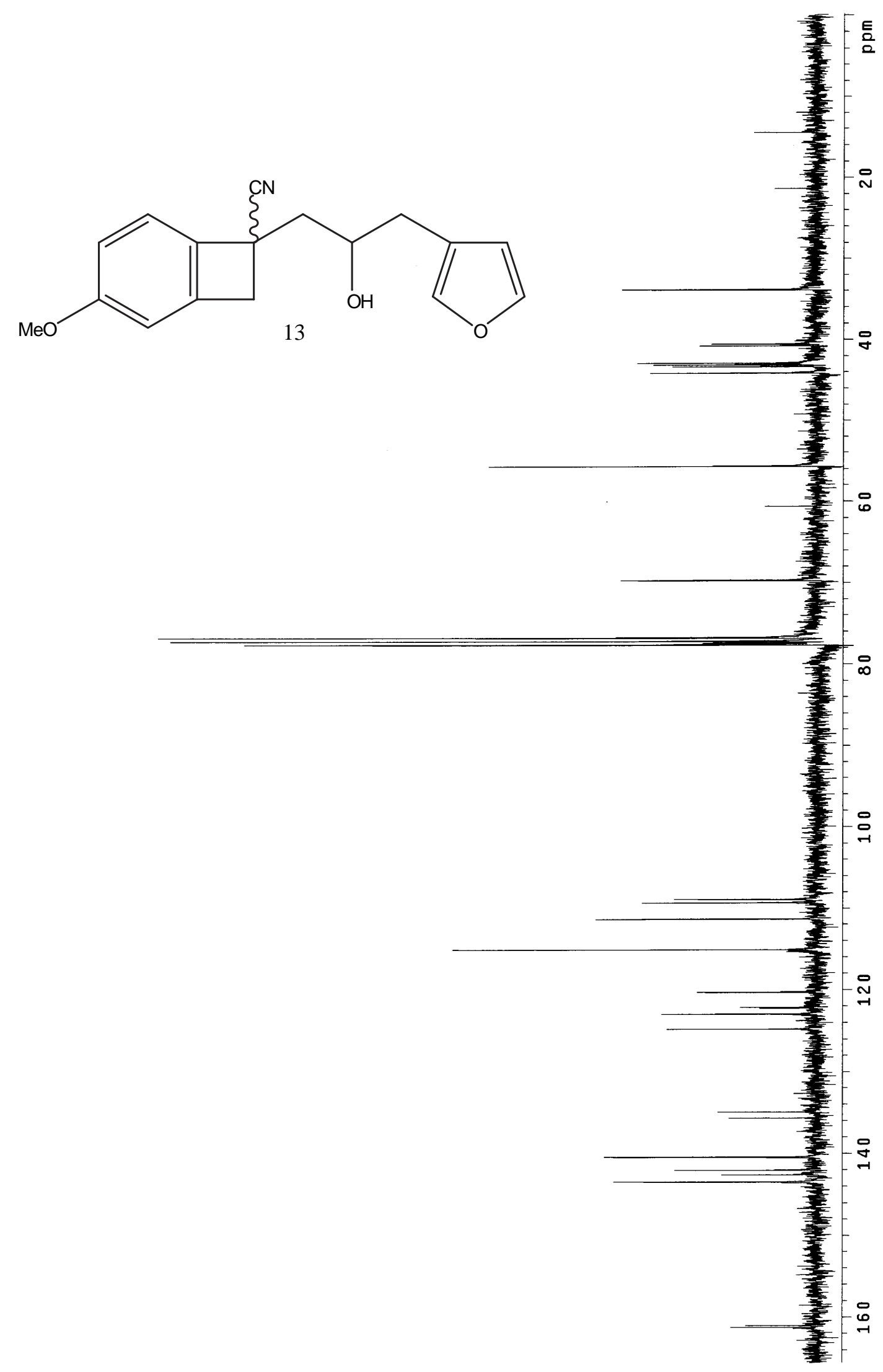




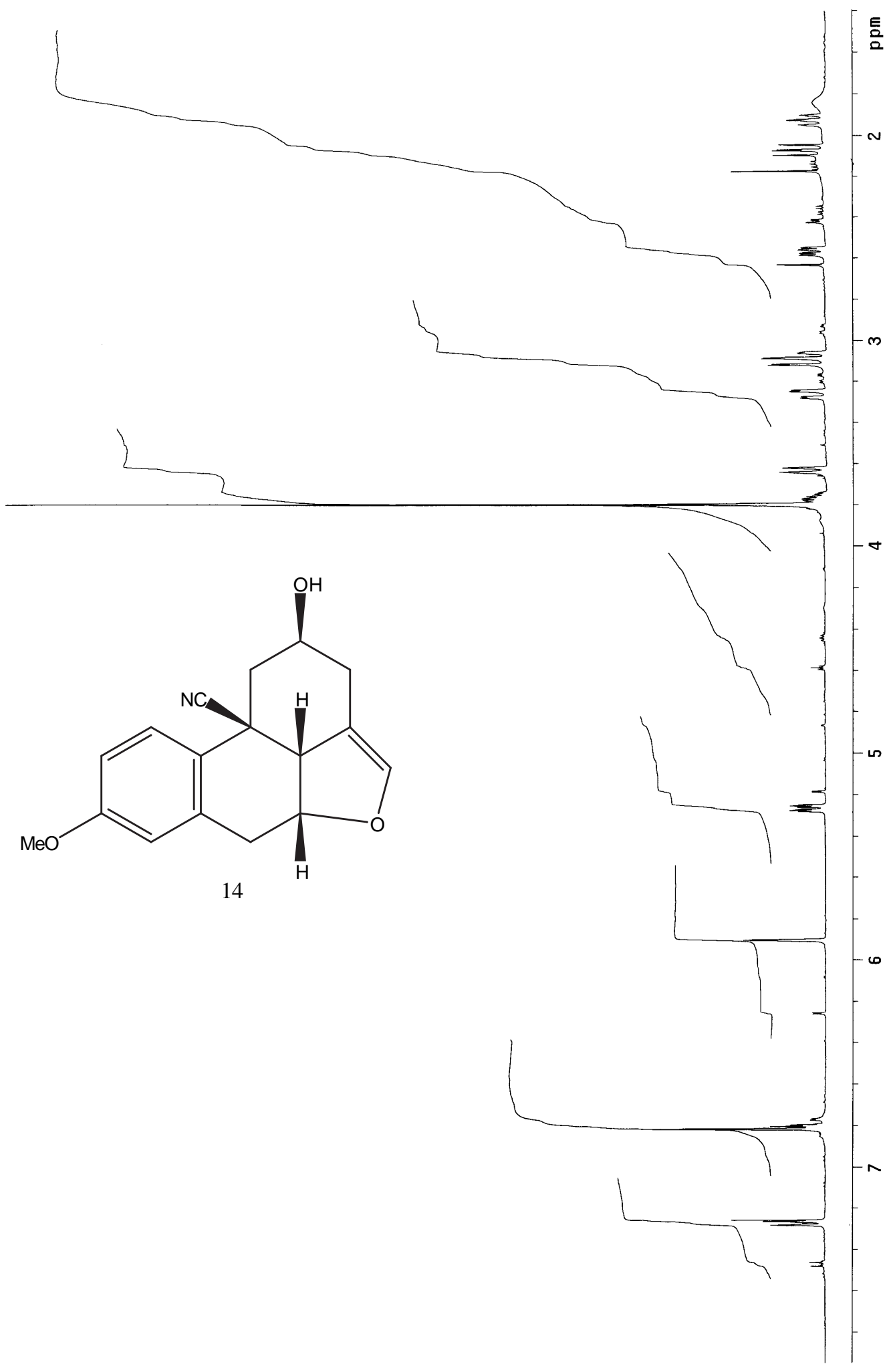



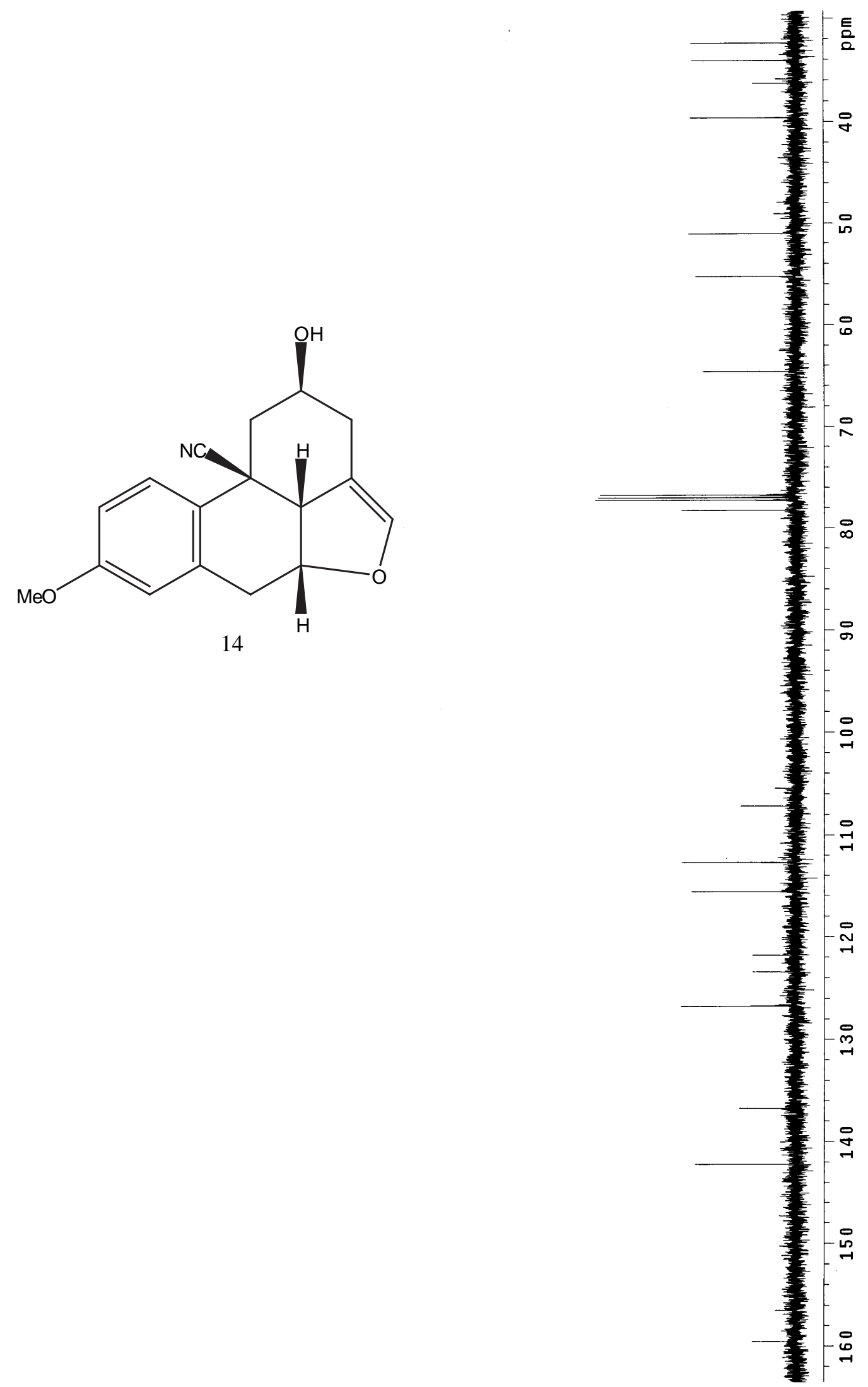


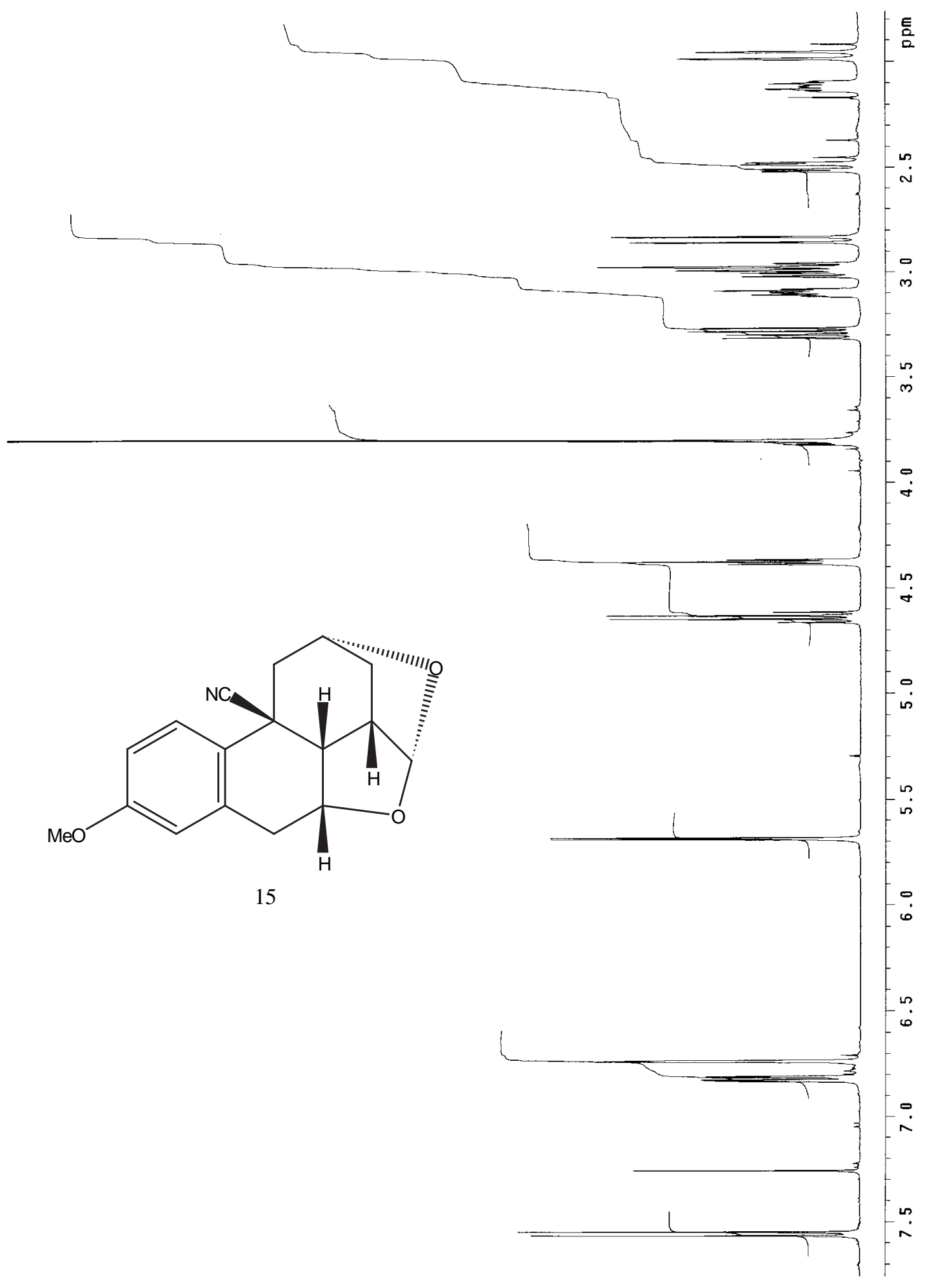




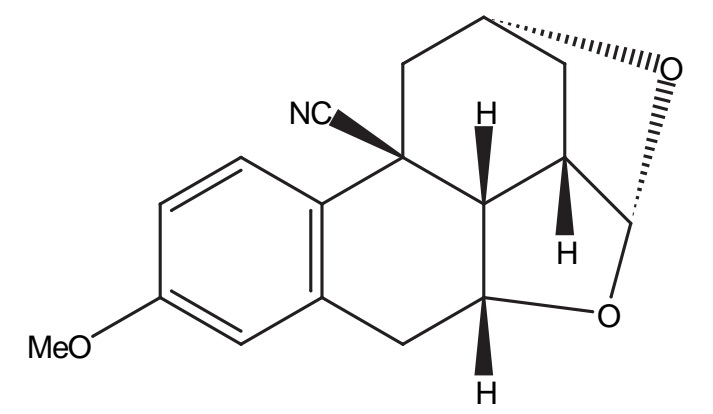

15

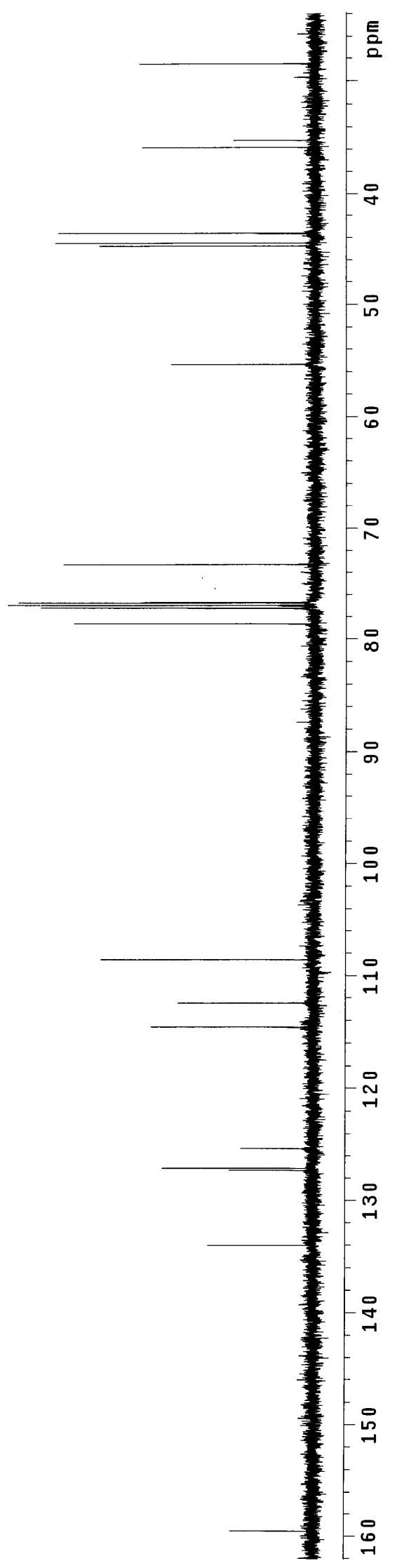




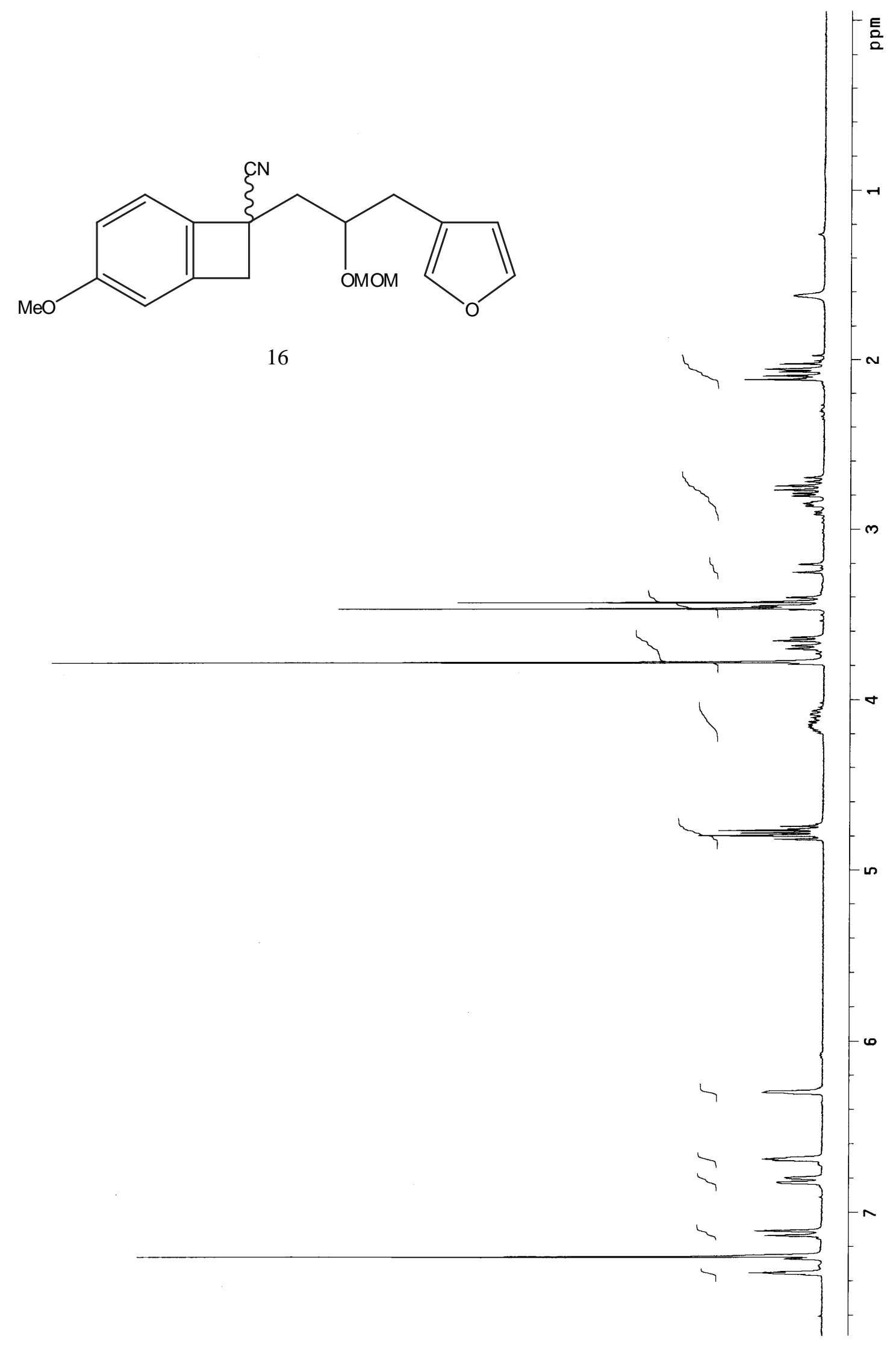




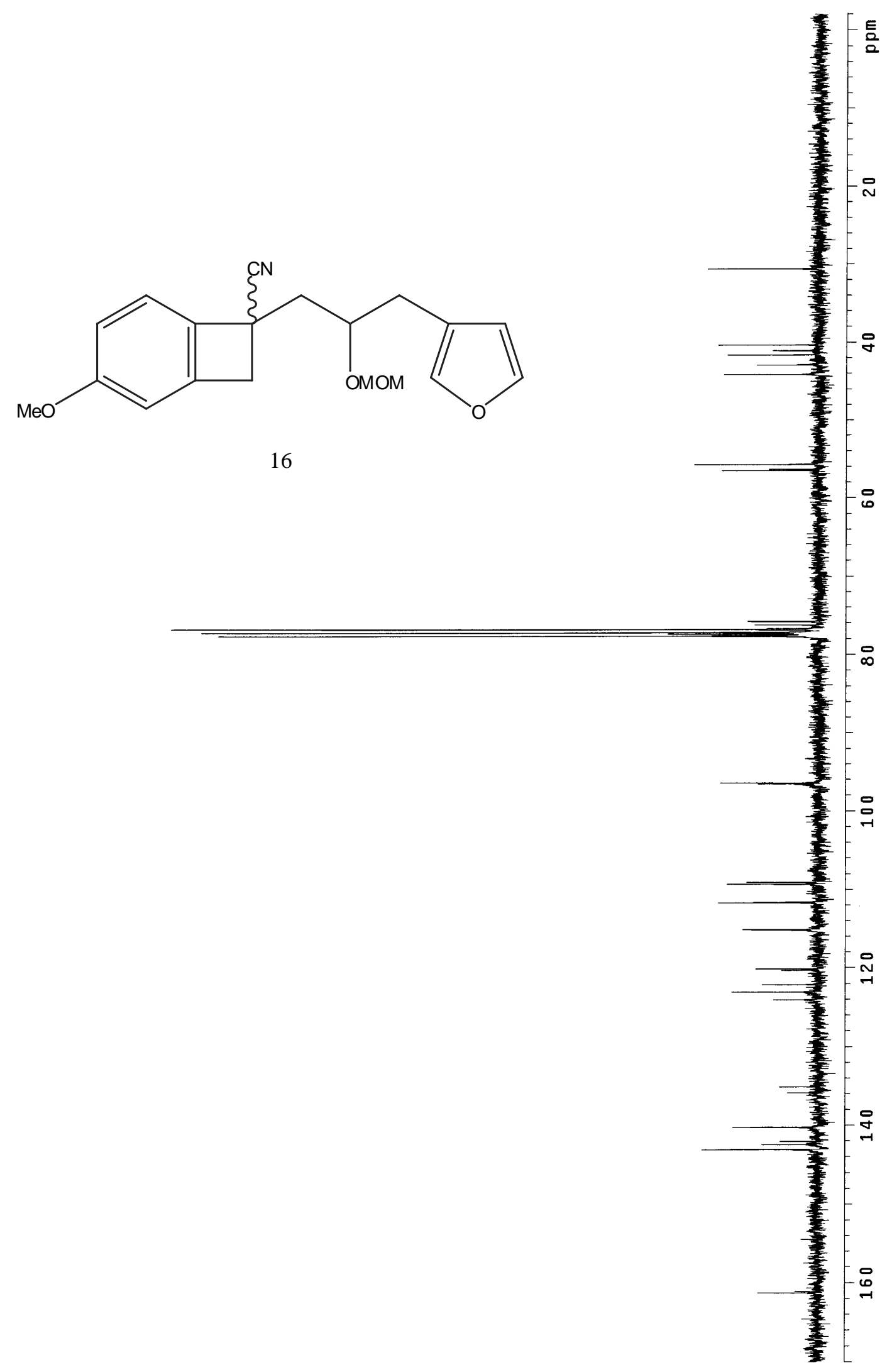




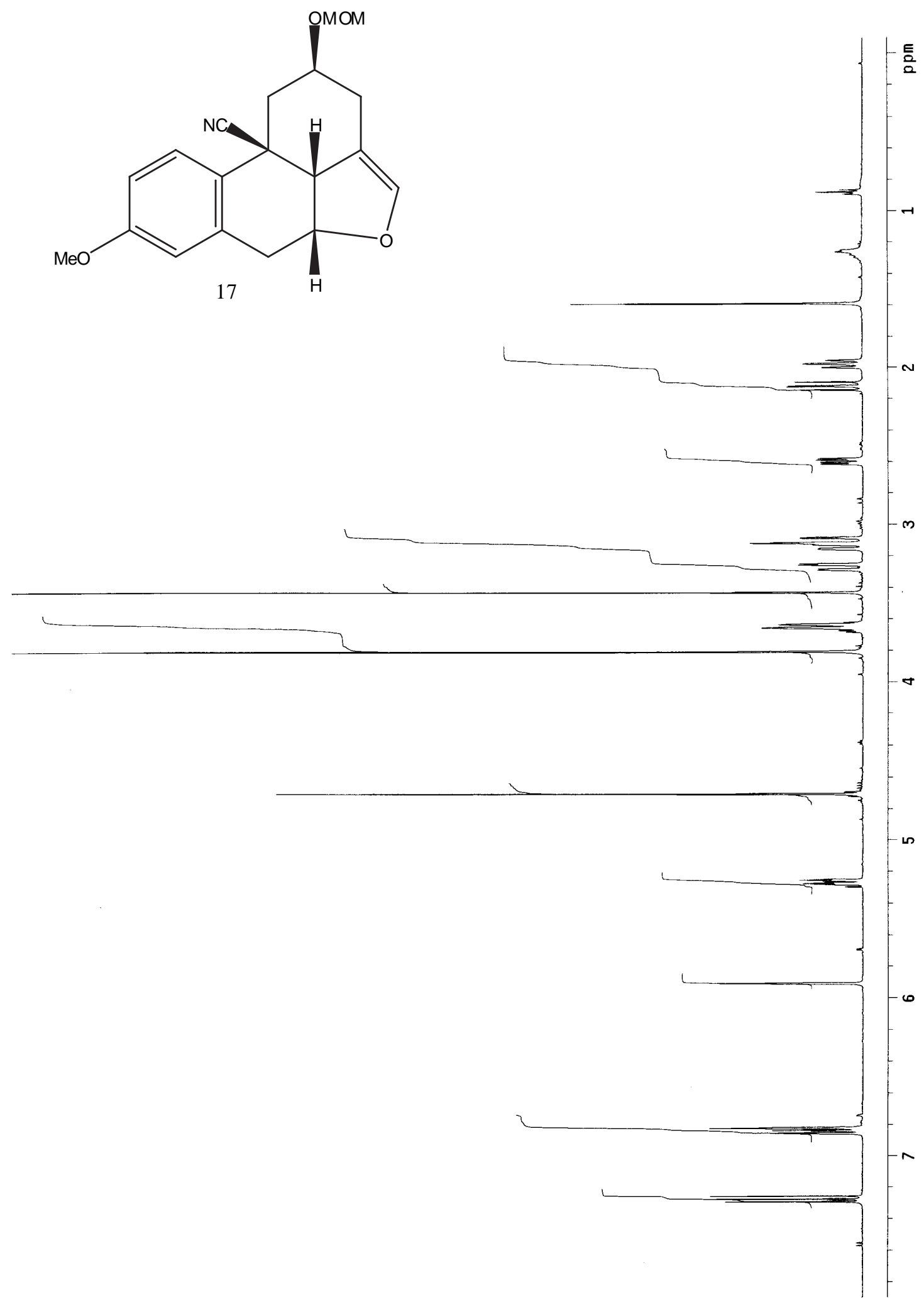



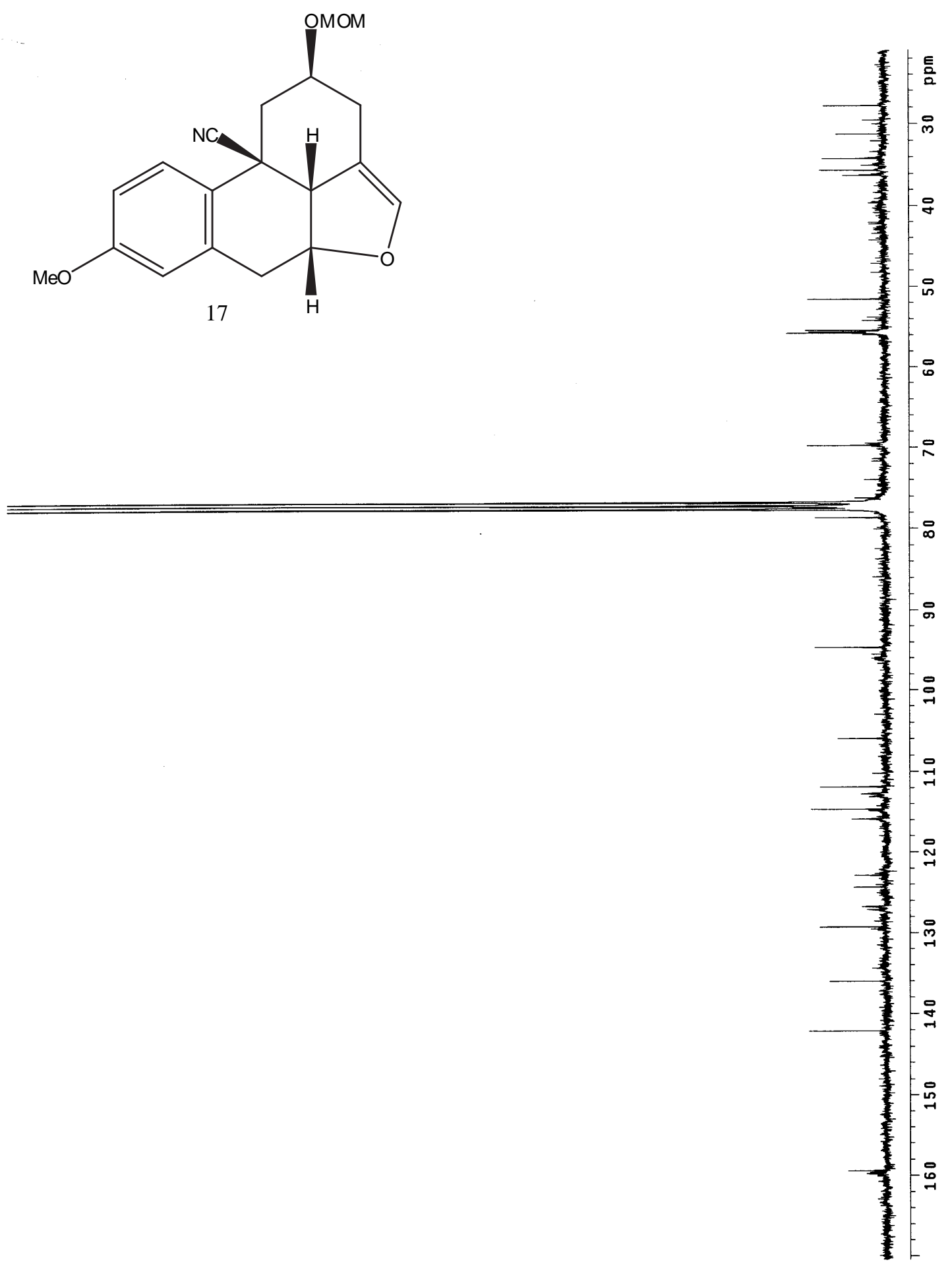


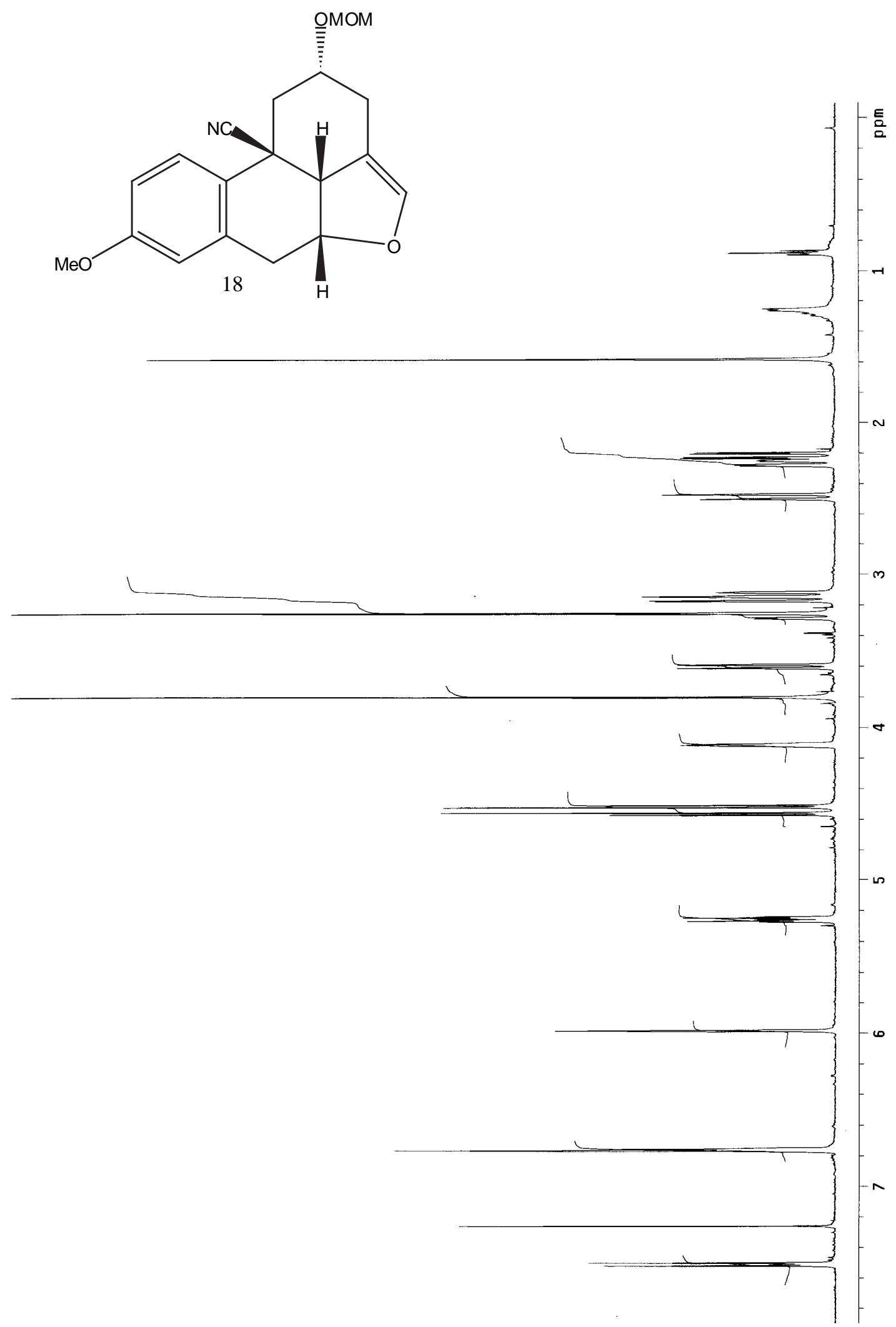



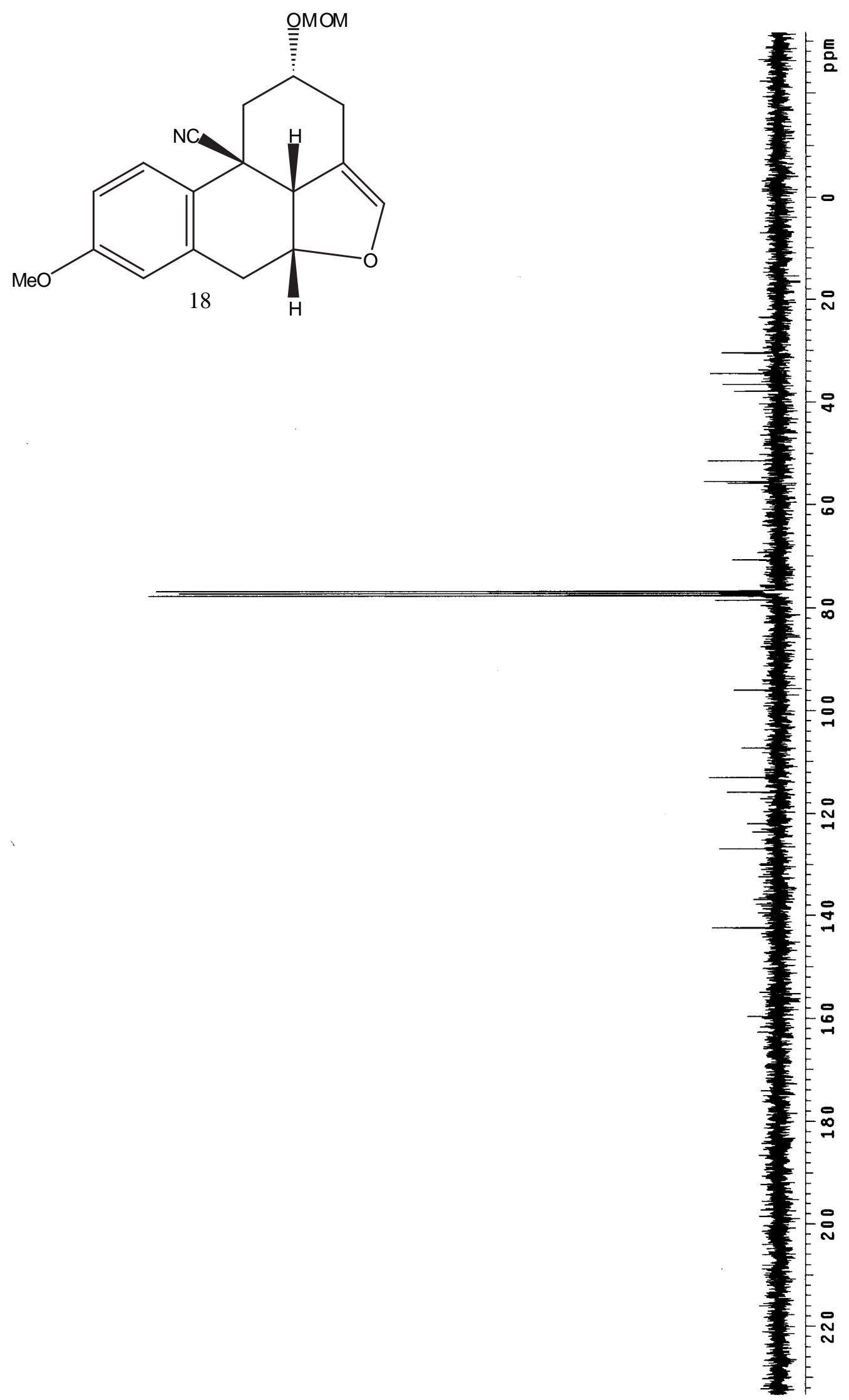


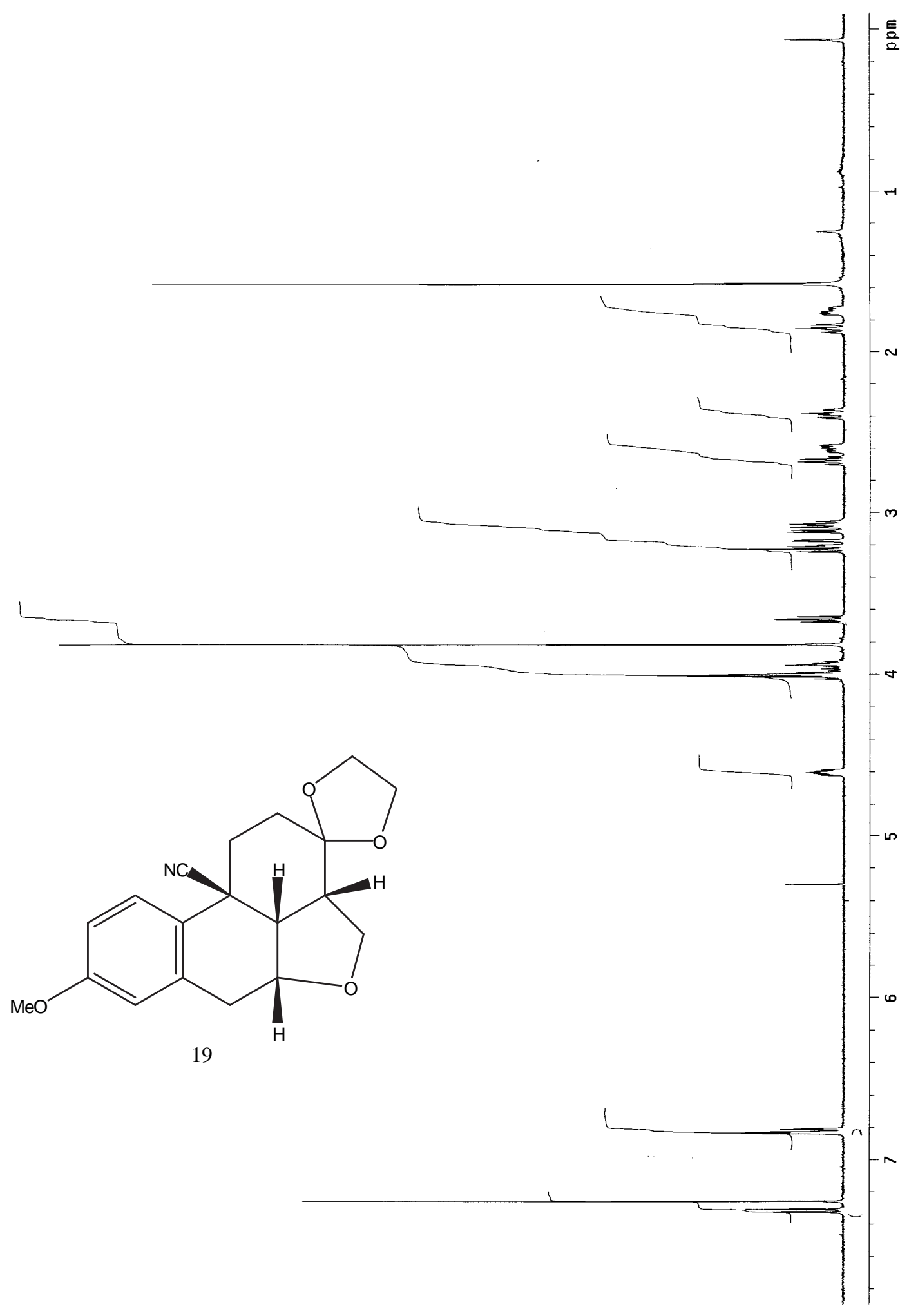



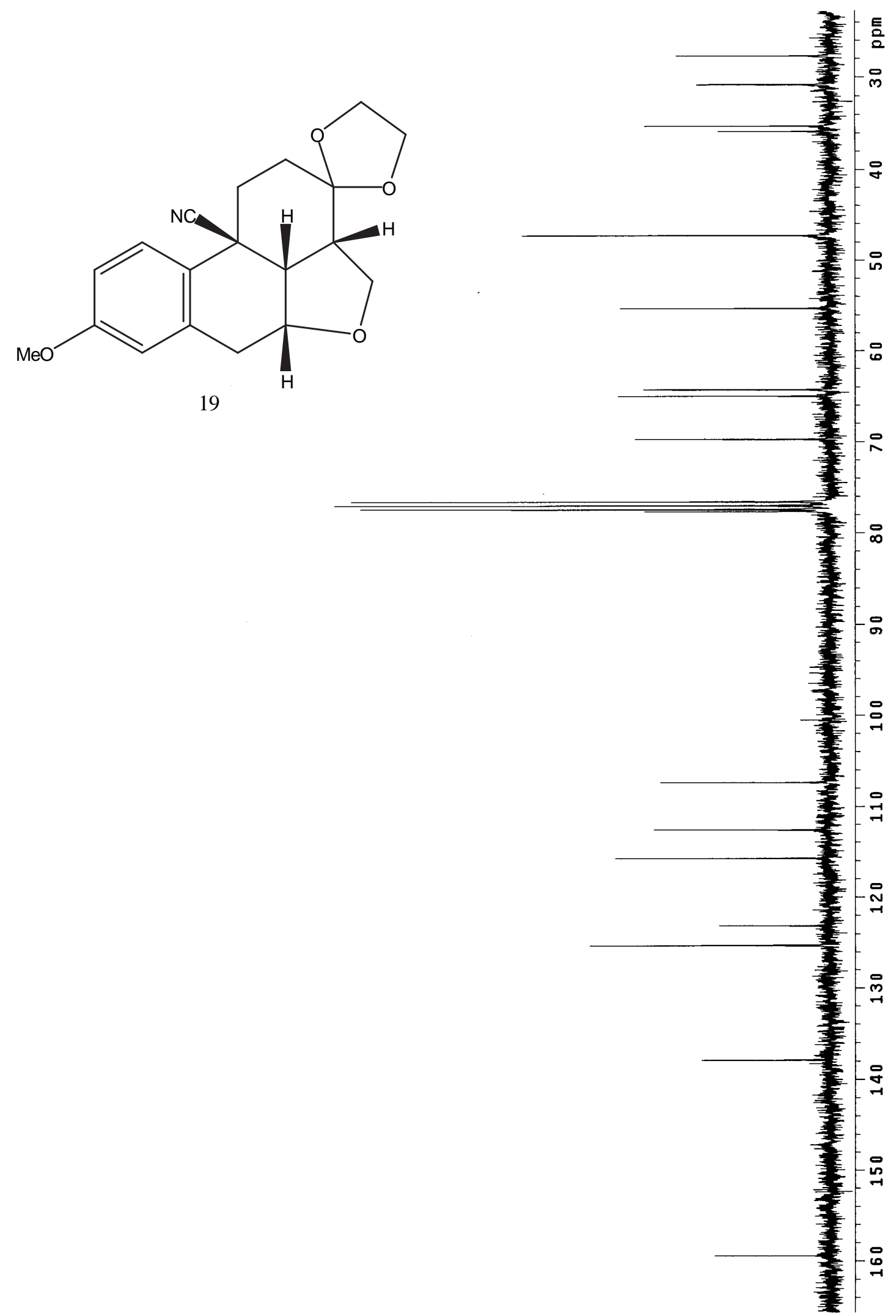


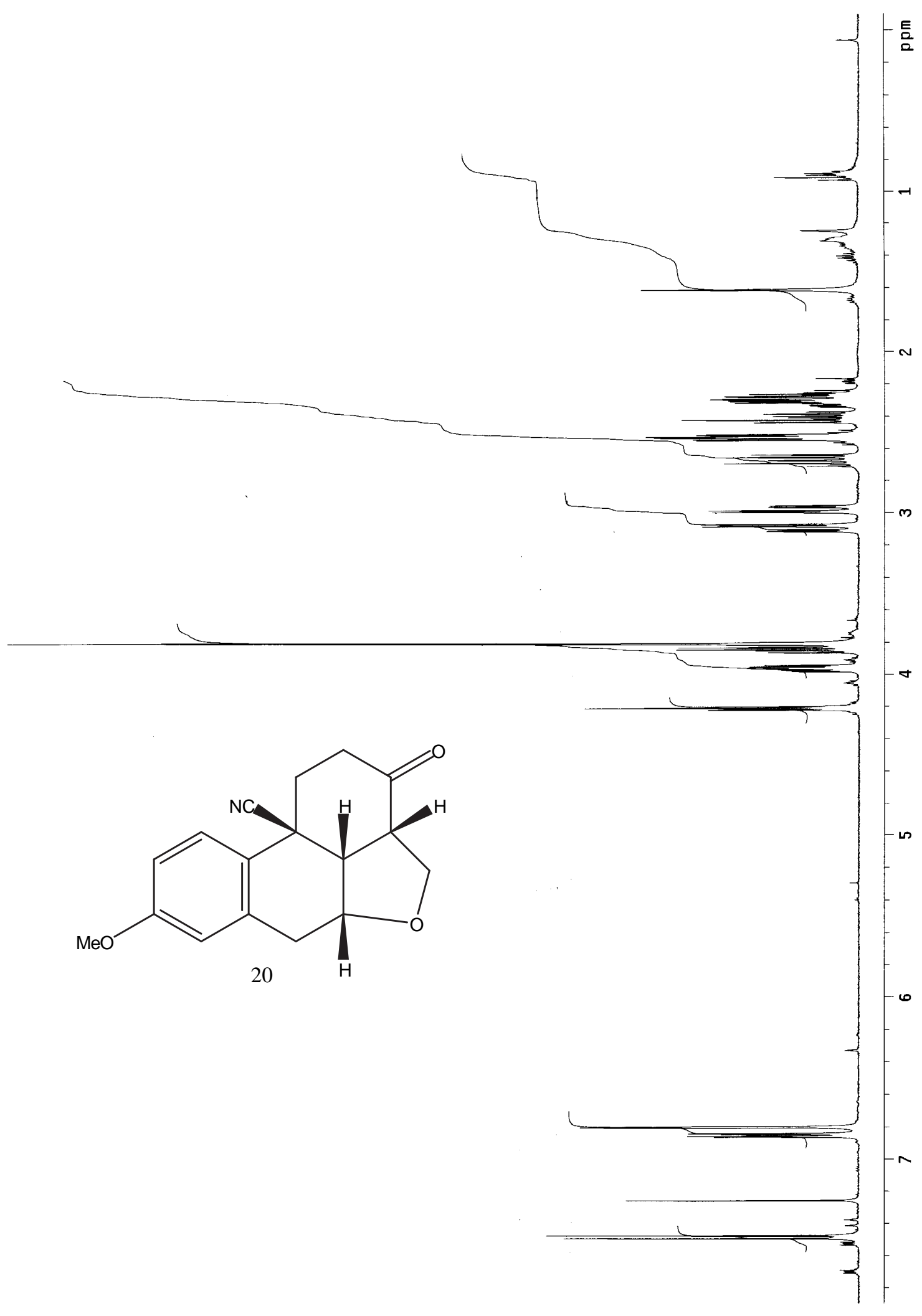




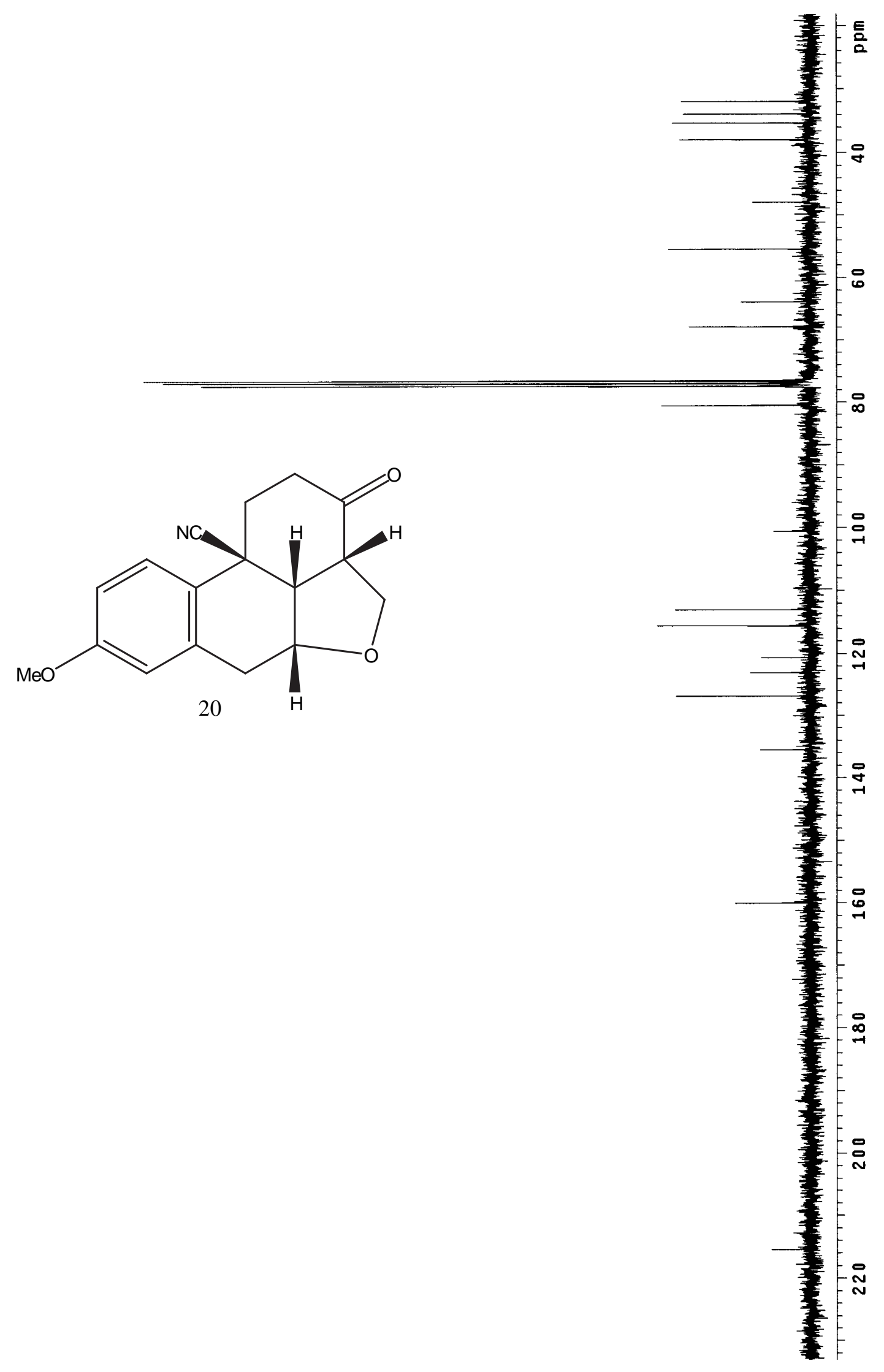




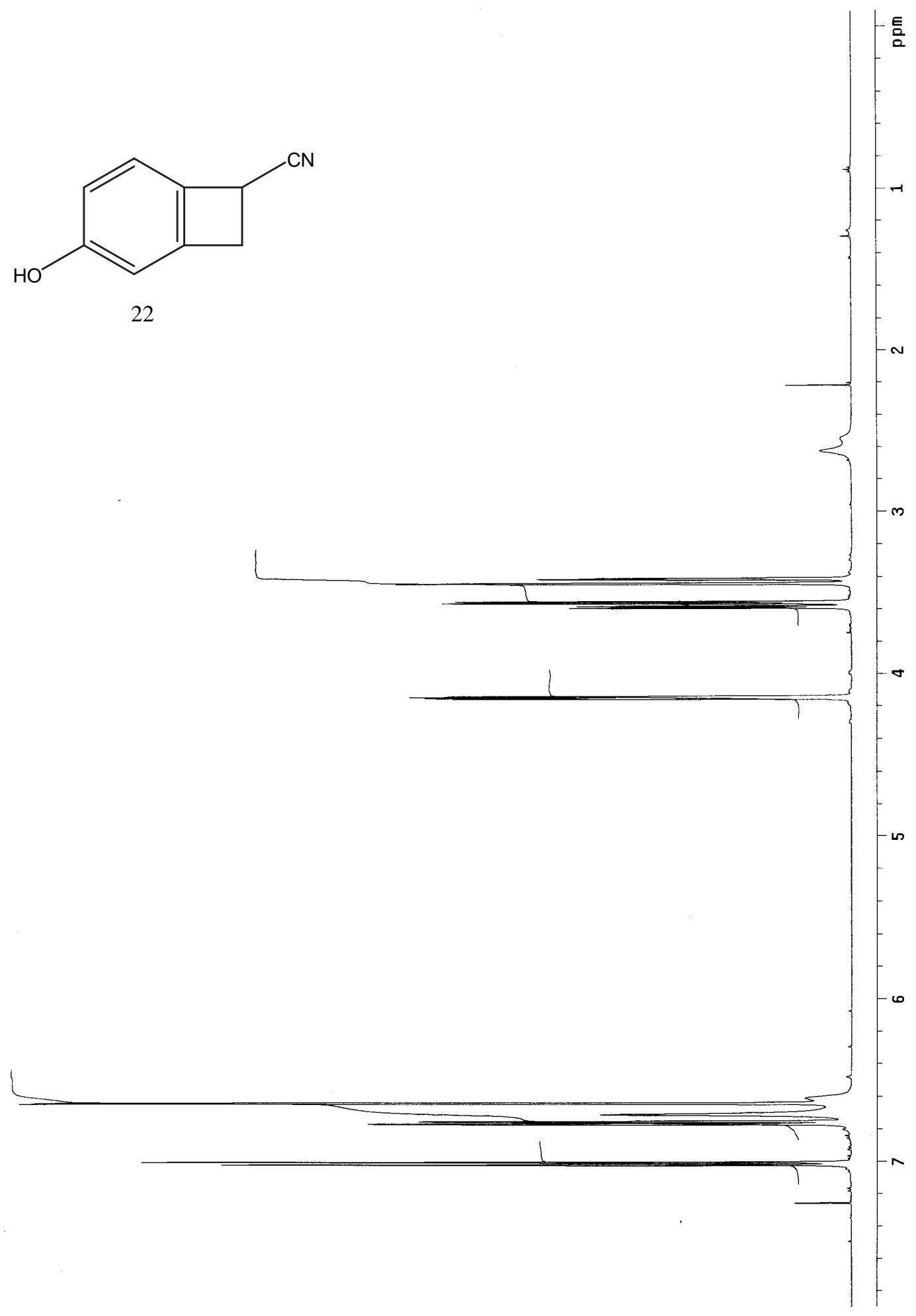




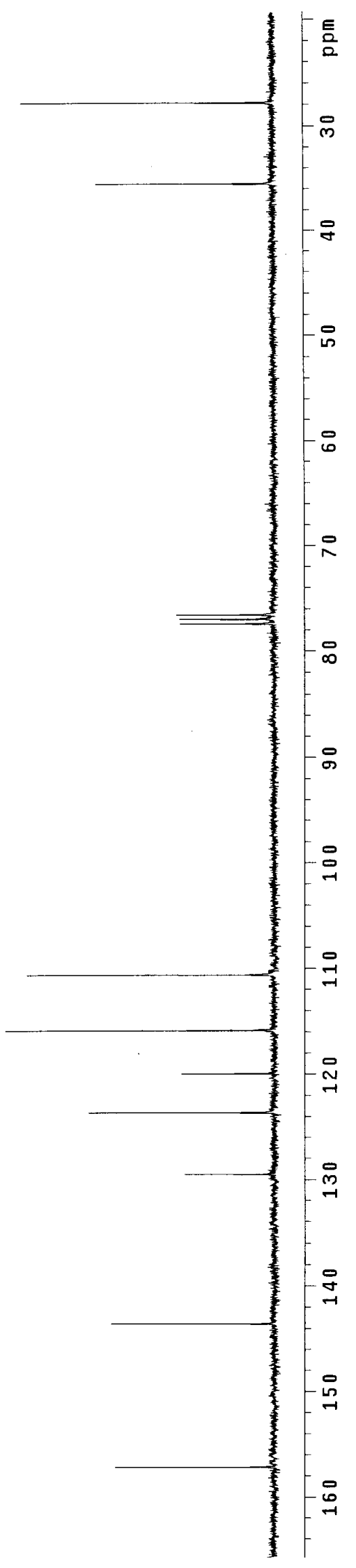




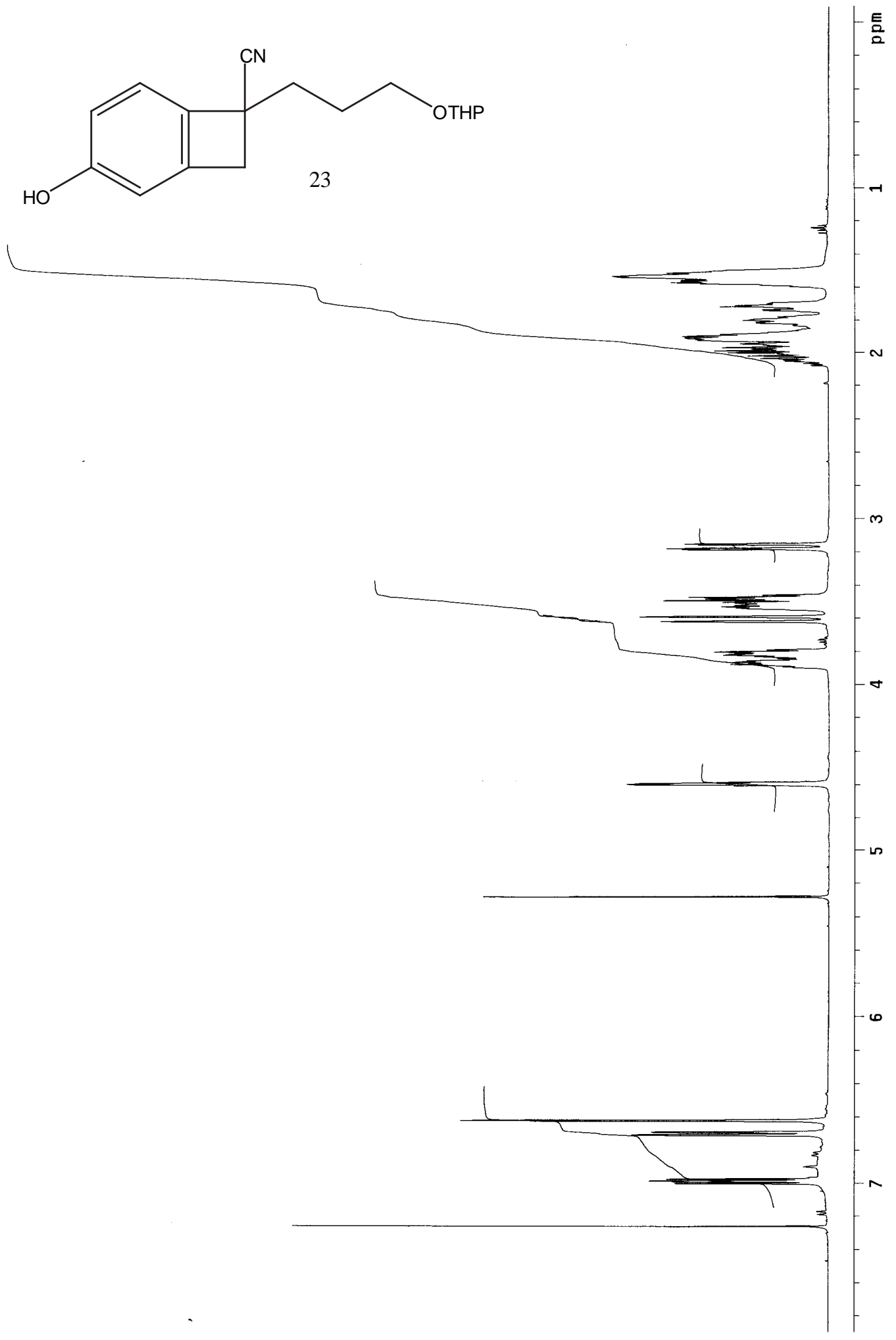




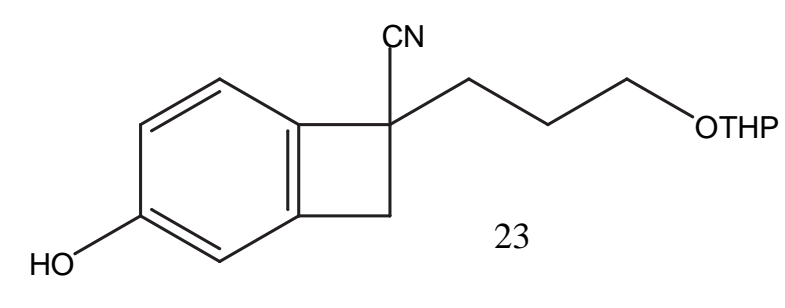

23

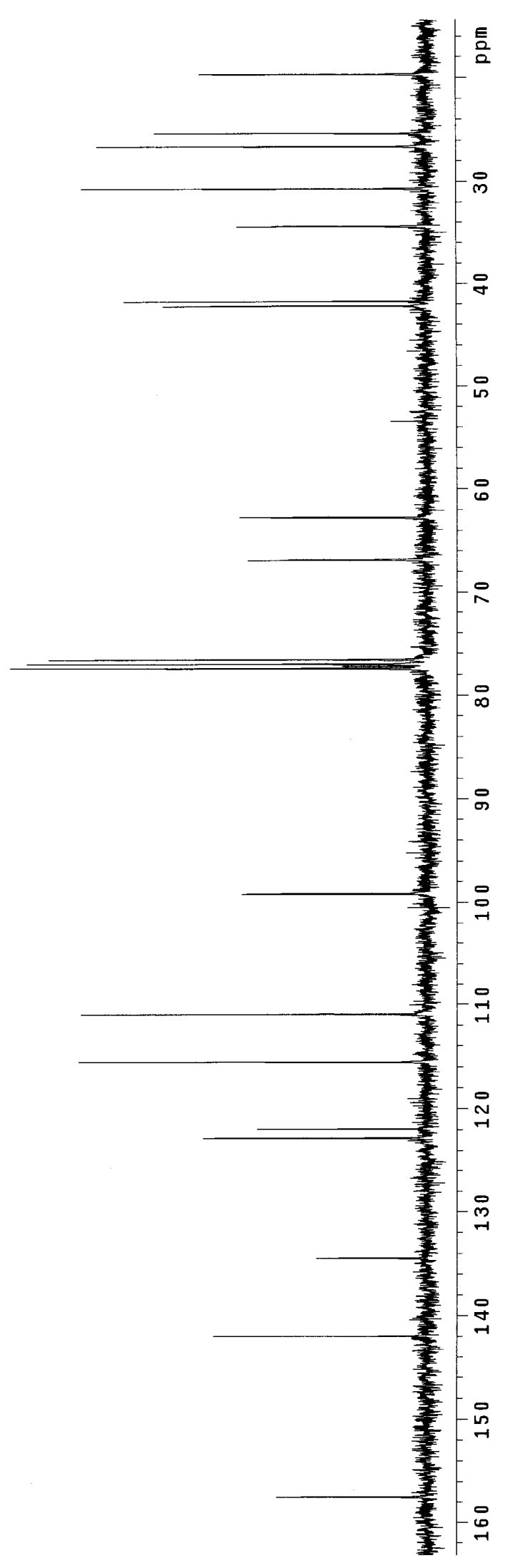

S67 


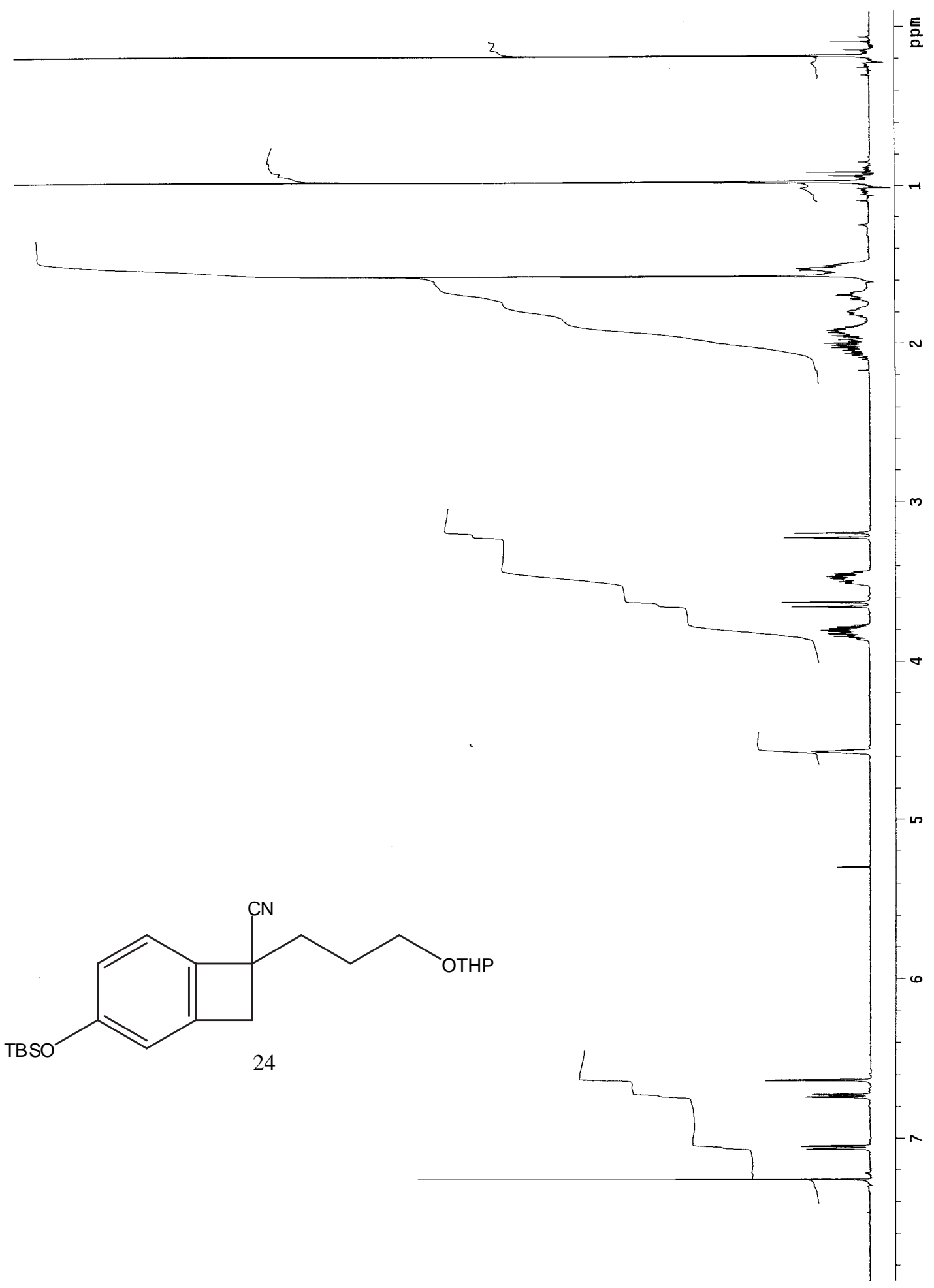



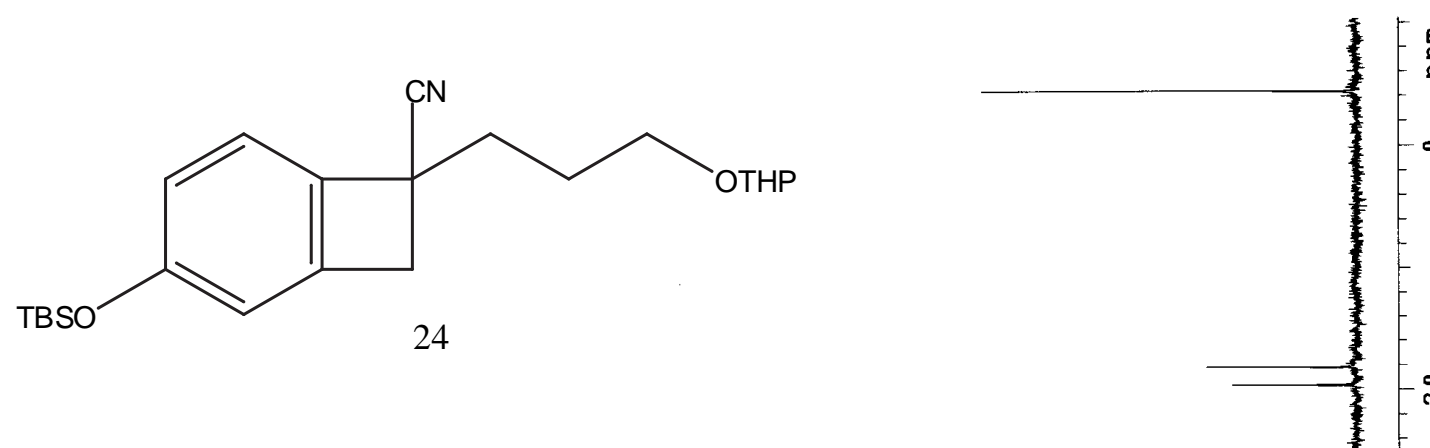

틈
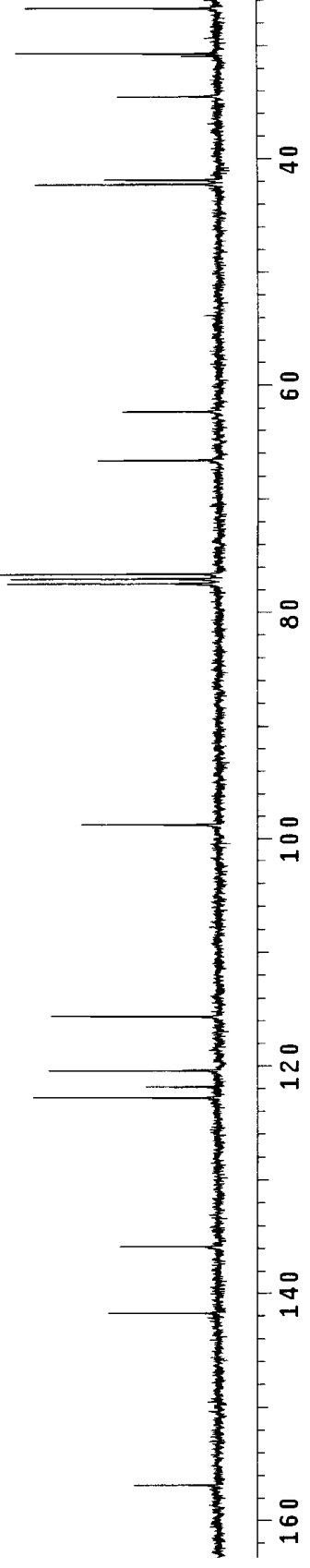


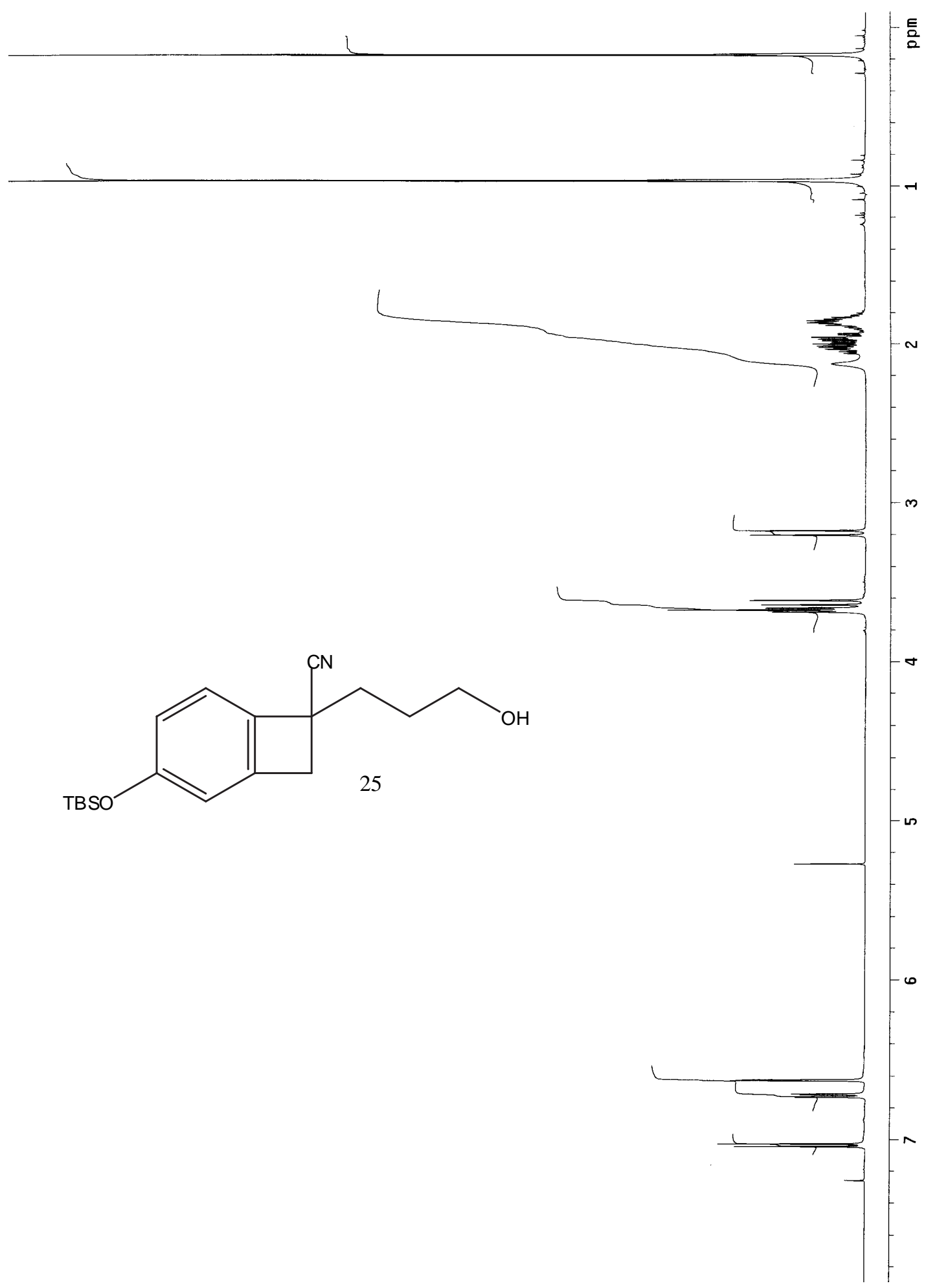



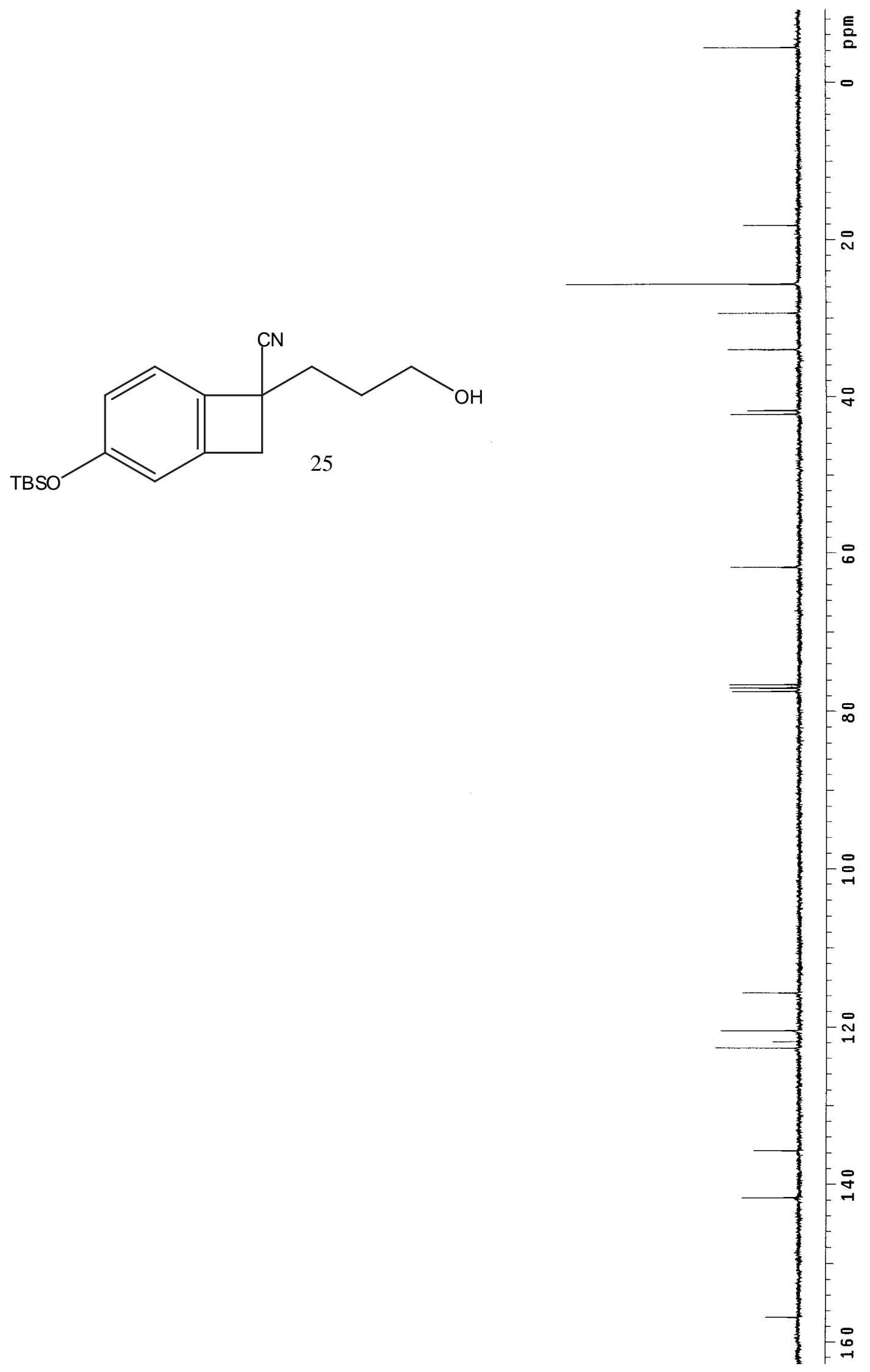


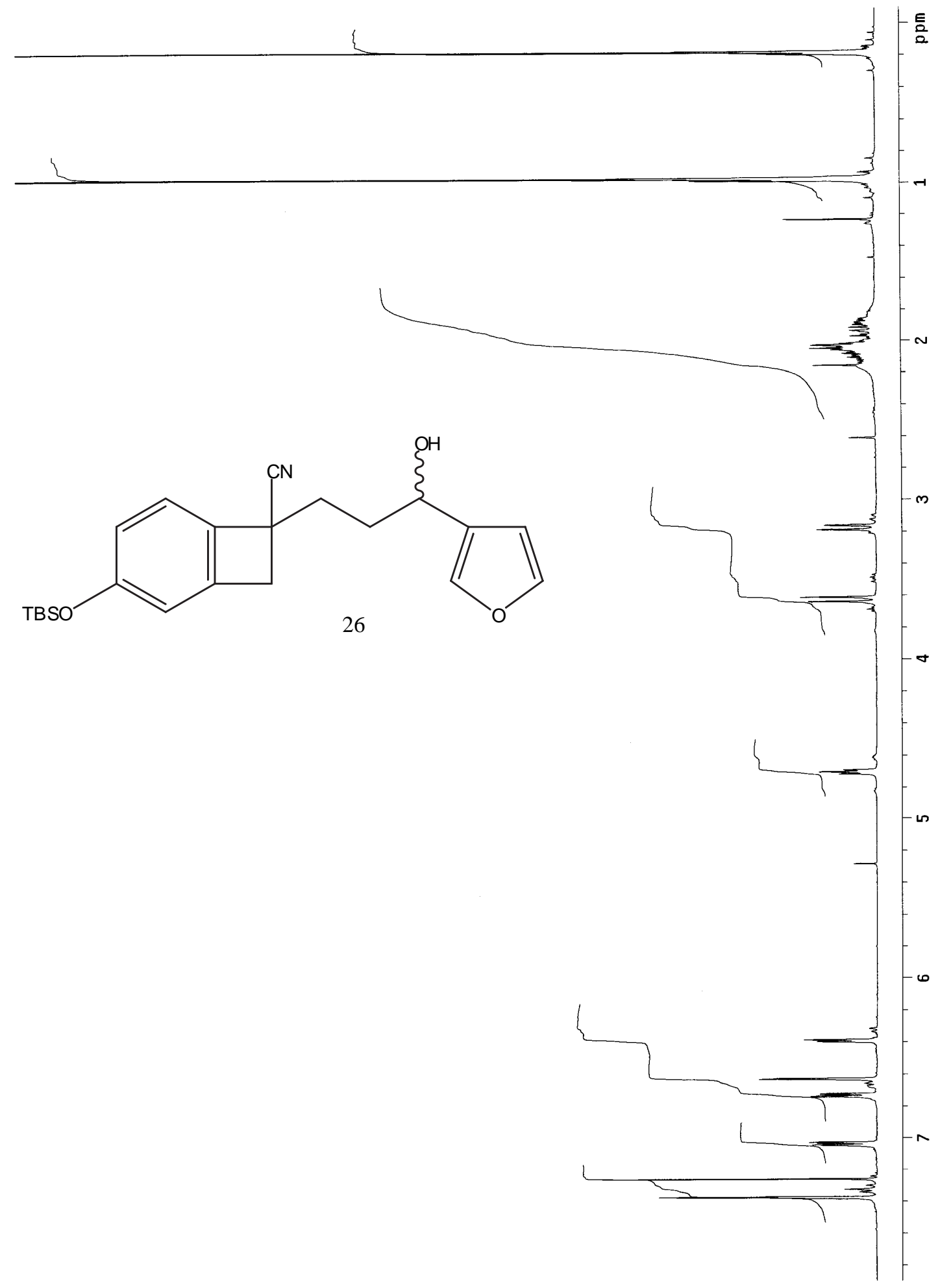




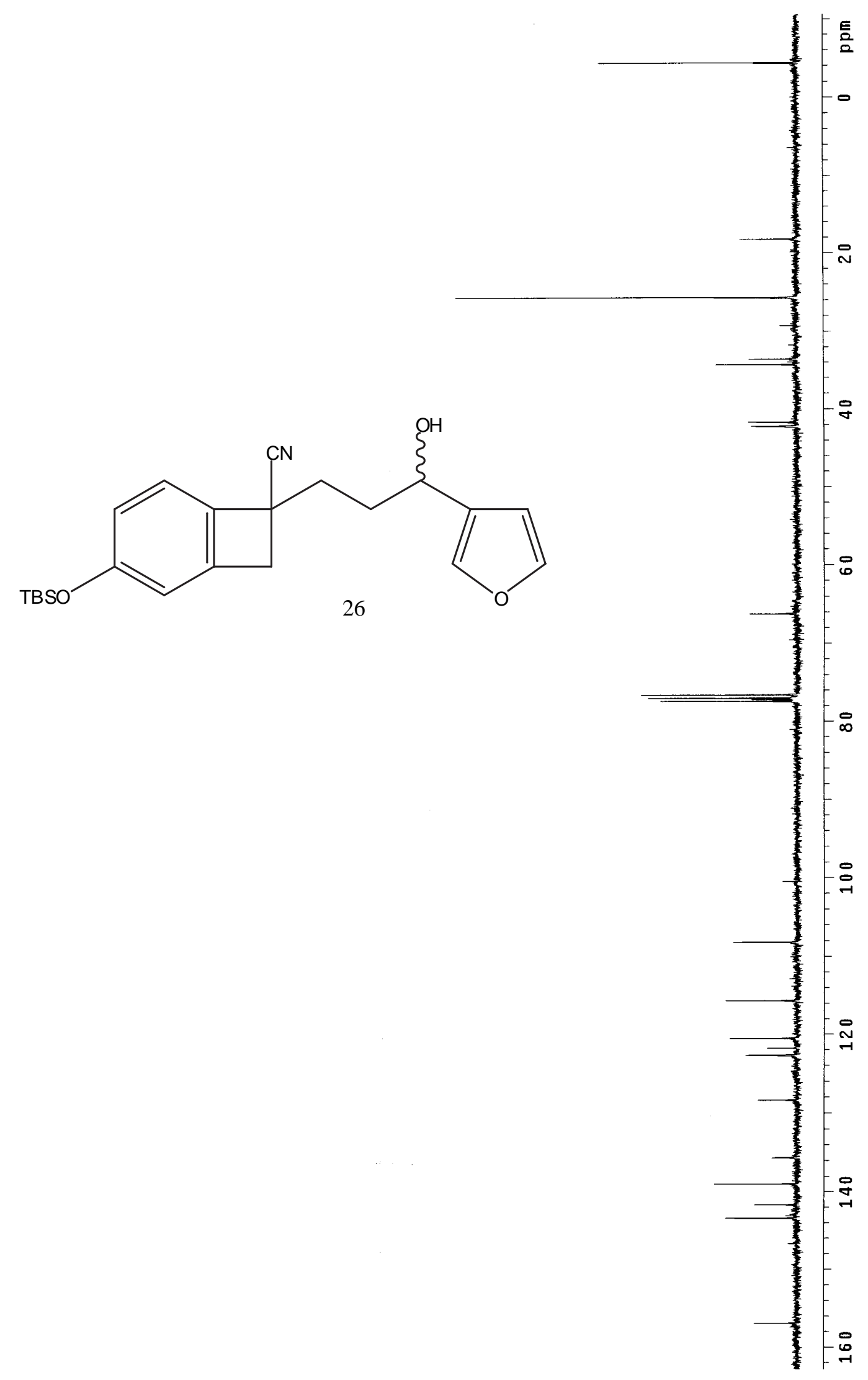




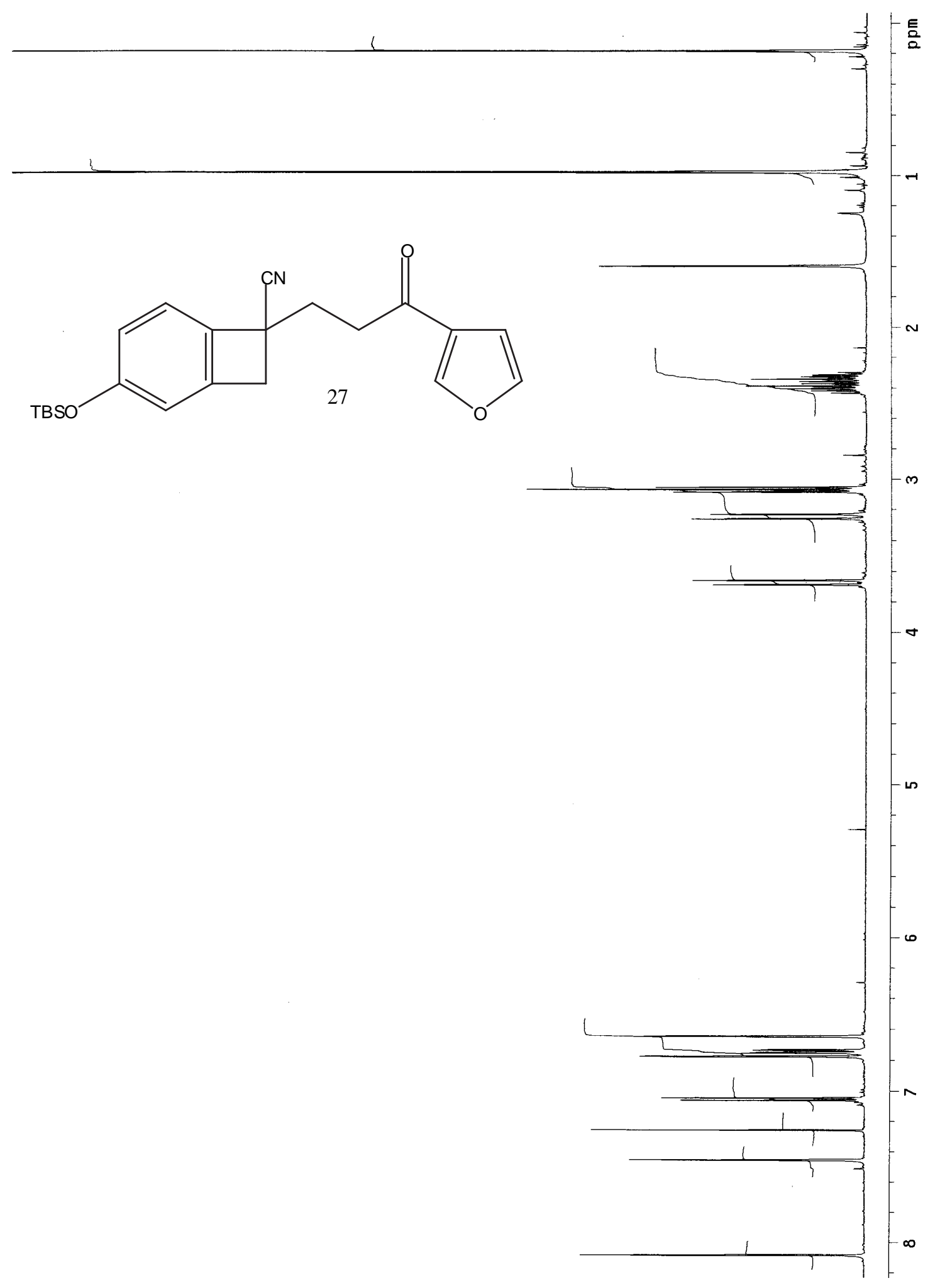



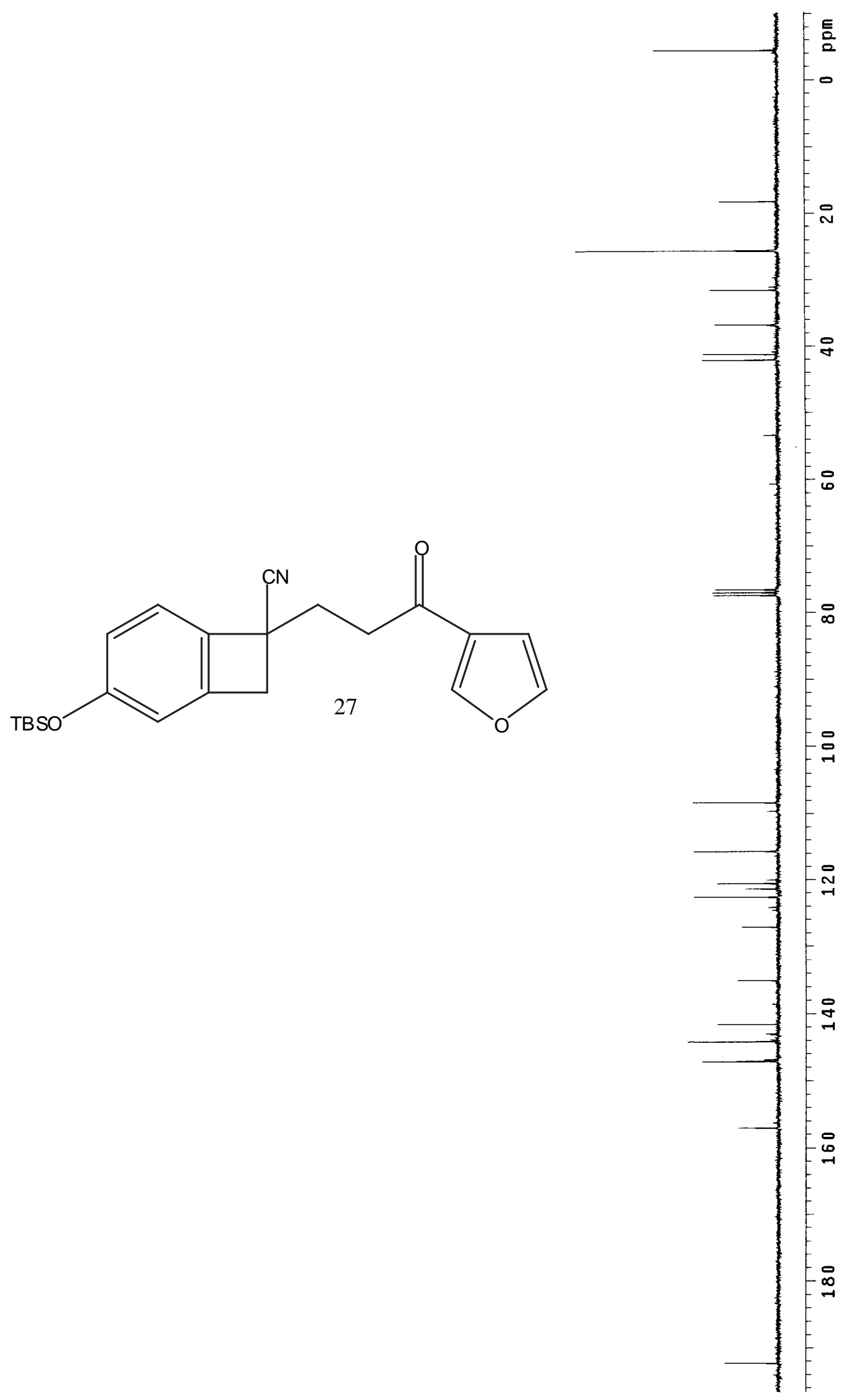


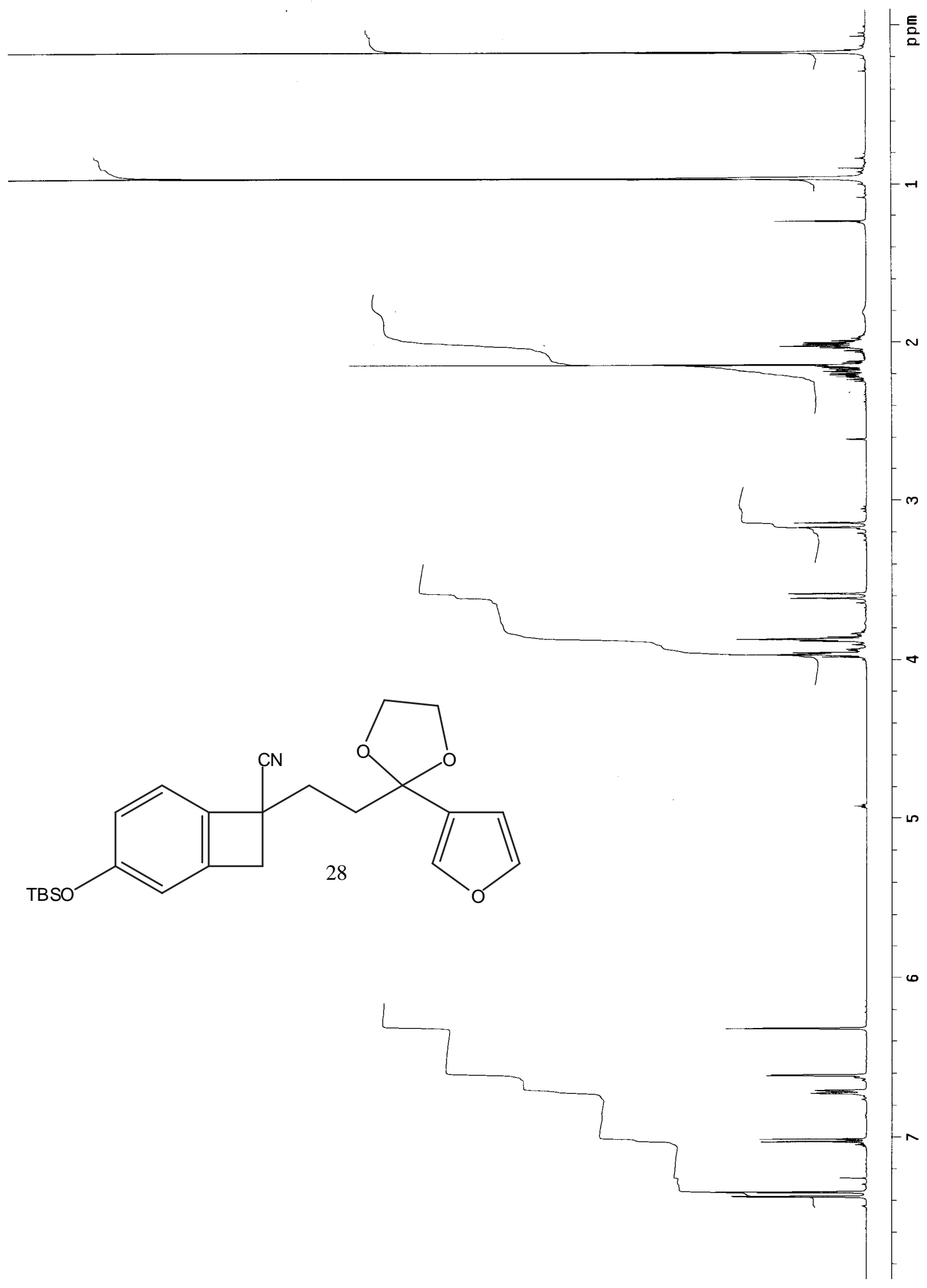




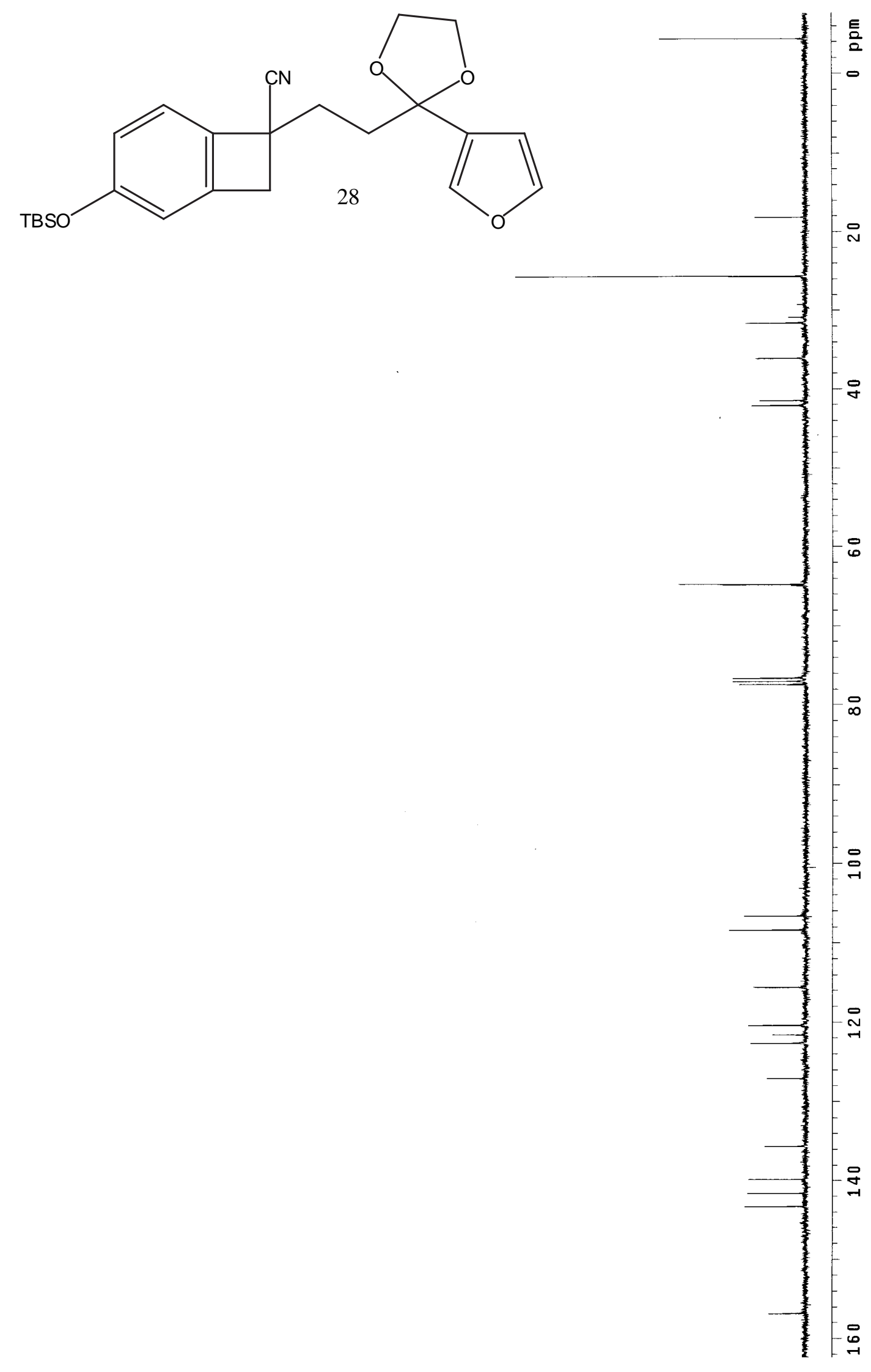




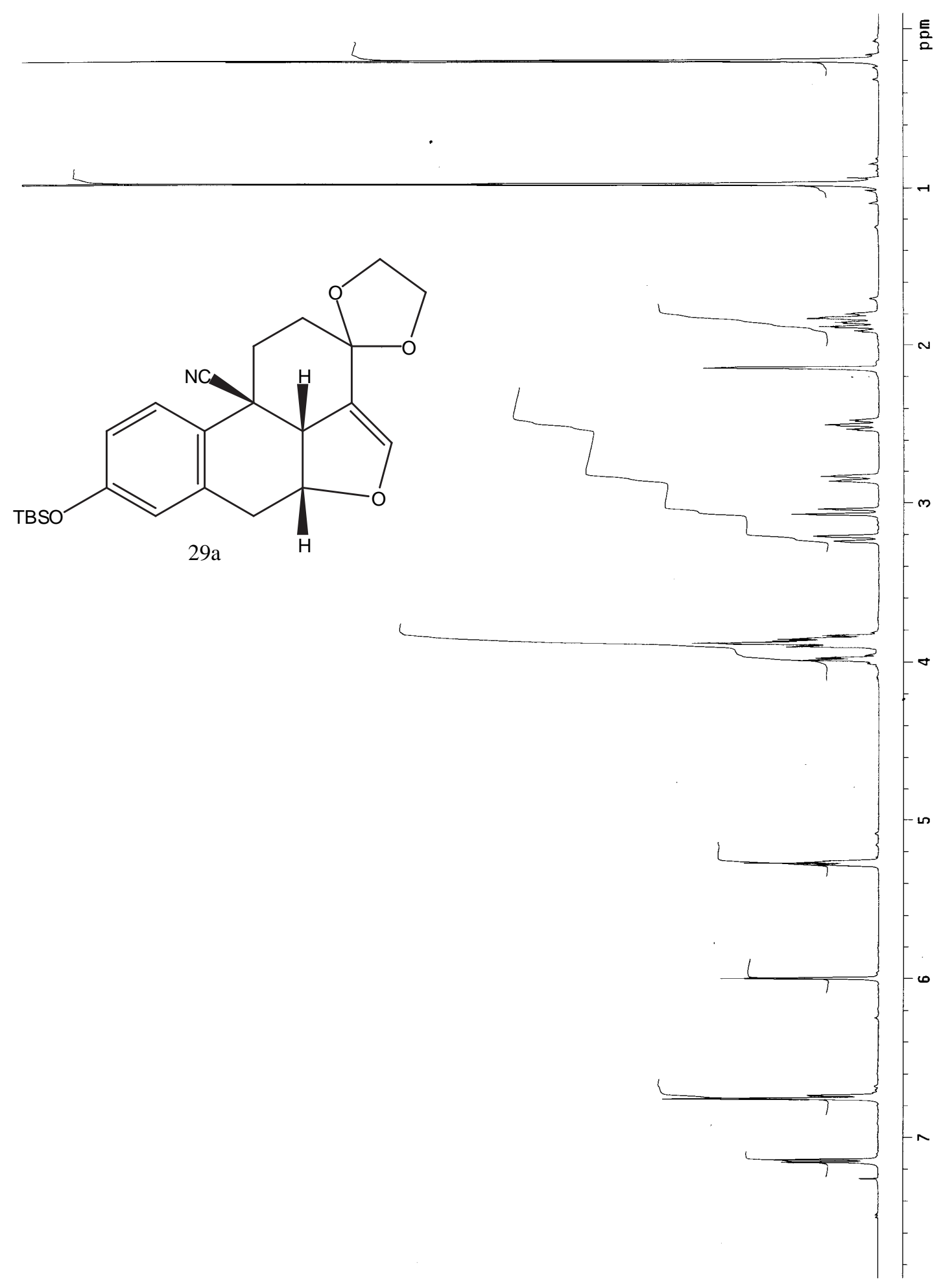




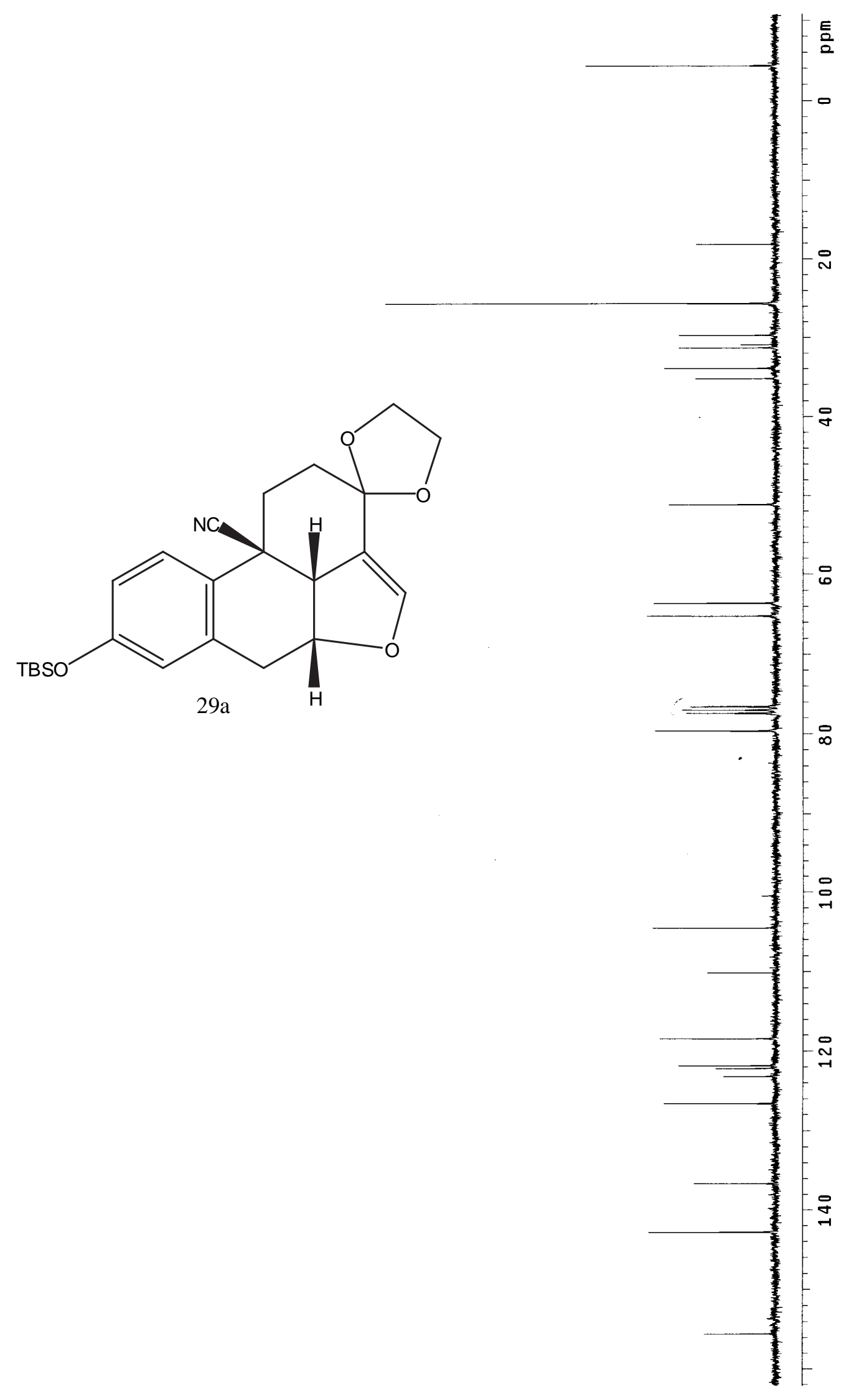




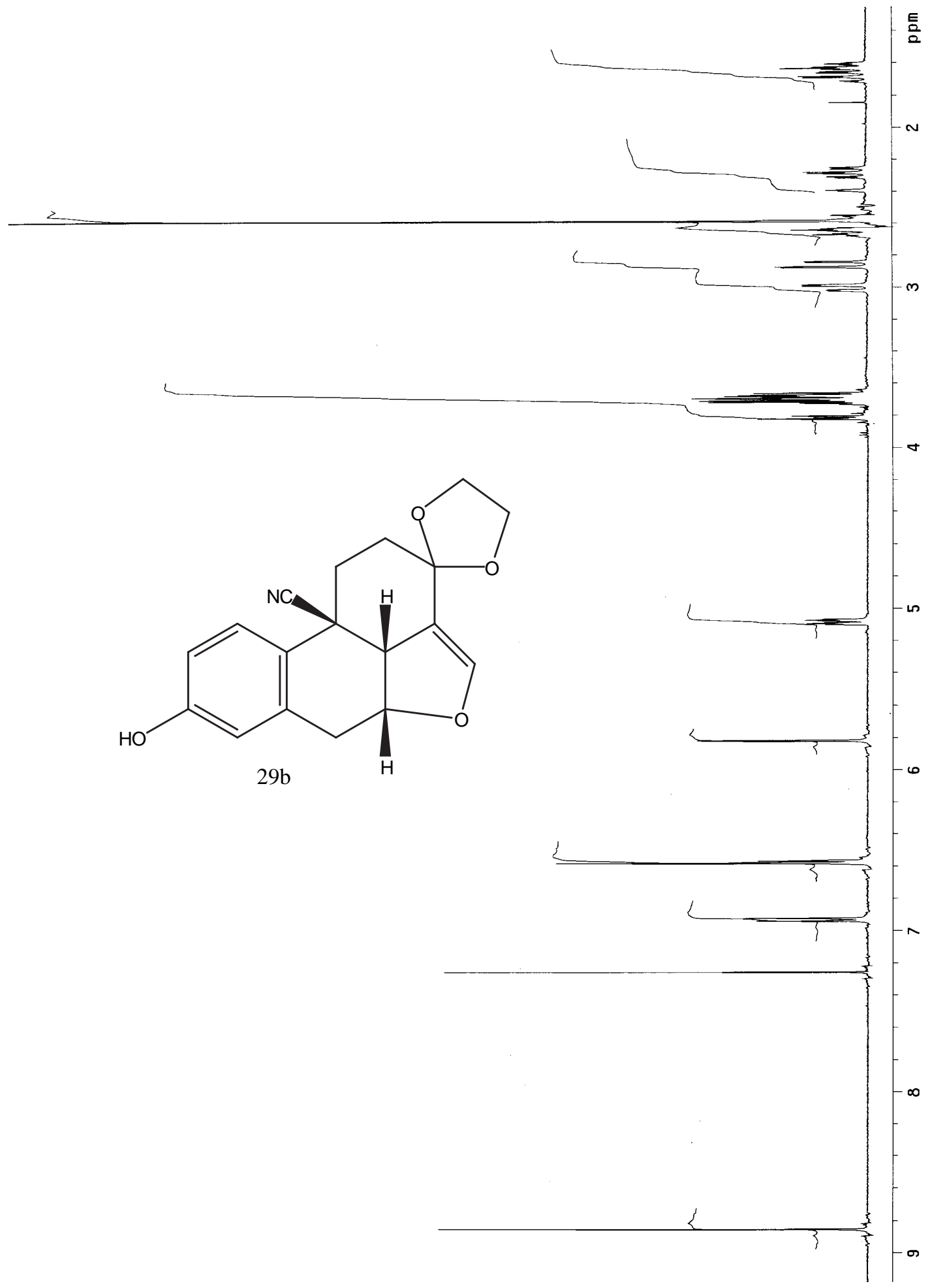




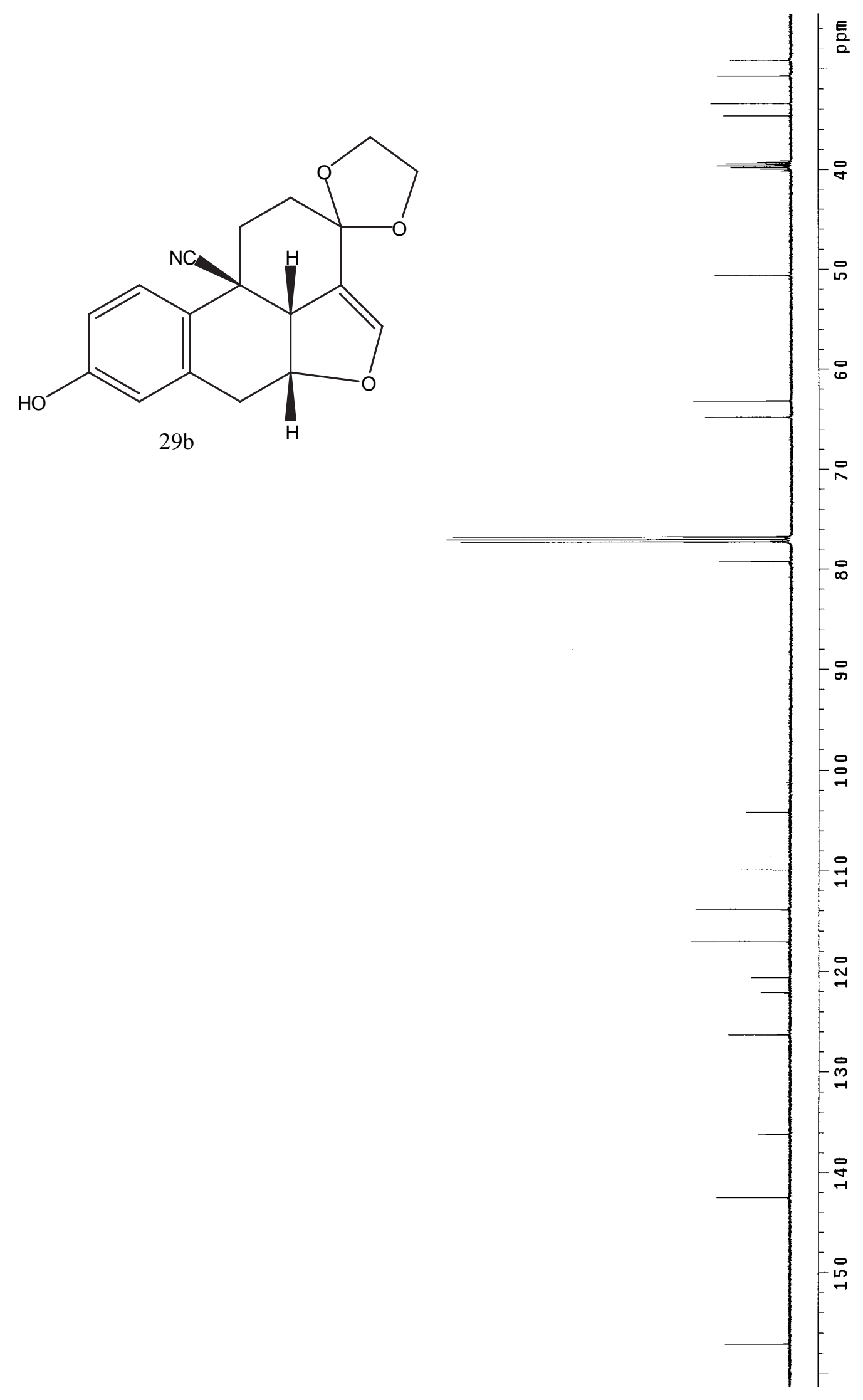




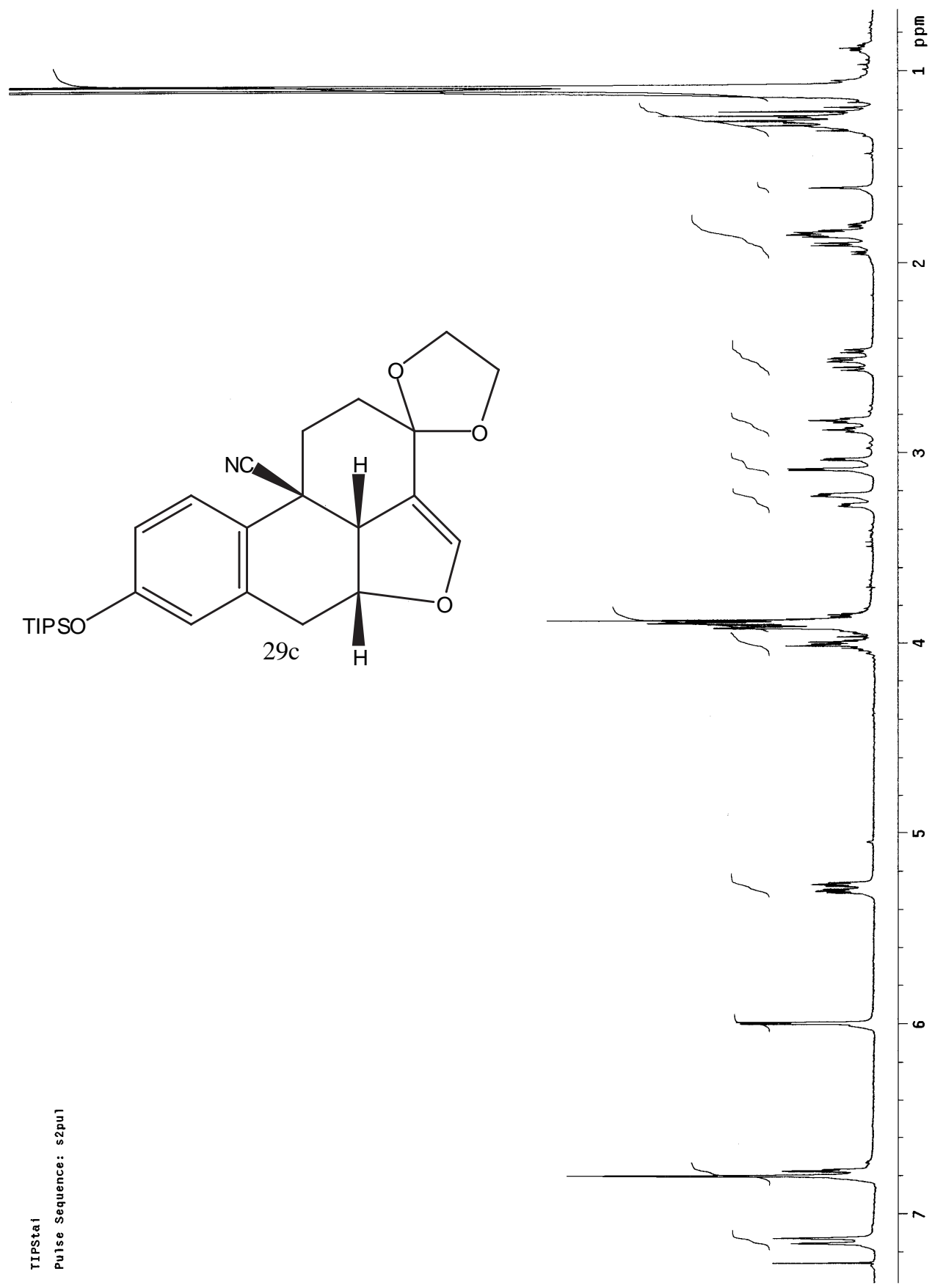



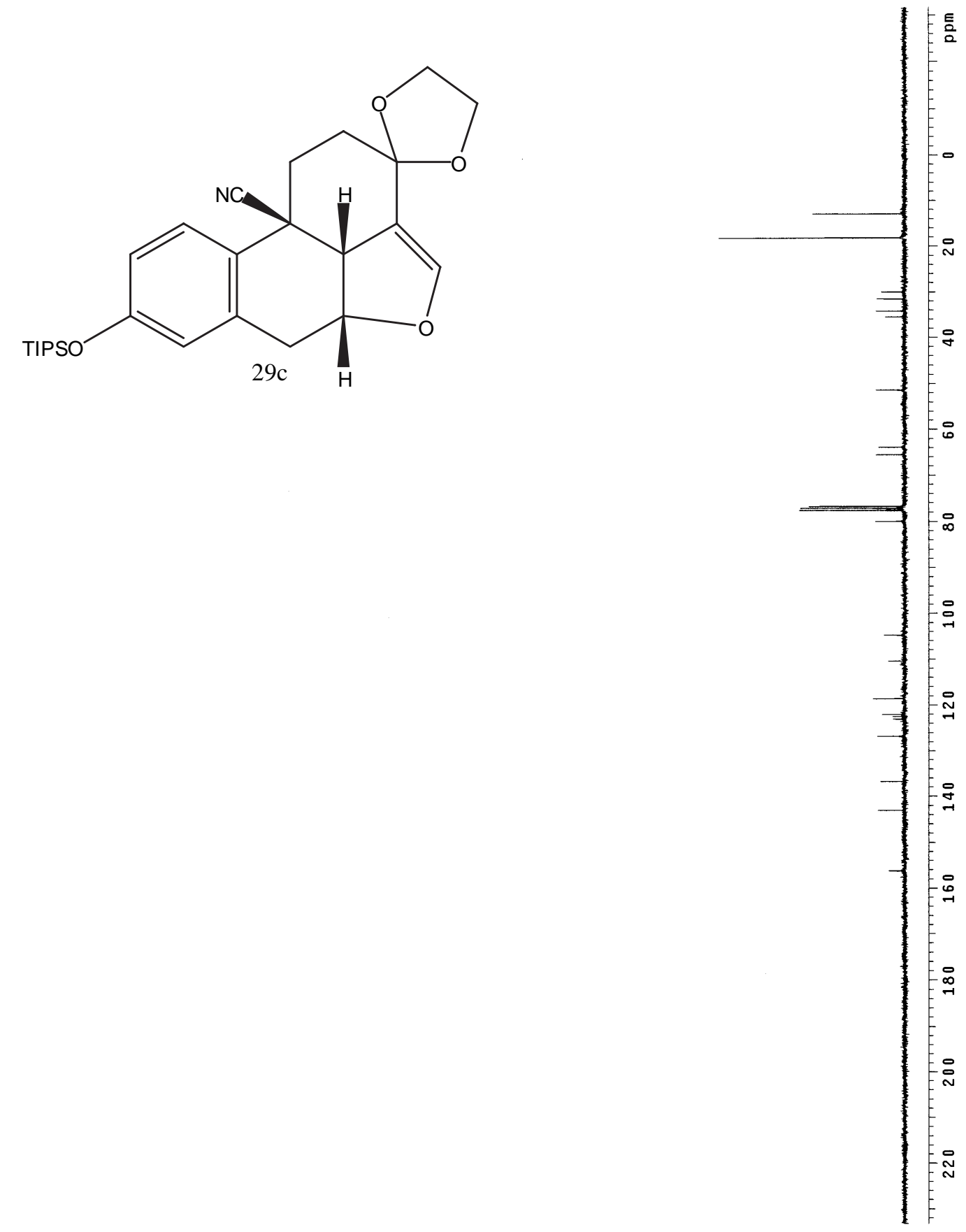


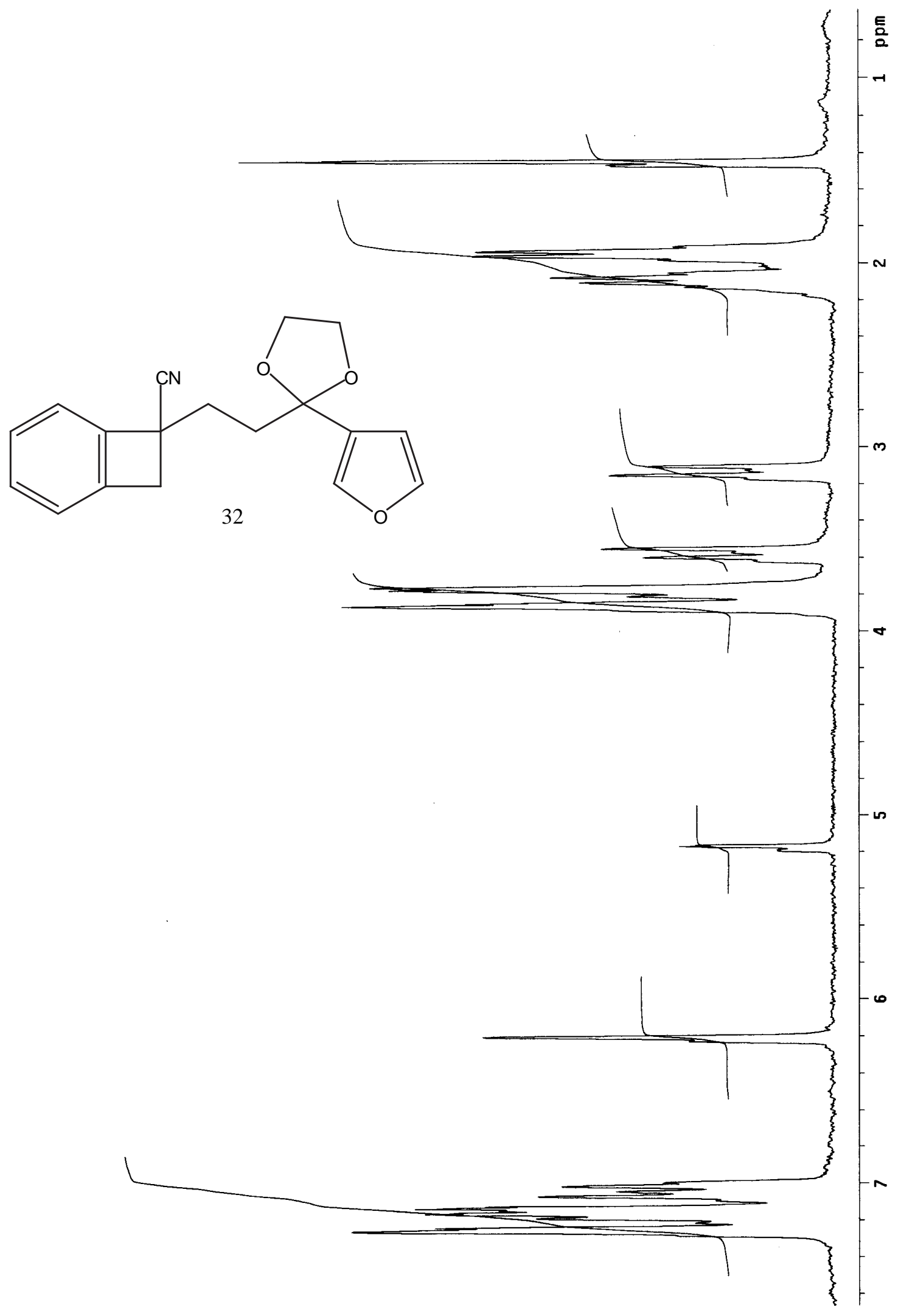



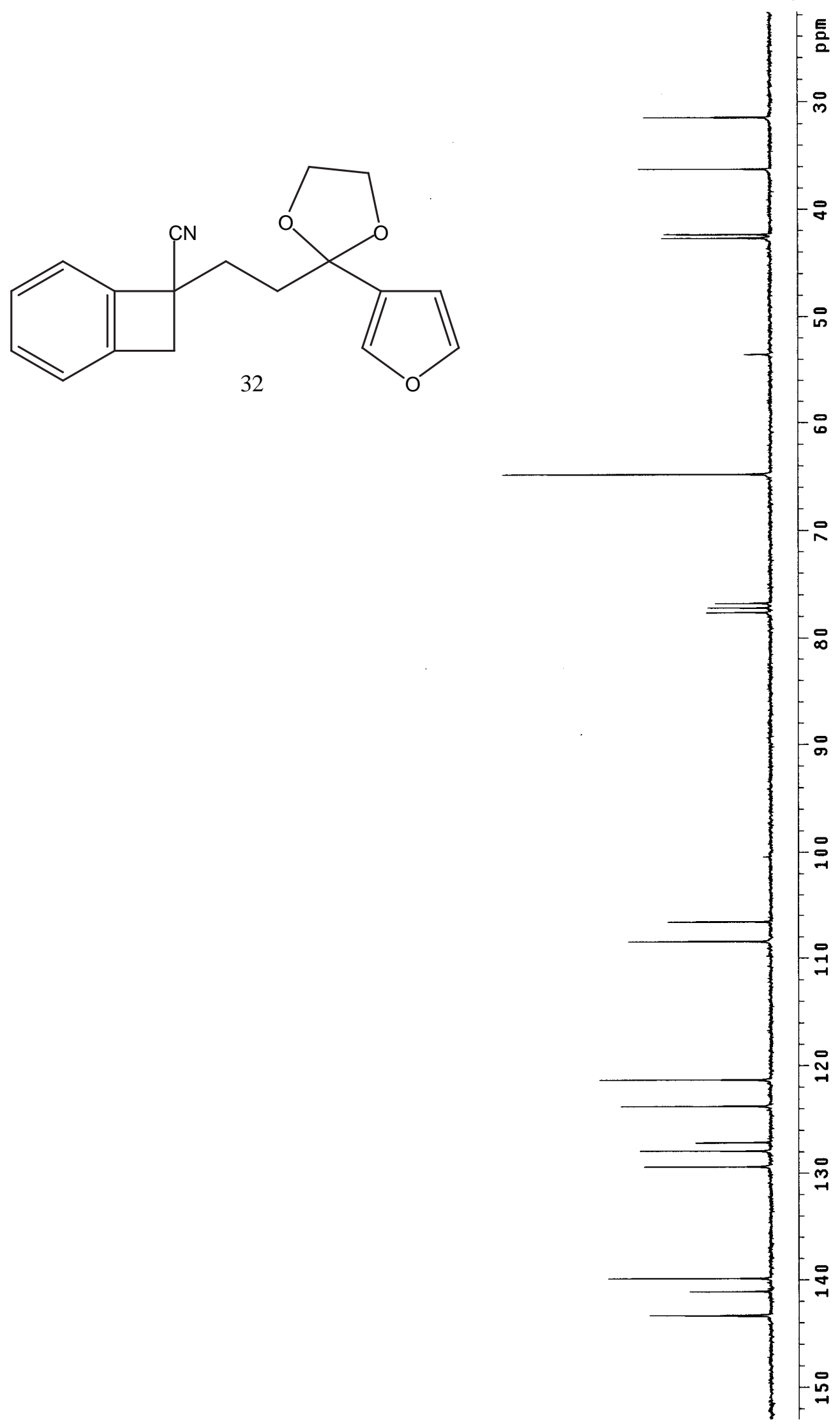

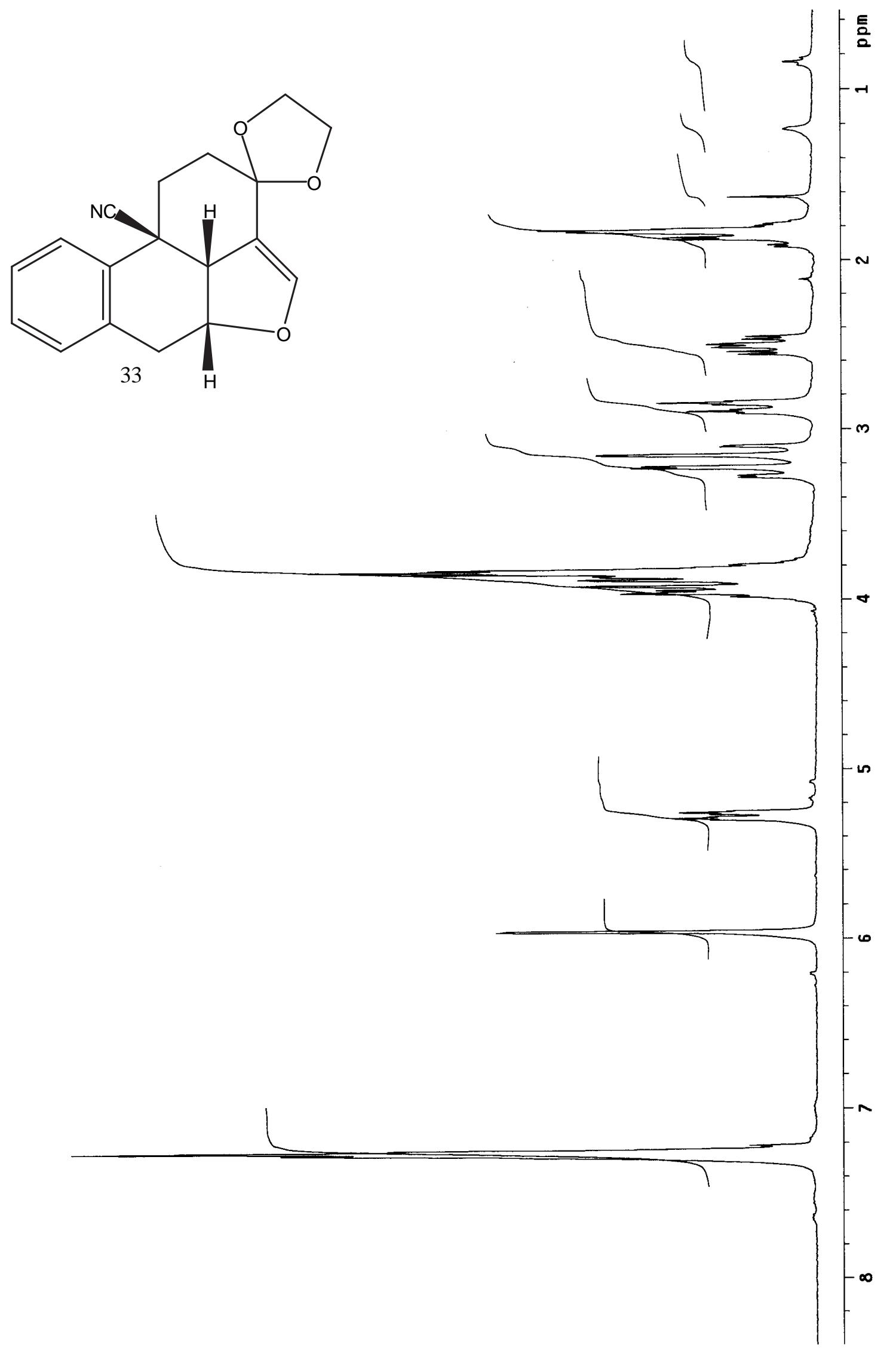

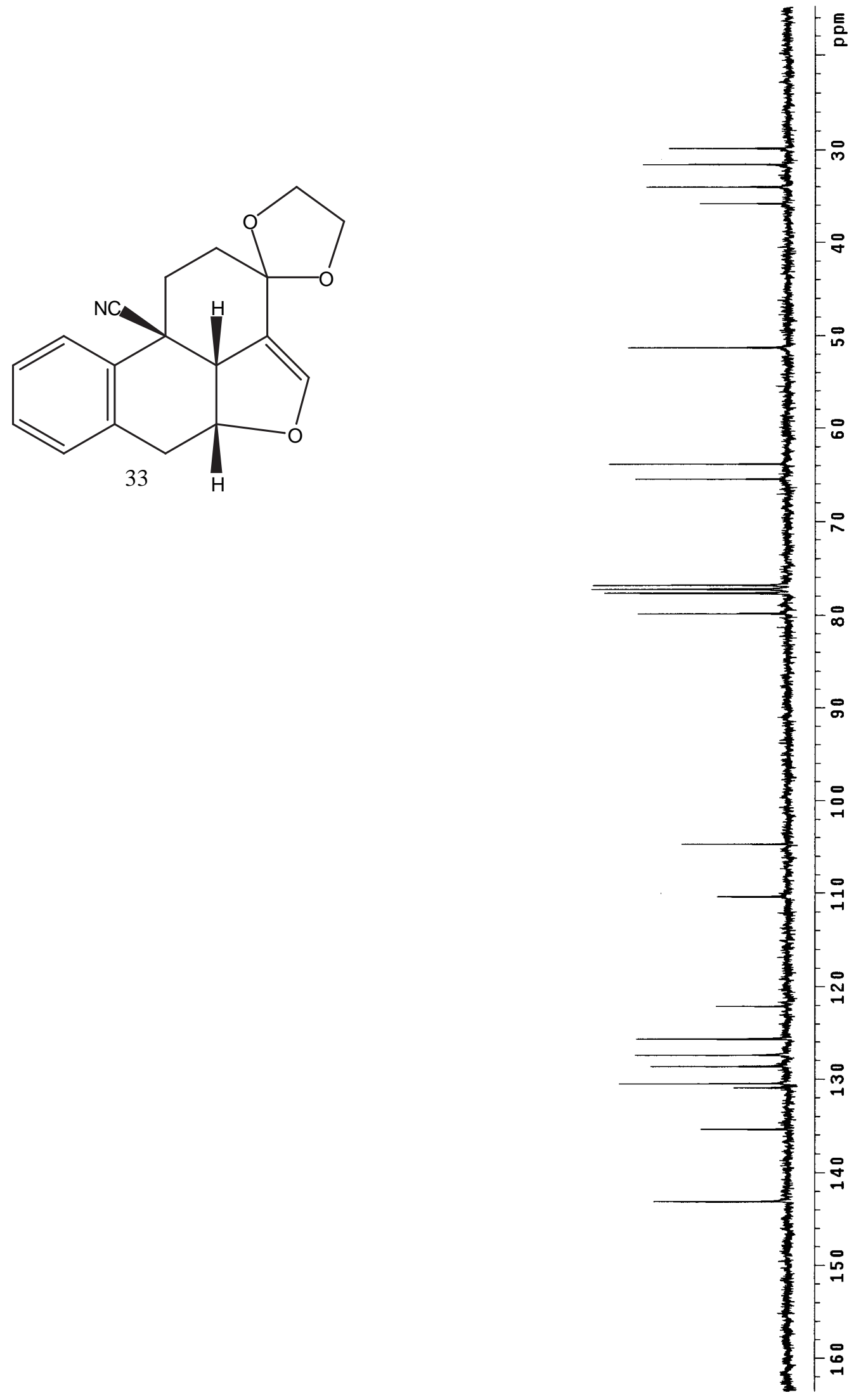